Office of Civilian Radioactive Waste Management Program Management System

\title{
Performance Assessment Implementation Plan for the Geologic Repository Program
}




\section{DISCLAIMER}

This report was prepared as an account of work sponsored by an agency of the United States Government. Neither the United States Government nor any agency thereof, nor any of their employees, make any warranty, express or implied, or assumes any legal liability or responsibility for the accuracy, completeness, or usefuiness of any information, apparatus, product, or process disclosed, or represents that its use would not infringe privately owned rights. Reference herein to any specific commercial product, process, or service by trade name, trademark, manufacturer, or otherwise does not necessarily constitute or imply its endorsement, recommendation, or favoring by the United States Government or any agency thereof. The views and opinions of authors expressed herein do not necessarily state or reflect those of the United States Government or any agency thereof. 


\section{DISCLAIMER}

Portions of this document may be illegible in electronic image products. Images are produced from the best available original document. 
1. INTRODUCTION .................... 1-1

1.1 NEED AND OBJECTIVES FOR A PERFORMANCE ASSESSMENT

STRATEGY .................. 1-1

1.2 SCOPE OF THE PERFORMANCE ASSESSMENT STRATEGY . . . . . 1-1

1.3 RELATIONSHIP OF THE STRATEGY TO OTHER PROGRAM PLANS . . 1-2

1.4 STRUCTURE OF THE PASP ............... 1-4

2. PERFORMANCE ASSESSMENT IN THE GEOLOGIC REPOSITORY PROGRAM ... 2-1

2.1 DEFINITION OF PERFORMANCE ASSESSMENT . . . . . . . 2-1

2.1.1 Technical Criteria of 10 CFR Part $60 \ldots . . .2-1$

2.1.2 Development of the Repository System ..... 2-2

2.2 ISSUES HIERARCHY ............... 2 . . 2-4

2.3 ISSUE-RESOLUTION STRATEGIES . . . . . . . 2-7

2.4 OVERVIEW OF GEOLOGIC REPOSITORY PROGRAM MILESTONES . . . 2-7

3. CONCEPTS AND STRATEGIES FOR PERFORMANCE ASSESSMENT ..... 3-1

3.1 PERFORMANCE MEASURES . . . . . . . . . . . 3-1

3.1.1 Performance Measures from the Performance

Objectives of 10 CFR Part $60 \ldots 3-1$

3.1.1.1 Performance measures for preclosure radiological safety. ....... 3-1

3.1.1.2 Measures of postclosure performance of the total system ....... 3-3

3.1.1.3 Measures of postclosure performance for the engineered-barrier system . . 3-3

3.1.1.4 Measures of performance for the natural barriers........ 3-4

3.1.2 Siting Criteria of 10 CFR Part 60..... 3-4

3.1.3 Design Criteria of 10 CFR Part 60..... 3-4

3.1.4 Performance Measures for Other Analyses ... 3-5

3.1.5 Surrogate Performance Measures ....... 3-5 
TABLE OF CONTENTS (CONTINUED)

3.2 CONCEPTUAL MODELS . . . . . . . . . . . . 3-6

3.3 COMPUTATIONAL MODELS ............... . . 3-6

3.4 QUANTITATIVE ANALYSIS OF PERFORMANCE MEASURES . . . . . 3-8

3.4.1 Use of Deterministic and Probabilistic

Calculations . . . . . . . . . . 3-8

3.4.2 Conservatisn in the Analyses ........ 3-8

3.5 SENSITIVITY AND UNCERTAINTY ANALYSIS . . . . . . . 3-9

3.5.1 Types of Uncertainty in the Assessments . . . 3-9

3.5.2 Sensitivity Analyses .......... 3-10

3.5.3 Uncertainty Analyses . . . . . . . . 3-10

3.5.4 Model Validation............. 3-11

3.5.5 Performance Confirmation ........ 3-12

3.6 PERFORMANCE ASSESSMENT STRATEGIES . . . . . . . . 3-12

3.6.1 General Strategy for Assessment of the

Postclosure Performance of the Total System . . 3-12

3.6.1.1 Summary of the strategy ..... 3-12

3.6.1.2 Conceptual models for

total system performance... . . 3-19

3.6.1.3 Computational models....... . 3-22

3.6.1.4 Analyses .......... . . 3-22 
3.6.2 General Strategy for Assessing the Performance

of the Engineered-Barrier System . . . . . . 3-23

3.6.2.1 Conceptual models ........ 3-24

3.6.2.2 Computational models ....... 3-26

3.6.2.3 Calculation of the performance measures ........... 3-27

3.6.2.4 Sensitivity and uncertainty analyses . 3-28

3.6.3 General Strategy for Assessing the Performance

of the Natural Barriers ......... 3-28

3.6.3.1 Conceptual models ........ 3-29

3.6.3.2 Computational models....... 3-30

3.6.3.3 Calculation of the ground-water

trave1 time ........ 3-30

3.6.3.4 Sensitivity and uncertainty analyses . . . . . . . . . 3-31

3.6.4 General Strategy for the Preclosure Safety

Assessment ............ 3-31

3.6.4.1 Assessment for normal operations . . 3-31

3.6.4.2 Assessment for accident conditions . 3-34

4. PERFORMANCE ASSESSMENT SUPPORT TO THE SAFETY ANALYSIS

REPORT . . . . . . . . . . . . . . . . . 4-1

4.1 DESCRIPTION OF THE SAFETY ANALYSIS REPORT . . . . . . 4-1

4.2 PERFORMANCE ASSESSMENT ACTIVITIES FOR THE SAR . . . . . 4-1

4.2.1 Preclosure Safety Assessment for the SAR . . . 4-1

4.2.2 Postclosure Performance Assessment for the

SAR ................. 4-3

4.3 MILESTONES AND SCHEDULE ................ 4-4 
5. PERFORMANCE ASSESSMENT SUPPORT TO THE ENVIRONMENTAL

IMPACT STATEMENT . . . . . . . . . . . . . . . 5-1

5.1 DESCRIPTION OF THE ENVIRONMENTAL IMPACT STATEMENT... 5-1

5.2 REQUIREMENTS FOR PERFORMANCE ASSESSMENT....... . 5-2

5.3 PERFORMANCE ASSESSMENT ACTIVITIES FOR THE EIS . . . . . 5-3

5.3.1 Preclosure-Safety Assessment for the EIS . . . 5-3

5.3.1.1 Assessment of radiation impacts .. 5-3

5.3.1.2 Analysis of accidents beyond the design

basis .......... 5-4

5.3.1.3 Conversion of doses to health

effects .......... . 5-4

5.3.1.4 Input-data requirements . . . . 5-5

5.3.2 Postclosure Performance Assessment for the

EIS . . . . . . . . . . . . . 5-5

5.4 MILESTONES AND SCHEDULES . . . . . . . . . . . . 5-5

6. PERFORMANCE ASSESSMENT SUPPORT TO SITE-SUITABILITY ANALYSES . - 6-1

6.1 DESCRIPTION OF THE SITE-SUITABILITY ANALYSES . . . . . . 6-1

6.2 PERFORMANCE ASSESSMENTS FOR THE SITE-SUITABILITY ANALYSES 6-2

6.2.1 Early Site Evaluations ........... 6-2

6.2.2 Comprehensive Site Evaluation ........ 6-3

6.3 MILESTONES AND SCHEDULE ............... 6-3

7. PERFORMANCE ASSESSMENT SUPPORT TO SITE CHARACTERIZATION

AND CONFIRMATION TESTING . . . . . . . . . . . . . 7-1

7.1 DESCRIPTION OF SITE INVESTIGATION PROGRAMS . . . . . . 7-1

7.1.1 Site Characterization Program ......... 7-1

7.1.2 Performance Confirmation Program ....... 7-2

7.2 PERFORMANCE ASSESSMENT ACTIVITIES IN SUPPORT OF SITE

INVESTIGATIONS .................... 7-2 
TABLE OF CONTENTS (CONTINUED)

7.3 MILESTONES AND SCHEDULE . . . . . . . . . . . 7-3

8. PERFORMANCE ASSESSMENT SUPPORT TO REPOSITORY DESIGN . . . . 8-1

8.1 DESCRIPTION OF DESIGN PHASES . . . . . . . . . 8-1

8.1.1 Design of the Exploratory-Shaft Facility . . . 8-1

8.1.2 Advanced Conceptual Design ......... 8-2

8.1.3 License Application Design .......... 8-2

8.1.4 Final Procurement and Construction Design . . 8-2

8.2 REQUIREMENTS FOR PERFORMANCE ASSESSMENT . . . . . . . 8-2

8.2.1 Interfaces between Performance Assessment

and Design ................ 8-2

8.2.2 The Resolution of Design Issues . . . . . 8-3

8.2.3 Assessment of Exploratory-Shaft Facility Design 8-3

8.3 MILESTONES AND SCHEDULE . . . . . . . . . . . . 8-4

9. PERFORMANCE ASSESSMENT INTERFACES WITH OTHER

WASTE-MANAGEMENT FACILITIES . . . . . . . . . . . . . 9-1

9.1 DESCRIPTION OF INTERFACES ............. . . 9-1

9.2 PERFORMANCE ASSESSMENT SUPPORT . . . . . . . . . . 9-2

9.3 PERFORMANCE ASSESSMENT ACTIVITIES . . . . . . . . . 9-3

10. PERFORMANCE-ASSESSMENT INTERACTIONS WITH INTERNATIONAL

PROGRAMS .................... 10-1

10.1 OVERVIEW . . . . . . . . . . . . . . . . . 10-1

10.2 INTERNATIONAL CODE VERIFICATION AND MODEL VALIDATION • • 10-2

10.2.1 INTRACOIN ............... 10-2 
10.2.2 HYDROCOIN ............... 10-3

10.2.3 INTRAVAL ............. 10-4

10.3 INTERNATIONAL COOPERATION IN RESEARCH AND

DEVELOPMENT . . . . . . . . . . . . . . . . 10-5

10.3.1 Pocos de Caldas Project, Brazil ....... 10-5

10.3.2 Bilateral Cooperation with Canacia ..... 10-6

10.3.3 Bilateral Activities with SKB, Sweden .... 10-6

10.3.4 OECD/NEA Stripa Project, Sweden . . . . . 10-6

10.3.5 Bilateral cooperation with Switzerland . . . 10-8

10.4 INTERNATIONAL PERFORMANCE ASSESSMENT WORKING AND

COORDINATING GROUPS ................ 10-9

10.4.1 Participation in the OECD/NEA ....... 10-9

10.4.2 Participation in the CEC ........... 10-10

10.5 OTHER INTERNATIONAL EFFORTS . . . . . . . . . 10-10

10.6 MILESTONES AND SCHEDULES . . . . . . . . . . . . 10-11

11. INTEGRATION OF THE GEOLOGIC REPOSITORY PERFORMANCE ASSESSMENT

PROGRAM . . . . . . . . . . . . . . . . . . . 11-1

11.1 OVERVIEW OF THE PERFORMANCE ASSESSMENT PROGRAM SCHEDULE. - 11-1

11.1.1 Geologic Repository Program Milestones .... . 11-1

11.1.2 Constraints of the Site Characterization and Design Programs on the Performance Assessment

Schedule.............. . 11-1

11.1.3 Phases of the Performance Assessment

Program ................. 11-2

11.2 INTEGRATED PROGRAM FOR PERFORMANCE ASSESSMENT AREAS • - 11-10

11.2.1 Assessments of Total System Performance . . . 11-10

11.2.2 Assessments of Engineered-Barrier System

Performance .............. 11-11

11.2.3 Assessments of the Performance of Natural

Barriers ................ 11-12

11.2.4 Preclosure Safety Assessments . . . . . . 11-13 
TABLE OF CONTENTS (CONTINUED)

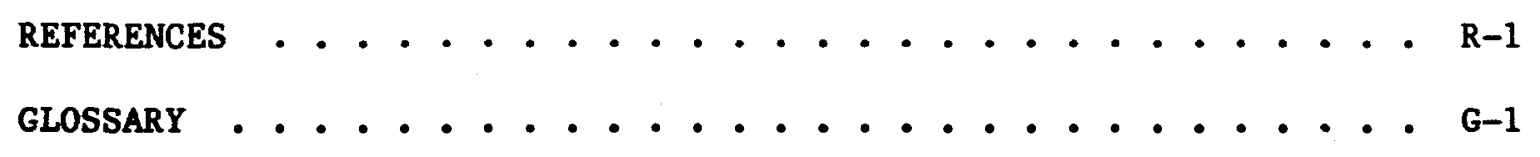

APPENDIX A. POSTCLOSURE PERFORMANCE ASSESSMENT ACTIVITIES . . . A-1

APPENDIX B. PRECLOSURE SAFETY ASSESSMENT ACTIVITIES . . . . . B-1 
$\underline{\text { Table }}$

2-1 Key Issues and Issues ............... 2-5

2-2 Major Program Milestones .............. 2-11

3-1 Performance Measures for the Repository System . . . . 3-2

4-1 SAR Topics Involving Performance Assessment . . . . . 4-2

6-1 Studies that Address Potentially Adverse Conditions and Features of the Yucca Mountain Site ........ 6-3

10-1 Major Milestones in International Activities . . . . . 10-13

11-1 General Schedule of Performance Assessment Analyses Supporting Geologic Repository Program Efforts . . . . . . 11-8 
1-1 Relationship of PASP to other repository program planning documents ................. 1-3

2-1 Issue resolution strategy ............. 2-8

2-2 The performance assessment process .......... 2-9

4-1 Sequence of performance assessment support for the SAR . . 4-7

5-1 Sequence of performance assessment support for the EIS . . 5-7

6-1 Sequence of performance assessment support for site-suitability assessments . . . . . . . . . . 6-7

7-1 Sequence of performance assessment support for site investigations ................. 7-4

8-1 Sequence of performance assessment activities in support of design activities .............. 8-5

10-1 Schedule of major international activities . . . . . 10-11

11-1 General schedule for performance assessment activities . . 11-6 


\section{INTRODUCTION}

Performance assessment is a major constituent of the program being conducted in the Civilian Radioactive Waste Management (CRWM) Program of the U.S. Department of Energy (DOE) to develop a geologic repository. Performance assessment is the set of activities needed for quantitative evaluations of repository-system performance to assess compliance with regulations and to support the development of the geologic repository. To define the strategy. for these evaluations, the DOE has developed this performance assessment strategy plan. This chapter discusses the need for such a strategy, the objectives and scope of the strategy plan, the relationship of the plan to other program plans, and the structure of this document.

\subsection{NEED AND OBJECTIVES FOR A PERFORMANCE ASSESSHENT STRATEGY}

It is important that those who conduct performance assessments of a geologic repository, those who supply information for the assessments, and those who receive guidance from the assessments have a common understanding of the general strategy and methodology for those assessments. The principal objective of this document is to provide this common understanding. To this end, this document defines the role of performance assessment, identifies the requirements placed on performance assessment by the major program milestones that performance assessment must support, states the goals of performance assessment and relates them to the program goals, identifies sets of analyses, provides performance assessment milestones and schedules, and places these efforts and their products into the context of evaluating site suitability and compliance with applicable requirements.

The strategy provides a consistent foundation for the planning and conduct of performance assessment activities. Such consistency will contribute to the timely accomplishment of the goals at each stage of the program.

\subsection{SCOPE OF THE PERFORMANCE ASSESSMENT STRATEGY}

In the Nuclear Waste Policy Amendments Act (1987), the U.S. Congress selected Yucca Mountain in Nevada as the candidate repository site to be characterized in detail. This characterization is to determine whether the site is suitable for a repository system capable of containing and isolating high-level waste and spent nuclear fuel. This performance assessment strategy applies to that site and covers the performance assessments to be conducted by the Office of Civilian Radioactive Haste Management and its contractors and the Yucca Mountain Project participants. It emphasizes the performance assessment activities and milestones scheduled for the period preceding the subaittal of the License Application to the Nuclear Regulatory Commission.

The performance assessment program will provide analyses that assist in determining site suitability, assist in guiding site testing programs, contribute to the 1 icensing documents that will support DOE's License Application, and evaluate engineering and design. Performance assessments will continue after submittal of the License Application for construction 
authorization on through repository construction, operation, permanent closure, and decommissioning; to assist in obtaining any amendments to the license application; to ensure that the repository system and its elements-the site, the repository, and the waste package--are performing as expected; and to ensure that operating procedures are protecting the health and safety of workers and the public. The performance assessment program includes all the analyses and supporting activities associated with the preclosure safety and the postclosure performance of the repository. It does not include analyses of the other elements of the waste-management system authorized by the Nuclear Waste Policy Amendments Act: the MRS facility and the transportation system. However, assessment of interfaces between the repository and these other elements of the Civilian Radioactive Waste Management Program are part of the performance assessment program.

\subsection{RELATIONSHIP OF THE STRATEGY TO OTHER PROGRAM PLANS}

Figure 1-1 presents a simplified view of the relationship of this Performance Assessment Strategy Plan (PASP) to other, closely related, planning documents. It shows the relationship to the Performance Assessment Management Plan (PAMP), the Site Characterization Plan (SCP), the Environmental Impact Statement Implementation Plan (EISIP), the Licensing Plan, and the Performance Assessment Implementation Plan (PAIP).

The PAMP outlines the organization and management of the DOE's performance assessment activities for the repository program. The PAMP assigns responsibilities and identifies the management procedures for the conduct of the performance assessments by the various participants in the program. It identifies the top-level milestones that require performance assessment support. This information forms a background from which the PASP is developed.

The SCP describes the site, the preliminary designs for the repository and the waste package, and the waste-emplacement environment. It presents a strategy for resolving issues related to regulatory requirements and describes general strategies for resolving these issues, plans for obtaining the information needed for issue resolution, and a general plan for the performance assessments that will be conducted in support of issue resolution. The performance assessment strategy presented here guides the plans for analyses to support the issue resolution.

The EISIP describes the technical strategy for the Environmental Impact Statement. The EISIP will not be prepared until the EIS scoping exercise is completed. This scoping exercise, scheduled to begin soon after the start of exploratory-shaft construction, is a formal process for defining the content of the EIS. The full scope of the performance assessment support to the EIS will not be known until the EIS scoping is completed. Although it is likely that at least some of the analyses performed for other purposes-for example, the Safety Analysis Report and the site-suitability analysis-will be applicable to the EIS, some unique requirements are expected for the EIS. When the EISIP is completed, the performance assessment strategy will be reviewed and revised as necessary to address the specific needs for the EIS. 


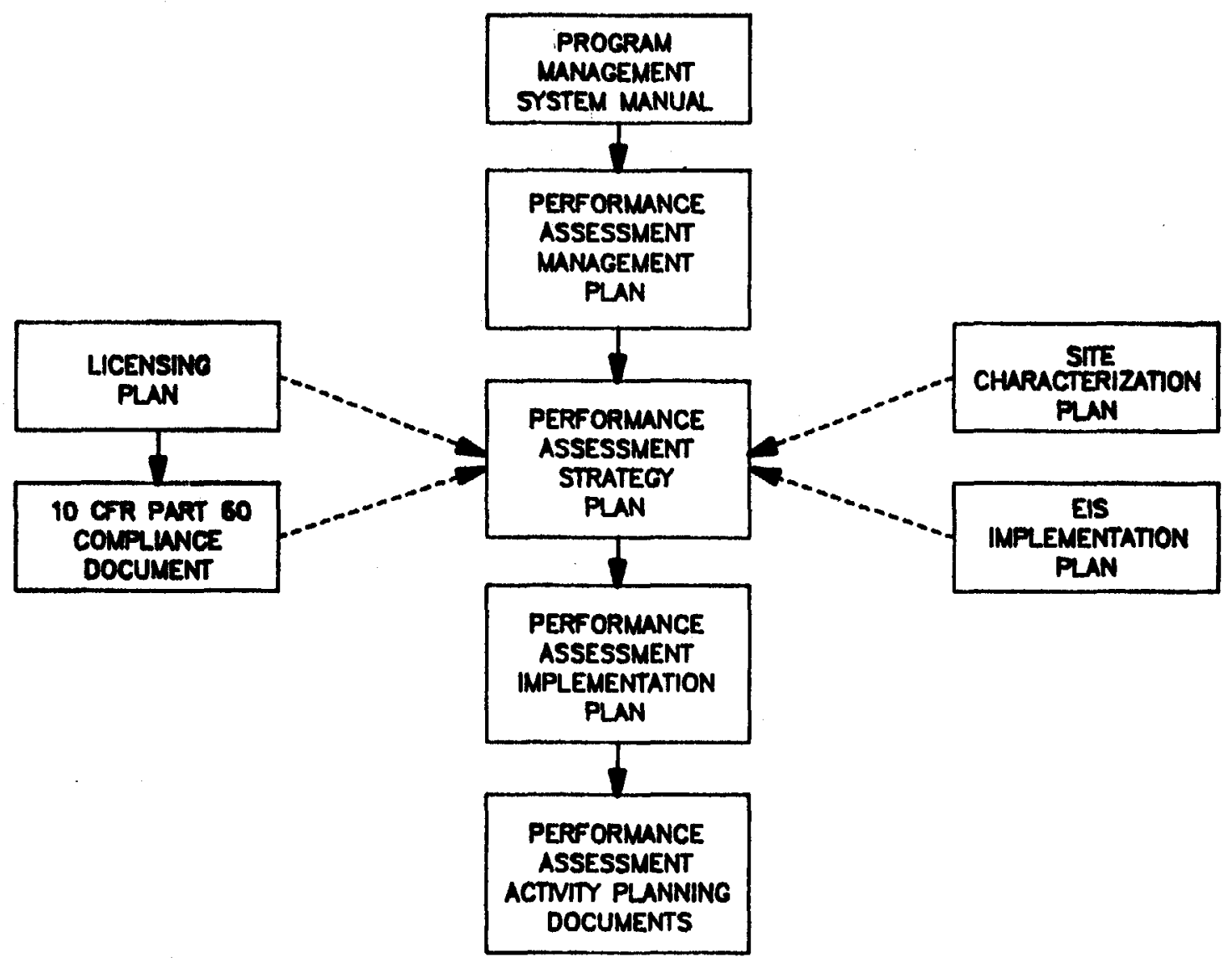

Document hierorchy flowdown

........ Informotion/coordination

Figure 1-1 Relotionship of PASP to other repository program planning documents. 
The Licensing Plan addresses the legal and technical aspects of the licensing process. It is the strategic plan that describes how the DOE intends to pursue its licensing philosophy and policy. A subtier document to the Licensing Plan, the 10 CFR Part 60 Compliance Document, discusses the DOE's strategies to be used to demonstrate the licensability of various components of the repository and to ensure compliance with the requirements of 10 CFR Part 60 . The strategies in the PASP must be consistent with these documents.

The implementation of the strategy presented in the PASP and the activities required to accomplish the performance assessments are described in periodic PAIPs. The activities include methodology development, conceptual-model development, code development and testing, and the conduct. and documentation of the analyses. The PAIPs also identify the specific program participants who will perform each assessment. Where appropriate, more-detailed activity plans identify the data, models, and codes to be used, and the resources required to conduct the activities.

\subsection{STRUCTURE OF THE PASP}

The first two chapters present overviews of the PASP and of the performance assessment strategy for the geologic-repository program. Chapter 2 begins with a definition of performance assessment and then describes the roles of performance assessment in the program, the importance of the issues hierarchy to performance assessment, and a general approach to conducting performance assessments. It concludes with an overview of the performanceassessment milestones and schedule.

Chapter 3 presents a brief discussion of the general strategies for postclosure performance and preclosure safety assessments, discusses the categories of activities to support these strategies, describes the approaches to modeling used in the assessments, and describes the general considerations in developing confidence in the predictions of performance.

Chapters 4 through 8 present brief discussions of performance assessment support to major repository-program milestones and programs: the Safety Analysis Report (Chapter 4), the Environmental Impact Statement (Chapter 5), the site-suitability analyses (Chapter 6), the site characterization program (Chapter 7), and the design program (Chapter 8). These chapters describe the program milestones being supported and the requirements that they place on performance assessment. They outline the performance assessment activities, their products, and schedules.

Chapter 9 discusses the performance assessment interfaces with other elements of the waste-management system, such as the waste-transportation system. Chapter 10 discusses performance assessment interactions with cooperative programs being conducted with other nations and by international organizations; it relates these performance assessment activities to the U.S. repository program. 
Chapter 11 presents an integrated picture of the performance assessment program. It identifies the major activities that support these assessments, the related milestones, and the schedules.

The report also contain appendices that outline the activities of the postclosure and preclosure performance assessment programs. The discussions in these appendices provide a bridge between the general strategies in this report and the activities presented in the periodic PAIPs. 


\section{PERFORMANCE ASSESSMENT IN THE GEOLOGIC REPOSITORY PROGRAM}

This section defines performance assessment and describes the roles of performance assessment in the program. It also discusses the issues hierarchy, the relationships of the issues to the criteria in the regulations, the issue-resolution strategies, and the role of performance assessments in those strategies. It ends with an overview of performance assessment milestones and schedule.

\subsection{DEFINITION OF PERFORMANCE ASSESSMENT}

In general, performance assessment is a tool of decision management that provides information from predictive evaluations of a complex system to the decision makers. These evaluations involve conceptual models of the system and the processes within the system and, characteristically, involve comparison of predicted behavior with established criteria. As applied to the geologic repository, performance assessment is defined as the set of activities needed for quantitative analysis of the behavior of the repository system and its components with respect to preclosure safety and postclosure performance to assess compliance with the technical criteria in $10 \mathrm{CFR}$ Part 60 and to support the development of the repository system.

Performance assessment involves calculations of those variables specified in the technical criteria to measure performance. The calculations of these variables, or performance measures, are used both for the regulatory compliance evaluations and for the repository system development. This development includes site characterization, design, and licensing of the facility. While there are numerous analyses that must be conducted in the course of repository development, performance assessment focuses on those associated with the regulatory performance measures.

\subsubsection{Technical Criteria of 10 CFR Part 60}

The NRC's technical criteria are given in Subpart E of 10 CFR Part 60 , and include performance objectives, siting criteria, and design criteria. The performance objectives are expressed in terms of preclosure safety and postclosure performance requirements. These performance objectives provide the basis for the siting and design criteria that relate to safety and waste isolation.

The preclosure safety objectives in $10 \mathrm{CFR} 60.111$ apply to radiation exposures and releases of radioactive material to unrestricted areas. The regulations in $10 \mathrm{CFR} 60.131$ specify design criteria for structures, systems, and components important to safety. To assess compliance with these performance objectives and criteria, the preclosure safety assessment evaluates the radiological safety of the workers and the general public during the construction, operation, closure, and decommissioning of the repository, and during operations that would be required for waste retrieval, should that need arise. The assessments must consider both normal operations and accidents. Requirements for preclosure safety assessments have also been 
established in DOE Orders 5480.11, 5400.3, and 6430.1A. These requirements reflect the performance measures associated with radiological safety and, as applicable, the numerical criteria for these performance measures as established in the regulations.

The postclosure performance objectives are divided by the NRC into overall (total) system performance objectives (10 CFR 60.112) and particular-barrier (subsystem) performance objectives (10 CFR 60.113). The overall system performance objectives reference the standards established by the U.S. Environmental Protection Agency (EPA) in 40 CFR Part 191, Subpart B. These standards address radionuclide releases to the accessible environment, individual protection, and ground-water protection. Although the EPA will repromulgate these standards in response to a court order, the DOE is using the existing (1985) standards as guidance and will revise its program as necessary when the standards are repromulgated. The existing EPA standards establish performance measures for each of the overall system performance objectives and numerical criteria for the performance measures. Specifically, requirements apply to (1) the cumulative releases of radionuclides to the accessible environment for 10,000 years after disposal, considering all significant processes and events; (2) the annual dose equivalent received by any member of the public for 1000 years after disposal, considering undisturbed performance of the repository system; and (3) the radionuclide concentrations in water withdrawn from any special source of ground water in the 1000-year period after disposal, considering undisturbed performance of the repository system.

The NRC's particular-barrier performance objectives in 10 CFR 60.113 establish two performance requirements for the engineered-barrier system and a performance requirement for the geologic setting. The requirements for the engineered-barrier system mandate substantially complete waste containment under anticipated processes and events for a period to be specified and limit the rate of radionuclide release after the containment period. The geologic-setting requirement establishes a desired minimum time of ground-water travel along the fastest path of likely radionuclide travel from the disturbed zone to the accessible environment.

\subsubsection{Development of the Repository System}

Development of the repository system requires evaluation of performance of the repository system to determine site suitability, to support regulatory compliance evaluations for licensing, to support site characterization, and to support design efforts.

Performance assessments will support the licensing process by providing analyses that will be presented in the Safety Analysis Report and which will be the subject of interactions between the NRC and the DOE as a part of the licensing process. In addition, performance assessments will be conducted for the Environmental Impact Statement, which, in addition to satisfying NEPA requirements, will be used in the licensing process. 
Performance assessments will also be used to support site characterization. Site characterization has the responsibility to collect the raw data on the natural system, process the data, and interpret the results to develop site and environmental conceptual models and the associated parameter values. To assist in defining the data to be collected and processed, performance assessment identifies the parameters and conceptual models needed for the assessments and specifies for the data the level of confidence needed for predicted performance. The guidance to site characterization began with contributions to the Site Characterization Plan, including contributions to the performance-allocation effort, the identification of site data needed for performance assessments, and assessment of the importance of those data and the confidence with which the data need to be known. Guidance will continue with (1) review of the site data as they are obtained to ensure that sufficient data are obtained for performance assessment, (2) assessments to ensure that the characterization activities do not compromise the performance of the repository, and (3) assistance in planning for performance confirmation.

In addition, performance assessments will be conducted as site characterization progresses, to evaluate the characteristics and features of the site, to determine on a preliminary basis whether any of these characteristics or features could be detrimental to repository performance. At the end of site characterization, a comprehensive performance assessment will be conducted to determine overall site suitability; if the site is found to have appropriate characteristics and if appropriate performance is predicted, this determination will form part of the basis for the Secretary of Energy's recommendation of the site to the President of the United States. Performance assessment support to the evaluation of site suitability will focus on those site characteristics that are identified to be important to radiological safety and waste isolation. This site-evaluation analysis will consider whether the site has characteristics that lead to predictions of compliance with the regulatory performance objectives and whether these characteristics are sufficiently understood to ensure compliance with high confidence. This latter consideration requires assessment of the sensitivity of system and subsystem performance to the site characteristics and an assessment of the uncertainty associated with the understanding of the characteristics and their effect on performance.

Performance assessment will also be used to support the design efforts. The interface between performance assessment and design is driven by the need to consider how the designs for the waste package, the repository, and the seal system affect the predicted performance. Therefore, the development of design requirements from the regulatory performance objectives and subsequent analyses of the design against the design requirements will involve performance assessments. The analyses might identify desirable changes in the design or the design requirements. Performance assessments will also be involved in the evaluation of design alternatives.

During construction, operation, and closure, the performance confirmation program will monitor conditions to ascertain whether the actual responses of the engineered system are within the envelope of predicted changes. During this time, performance assessment will use the updated information to 
determine whether long-term performance is still predicted to be within the regulatory requirements and be used in the evaluation of actions to be taken with respect critical elements of the design. After the start of waste emplacement at the repository, performance assessment will contribute to analyses that may be required regarding retrieval of the waste.

Repository development also involves interfaces with other programs (e.g. programs for temporary storage of spent fuel, defense programs that address defense high-level waste, and transportation programs that address logistics of delivery of the waste to the repository). The performance assessment support to these other elements of the waste-management system is initially concentrated on identifying those conditions or operations that could affect the performance of the repository. Assessments will then be conducted to develop an understanding of the potsential impacts on performance.

Finally, repository development benefit from cooperation with the repository programs being conducted by other nations and international organizations. Therefore performance assessment participates in those international programs that offer opportunities involving performance assessment methods and techniques.

\subsection{ISSUES HIERARCHY}

As indicated in the definition of performance assessment, the focus of the geologic repository performance assessments is the set of technical criteria of $10 \mathrm{CFR}$ Part 60 . The DOE has developed a hierarchy of issues that address those technical criteria as well as other requirements of the regulations that apply to the repository. This issues hierarchy is a three-tiered framework consisting of key issues, issues, and information needs. The first two key issues address the regulations that apply to postclosure and preclosure performance. Under each key issue are issues that address the requirements stated in the key issue and resolve them into separate questions associated with specific technical criteria. The third tier consists of the information needs to answer those questions. The issues and information needs are explained in more detail in other documents (DOE, $1986 \mathrm{a}, 1988 \mathrm{a})$. The key issues and the performance and design issues associated with each key issue are listed in Table 2-1.

The performance and design issues for the first two key issues, postclosure performance and preclosure radiation protection, are associated with particular technical criteria of Subpart $E$ of 10 CFR Part 60 . Those that are directly derived from the numerical criteria are issues $1.1,1.2$, and 1.3 (EPA postclosure environmental standards implemented by $10 \mathrm{CFR} 60.112$ ), issues 1.4 and 1.5 (numerical criteria for the engineered-barrier system in $10 \mathrm{CFR}$ 60.113), issue 1.6 (numerical criterion for the ground-water travel time), and issues 2.1, 2.2, and 2.3 (numerical criteria for preclosure safety). Issue 1.7 is related to the performance-confirmation program. Issue 1.8 addresses the favorable and potentially adverse conditions of the siting criteria in 10 CFR 60.122; performance assessments will be conducted to determine the effect of these conditions with respect to the numerical criteria associated with issues 1.1 through 1.6 . Issue 2.4 addresses waste retrievability, as noted in 10 CFR $60.111(\mathrm{~b})$; the performance assessments conducted in this case will be 
Table 2-1. Key Issues and Issues

Issue Descriptor

KEY ISSUE 1. POSTCLOSURE PERFORMANCE

Issue 1.1 Radionuclide releases to accessible environment

Issue 1.2 Individual doses in accessible environment

Issue 1.3 Protection of special sources of ground water

Issue 1.4 Waste-package containment

Issue 1.5 Rates of radionuclide release from engineered-barrier system

Issue 1.6 Pre-waste-emplacement ground-water travel time (GWTT)

Issue 1.7 Performance-confirmation program

Issue 1.8 Demonstrations for favorable and potentially adverse conditions

Issue 1.9 Postclosure siting guidelines

Issue 1.10 Waste-package design effects on predicted performance

Issue 1.11 Repository and éngineered-barrier design effects on predicted performance

Issue 1.12 Seal design effects on predicted performance

KEY ISSUE 2. PRECLOSURE RADIOLOGICAL SAFETY

Issue 2.1 Dose to members of the public during normal operations

Issue 2.2 Radiation safety of workers during normal operations

Issue 2.3 Radiation exposures of the public and workers during credible accidents

Issue 2.4 Preservation of waste-retrieval option

Issue 2.5 Preclosure siting guidelines

Issue 2.6 Waste-package design effects on predicted performance

Issue 2.7 Repository design effects on predicted performance

KEY ISSUE 3. ENVIRONMENTAL PROTECTION DURING REPOSITORY AND TRANSPORTATION ACTIVITIES AND PROTECTION OF PUBLIC HEALTH AND SAFETY DURING TRANSPORTATION

KEY ISSUE 4. FEASIBILITY OF REPOSITORY BASED ON REASONABLY AVAILABLE TECHNOLOGY AT REASONABLE COST

Issue 4.1 Siting guidelines on cost and feasibility

Issue 4.2 Effects of repository design and operating procedures

on nonradiological health and safety of workers

Issue 4.3 Adequacy of waste-package production technologies

Issue 4.4 Adequacy of repository technologies

Issue 4.5 Adequacy of waste-package and repository cost estimates 
related to the numerical criteria associated with issues $2.1,2.2$, and 2.3 . Issues 1.9 and 2.5 address the postclosure and preclosure system siting guidelines of $10 \mathrm{CFR}$ Part 960. Since these system guidelines reference the technical criteria of $10 \mathrm{CFR}$ Part 60 , the performance assessments for these two issues are related to those conducted for the other performance issues. The design of the repository is addressed by issues $1.10,1.11,1.12,2.6$, and 2.7. The postclosure design issues, $1.10,1.11$, and 1.12 are derived from the design criteria of $10 \mathrm{CFR} 60.133$ and 134 , which generally require that the design meet the postclosure performance objectives. Therefore, the performance assessments for these issues are closely related to those for issues 1.1 through 1.6. Issues 2.6 and 2.7 address general preclosure design considerations beyond those addressed by issues $2.1,2.2$, and 2.3 .

To resolve these issues, it is necessary to obtain information about the repository system and its subsystems. For the issues related to preclosure radiological safety, the major subsystems are the site, the repository, and the waste package. The site consists of the surface and the lithosphere within the controlled area. The surface includes the hydrologic and meteorologic conditions, the topographic features, and the surficial deposits that extend to the depth of the foundation of the surface facilities. The lithosphere includes the host rock in which the shafts, ramps, and the underground facility are constructed. The preclosure repository consists of the surface and underground facilities for the handling, disposal, and, if needed, retrieval of the radioactive wastes. For the purpose of preclosure safety analyses the waste package consists of the waste form and the container used for waste handling and emplacement.

For the postclosure performance issues, the major subsystems are the natural barriers and the engineered barriers. The natural barriers consist of all of the geologic barriers of the system, including the host rock, the other geologic units in the unsaturated zone, and the geologic units beneath the water table. The natural barriers include geologic units both inside and outside the controlled area. In regard to the natural barriers, the information needed to resolve the postclosure performance issues includes the geologic, geohydrologic, and geochemical conditions; tectonics; rock characteristics; and the climatic conditions that could affect the natural barriers.

The engineered barriers consist of the waste package, the repository engineered barriers, and the seals for shafts, ramps, and boreholes. The waste package consists of the waste form, the disposal container, and any other components, such as canisters, stabilizers placed into the disposal container, and any packing material. The repository engineered barriers consist of the openings in the host rock, the backfill materials placed into these openings, and any drift seals designed to reduce the movement of ground water or radionuclides through the openings. The shaft, ramp, and borehole seals consist of structures to reduce the flow of water to the underground facility or to inhibit the movement of radionuclides to the surface. Because of the definition in 10 CFR Part 60 and the requirements on these barriers, the "engineered-barrier system" includes all of the engineered barriers, except for the shaft, ramp, and borehole seals. In regard to this system, the information that is needed to resolve the postclosure-performance issues includes the fluid, chemical, thermal, mechanical, and radiation conditions that affect these subsystems. 


\subsection{ISSUE-RESOLUTION STRATEGIES}

The Site Characterization Plan (DOE, 1988a) describes the general plans for resolving each of the issues of the issues hierarchy, including the performance issues directly related to the numerical criteria of $10 \mathrm{CFR}$ Part 60. The Site Characterization Plan (SCP) provides only a summary of the performance assessments that will be used in the issue resolution. The role of performance assessments in the issue-resolution strategies is described in more detail here.

Figure 2-1 shows the general approach to the resolution of issues in the geologic repository program. Performance assessment plays a role in virtually all steps in this approach. Figure 2-2 shows the general logic of these performance assessments. Considering the description of the system to be evaluated and the specification of the issue in the issue resolution strategy, the first step in the performance assessments is then to identify the measures of performance and to determine a methodology for the evaluation. The second step is to develop conceptual models of the repository system and the conditions, processes, and events that must be considered in evaluating the performance measures. These models are developed with information from site characterization and the designs of the repository and the waste package.

The next step in performance assessment is to select the computational models (i.e., computer codes or other analytic techniques) that will be used in the evaluation of the performance measures. In many cases, the development of conceptual models and the selection of computational models will be very closely coupled. The next step in performance assessment is to apply the computational models to predict the performance measures. These analyses must be followed with both quantitative and qualitative analyses of the sensitivity of the performance measures to features of the system and of the uncertainties in the models and the data used in the performance assessments.

These steps in the performance assessment are discussed in more detail in Chapter 3. The simple, sequential logic in Figure 2-2 does not address the closely coupled nature of the steps of the performance assessments. For example, several of the steps may be completed in concert with one another. In addition, the logic diagram does not address the full scope of iteration that may actually take place. For example, after each step of the performance assessment, it is appropriate to ask whetler the existing information is adequate to proceed to the next step; if additional information is needed or if uncertainties are too great to proceed, then additional testing and design may be conducted to provide the needed information.

\subsection{OVERVIEW OF GEOLOGIC REPOSITORY PROGRAM MILESTONES}

Performance assessments are expected to provide information for major program documents, including the Safety Analysis Report (SAR), the Environmental Impact Statement (EIS), and the Site Recommendation Report. In addition, performance assessment will provide input into the testing and design programs and will therefore be required to meet the major milestones of these programs. Critical information for the performance assessments is 
$\frac{8}{8}$

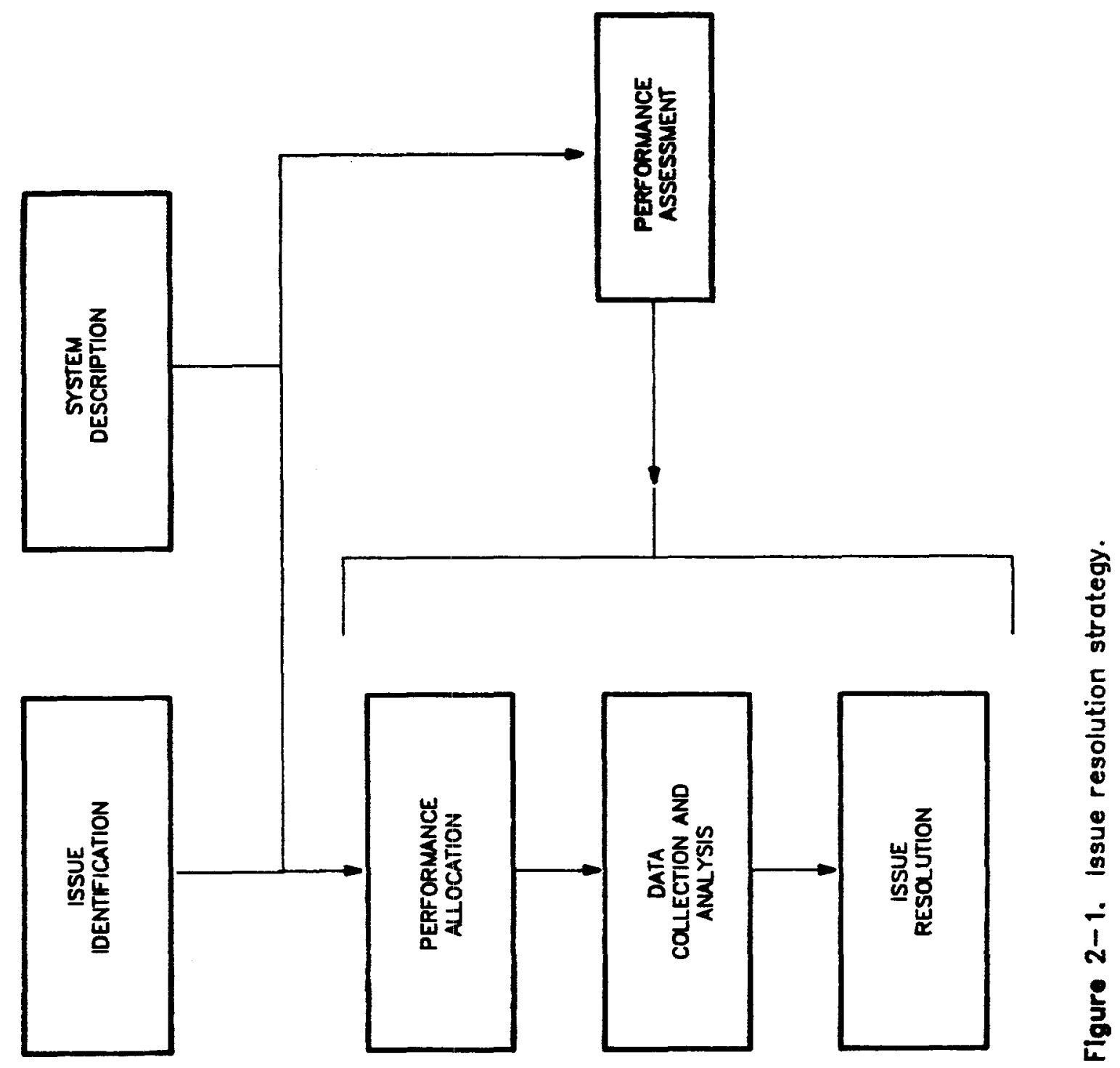




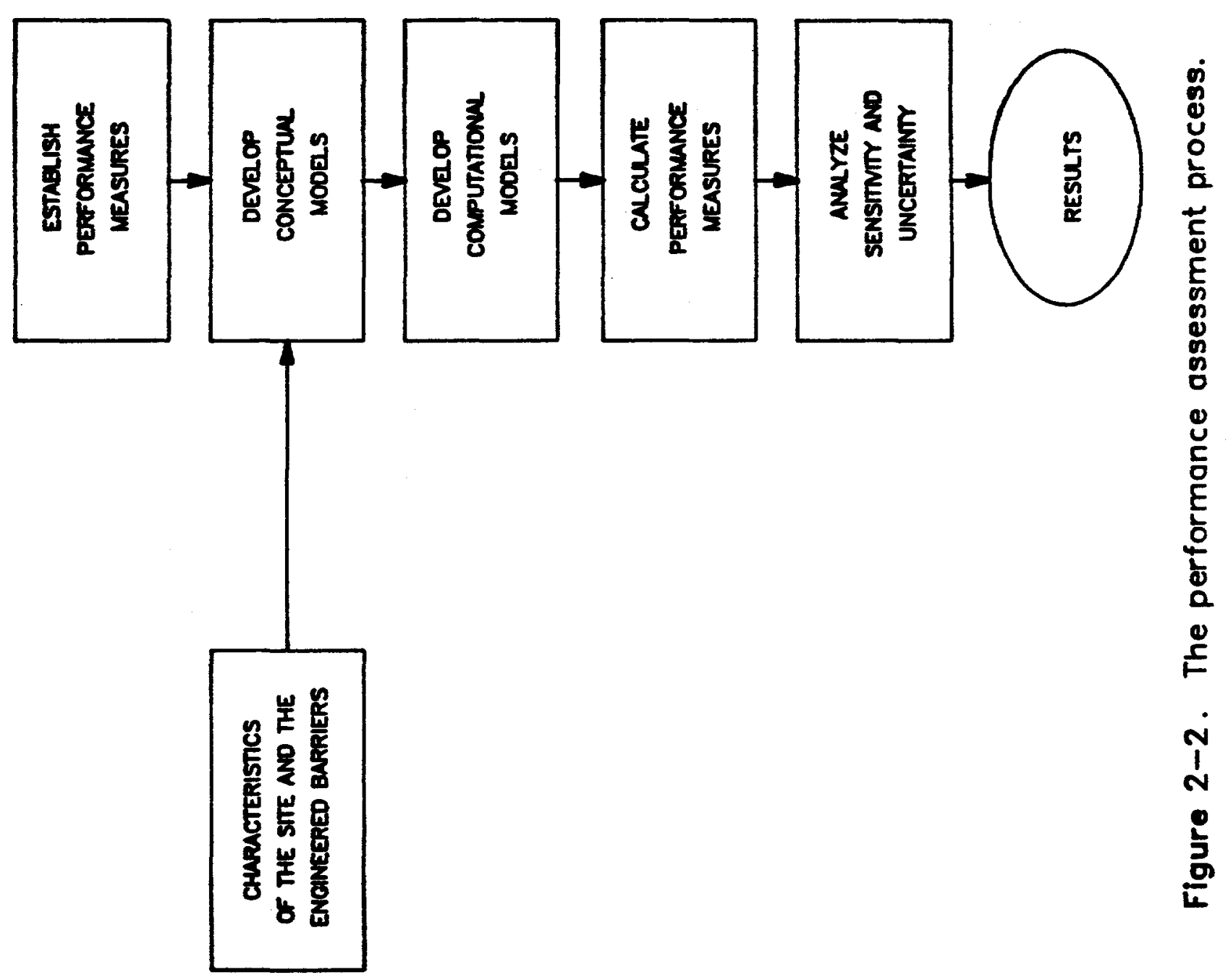


expected from the designs of the repository and the waste package, the surface-based drilling program and in-situ testing during site characterization and laboratory testing. The site characterization and design activities will provide the data, conceptual models, boundary conditions, and their associated limitations needed for the performance assessments.

The major program milestones that affect the scheduling of performance assessment activities are provided in Table 2-2. These milestones are based on the repository schedule presented in the November 1989 report to Congress on the reassessment of the Civilian Radioactive Waste Management Program (DOE, 1989b). These milestones and the activities required to accomplish them are discussed further in Chapters 4-10. An integrated performance assessment program schedule is presented in Chapter 11 . If the schedule for the major program milestones changes, the performance assessment program schedule will change; further, if the schedule changes significant1y, the strategy for conducting the performance assessments could change.

These milestones naturally define three phases for the performance assessment program. The first phase is the early site investigation phase during which the early surface-based testing is performed, the Exploratory Shaft Facility is designed and constructed, and the Advanced Conceptual Designs for the repository and the waste package are completed. The next phase is the "EIS PA" phase in which the performance assessments for the draft EIS are completed; in addition, analyses for the License Application Designs for the repository and the waste package and surface-based testing and in situ testing at depth are conducted during this phase. The third phase is the "SAR PA" phase in which the performance assessments for the SAR, for the LADs for the repository and the waste package, and for the Site Recommendation Report are completed. In addition, any analyses to support the final EIS would be conducted.

The major program milestones in Table 2-2 only include those up to and including submittal of the License Application (LA) to the Nuclear Regulatory Commission (NRC). Performance assessments will also be needed after submittal of the LA. For example, analyses will be needed to support the hearings on the LA, for any amendments to the IA, for evaluation of the performance confirmation program, and for other matters. The current strategy is focused on the performance assessments needed to support the milestones in Table 2-2; the strategy for performance assessments to be conducted after submittal of the LA will be developed later. 
Issue Waste Management System Requirements Document

Submit preliminary recommerdations on all. licensing strategies

Complete drill rig acceptance tests

$6 / 90$

Issue draft revision of ESF requirements

$6 / 90$

Complete Waste Package Program Plan

$8 / 90$

Complete required OCRWM QA qualification audits

$8 / 90$

Provide recommendations on all. licensing strategies

$9 / 90$

Issue recommendation on prioritization of surface-based testing

Complete report on prioritization of surface-based testing

$9 / 90$

Complete prerequisites for surface-based testing

$10 / 90$

Provide recommendations on ESF configuration

$10 / 90$

Complete Repository Program Plan

$11 / 90$

$12 / 90$

Obtain Yucca Mountain Site access

$12 / 90$

Start new surface-based testing

$1 / 91$

Start final ESF Title II design

$3 / 91$

Start ESF site preparation

$6 / 92$

Start waste package Advanced Conceptual Design

$10 / 92$

Start repository Advanced Conceptual Design

$10 / 92$

Start ESF shaft collar construction

$11 / 92$

$3 / 94$

$9 / 95$

$6 / 96$

Start waste package License Application Design

$6 / 96$

Start repository License Application Design

$10 / 97$

Issue geologic repository EIS notice of intent

$11 / 97$

Complete ESF underground drifting

Issue geologic repository EIS Implementation Plan

Issue draft EIS

Start repository Final Procurement and Construction Design

$2 / 98$

$10 / 99$

$1 / 01$

$3 / 01$

$4 / 01$

Issue Site Recommendation Report to the President

$4 / 01$

Submit License Application to the NRC

$10 / 01$

- Al1 milestone dates are from DOE (1989b). 


\section{CONCEPTS AND STRATEGIES FOR PERFORMANCE ASSESSMENT}

This section discusses concepts and general strategies needed for the performance assessments. These discussions address performance measures (Section 3.1), conceptual models (Section 3.2), computational models (Section 3.3 ), the calculation of performance measures (Section 3.4), and the treatment of uncertainties in the analyses (Section 3.5). The particular performance assessment strategies fall into several categories: assessments of the postclosure performance of the total system, the engineered-barrier system, the natural barriers, and preclosure safety assessment. The strategies for each of these four performance assessment areas are discussed in Section 3.6. These strategies were developed specifically for the resolution of the performance issues of the DOE issues hierarchy (see Sections 2.2 and 2.3) and the role of these strategies in the issue resolution strategy is given in the Site Characterization Plan (1988). References to specific sections of the Site Characterization Plan are given in Section 3.6 of this plan.

\subsection{PERFORMANCE MEASURES}

Performance measures are the variables used to gauge the performance of the repository system or its subsystems in the resolution of issues; they are the principal quantities evaluated in performance assessments. The performance measures must be specified before performance assessment can begin.

The performance measures that are to be evaluated in the performance assessments are summarized is Table 3-1. These are the performance measures specified in the performance objectives of 10 CFR Part 60 . Review of all the technical criteria of $10 \mathrm{CFR}$ Part 60 and other requirements applicable to the repository program indicates that these performance measures in fact provide a complete set for the performance assessment program. The review of the performance objectives and the other requirements to identity performance measures is discussed in the following subsections.

\subsubsection{Performance Measures From the Performance Objectives of 10 CFR Part 60}

The technical criteria of Subpart $E$ of 10 CFR Part 60 include performance objectives for the geologic repository that include requirements on certain variables of the repository system. These variables define performance measures for the system.

\subsubsection{Performance measures for preclosure radiological safety}

The preclosure performance objective of $10 \mathrm{CFR} 60.111$ (a) identifies measures of performance for the repository system before permanent closure and criteria for these measures. In particular, this objective requires that the radiation doses received by repository workers and members of the general public from preclosure operations conducted under normal conditions must meet the numerical criteria specified in 10 CFR Part 20 and 40 CFR Part 191, Subpart A. Therefore such doses are legitimate performance measures for the preclosure system. 
TABLE 3-1. Performance Measures for the Repository System

Preclosure radiological safety

- Doses to members of the general public from normal operations.

o Doses to repository workers from normal operations.

- Doses to members of the general public from preclosure accidents.

Postclosure performance of the total system

- Cumulative release of radionuclides to the accessible environment.

o Annual doses to individuals.

o Concentrations of radionuclides in special sources of ground water.

Postclosure performance of the engineered-barrier system

- Time of containment of wastes within waste packages.

- Rate of radionuclide release from the engineered-barrier system after the containment period.

Performance of the natural barriers

- Pre-waste-emplacement time of ground-water travel from the disturbed zone to the accessible environment along the fastest path of likely radionuclide travel. 
In the same vein, doses to members of the public could be used as measures of system performance for accidents that occur before permanent closure. Although no criteria are currently specified in the regulations for doses from accidents, such doses are usually evaluated in preclosure safety assessments and are used in $10 \mathrm{CFR} 60.2$ to define what is meant by systems, components, or structures important to safety. Therefore, it makes sense to consider the doses to members of the public from accidents as additional performance measures.

\subsubsection{Measures of postclosure performance of the total system}

The postclosure system performance objective of 10 CFR 60.112 implements the EPA environmental standards for postclosure system performance. The standards were specified in 40 CFR Part 191, Subpart B, but were remanded and vacated in July 1988. They specified performance measures as well as criteria for these measures. Subpart B will be repromulgated later.

Three quantitative criteria are specified in the vacated standards: containment requirements, individual protection requirements, and ground-water protection requirements. The containment requirements specify criteria for the probability of cumulative releases of radionuclides to the accessible environment. This performance measure is to be evaluated for undisturbed conditions, disturbances due to repository construction and waste emplacement (e.g., temperature increases due to the heat generated by the radioactive decay of the waste), and disruptive conditions due to processes or events that are reasonably likely to occur. The individual protection requirement applies to undisturbed performance only and specifies limits for the annual dose received by individuals outside the controlled area. The requirement for ground-water protection also applies only to undisturbed performance and specifies limits for concentrations of released radionuclides in special sources of ground water.

These performance measures apply to releases of radioactive material to the accessible environment and therefore provide the measures of waste isolation. While it is possible that some changes to these performance measures may be made in the repromulgated environmental standards, conceptually different measures are not likely; therefore, the performance assessment program has been structured around these measures. When the standards are repromulgated, appropriate modifications can be made in the program, if necessary.

\subsubsection{Measures of postclosure performance for the engineered-barrier system}

The subsystem performance objectives of 10 CFR 60.113 specify criteria for the performance of the engineered-barrier system (i.e., the set of engineered barriers excluding the shaft, ramp, and borehole seals) under anticipated processes and events. These criteria require that the containment of the waste within the waste packages be substantially complete for a specified period after permanent closure and that the annual release of any 
radionuclide from the engineered-barrier system after the containment period be less than a specified fraction of the 1000-year inventory of that

radionuclide or of the total inventory. The DOE performance allocation process has defined the performance measures to which the numerical criteria are applied as the time to the loss of containment by the waste package and the rate of radionuclide release from the waste package after the containment period.

\subsubsection{Measures of performance for the natural barriers}

The only criterion in 10 CFR Part 60 that applies to the natural barriers is the requirement in $10 \mathrm{CFR} 60.112$ on the pre-waste-emplacement time of ground-water travel along the fastest path of likely radionuclide travel from the disturbed zone to the accessible environment. The pre-waste-emplacement ground-water travel time therefore is used in the strategy as the performance measure for the natural barriers. Additional performance measures could certainly be considered for the natural barriers. An example is the time of travel to the accessible environment for radionuclides either by the ground-water pathways or by gas pathways in the unsaturated zone. However, the current DOE strategy focuses on the performance measure defined in 10 CFR 60.113 .

In general, the time of ground-water travel would be calculated as a distributed quantity because of uncertainty in models and data and because of the natural heterogeneity in geohydrologic parameters. Therefore, the actual performance measure around which assessments of natural-barrier performance are structured is the cumulative distribution function for the ground-water travel time.

\subsubsection{Siting Criteria of 10 CFR Part 60}

The siting criteria of 10 CFR 60.122 specify a number of specific favorable and potentially adverse conditions that must be explicitly investigated for the site. Part of these investigations is to determine the effect on waste isolation of the potentially adverse conditions that may be present at the site. The measures of performance in this case are the measures identified with waste isolation--namely, those specified in the EPA postclosure environmental standards. These performance measures are discussed in Section 3.1.1.2.

\subsubsection{Design Criteria of 10 CFR Part 60}

The design criteria of 10 CFR $60.130-135$ do not identify any performance measures beyond those specified for the performance objectives of $10 \mathrm{CFR}$ 60.111-113. For example, the section on general design criteria references the limits specified in $10 \mathrm{CFR}$ Part 20 and specifies quantitative considerations for systems, components, and structures important to safety. Likewise, the section on additional design criteria for surface facilities, 10 CFR 60.132, references the requirements of 10 CFR $60.111(\mathrm{a})$. The applicable performance measures in these cases are those identified in Section 3.1.1. 
The additional criteria for the underground facility (10 CFR 60.133), the criteria for the design of seals (10 CFR 60.134), and the criteria for the waste packages ( $10 \mathrm{CFR} 60.135$ ) require that these elements contribute to waste containment and isolation or do not compromise the ability to meet the associated performance objectives. Therefore, the performance measures in this case are those identified for the performance objectives of $10 \mathrm{CFR}$ 60.111-113. It is noted that the design criteria for the seals of shafts, ramps, and boreholes also specify that the seals are not to create preferential pathways for the migration of radionuclides. This requirement is interpreted to mean that release to the accessible environment is not to be increased by the seals, and again the performance measures in this case are those identified in Section 3.1.1.

\subsubsection{Performance Measures for Other Analyses}

The performance measures associated with the numerical criteria of $10 \mathrm{CFR}$ Part 60 are those that must be addressed in the safety analysis report (SAR) that is to be included in the license application to the NRC. There are other analyses that must be conducted. For example, analyses will be conducted for the environmental impact statement (EIS), for the evaluation of site suitability, and for the design and testing programs.

The particular analyses that will be conducted for the EIS will be defined during the scoping of the EIS, and the precise form of the performance measures cannot be determined until the scoping process has been completed. However, the guidelines issued by the Council on Environmental Quality (CEQ) in 40 CFR Part 1500 for the preparation of environmental documentation and previous experience provide general guidance that is helpful. This guidance suggests that environmental impacts like radiation doses or health effects should be evaluated. The CEQ guidelines also indicate that the consequences and probabilities of worst-case accidents and disruptions should be evaluated. Furthermore, it is expected that these effects would be evaluated for a long time after permanent closure, perhaps 1onger than the 10,000-year period specified in the EPA postclosure environmental standards. Therefore, it is possible that the performance assessments conducted for the EIS may be required to evaluate measures somewhat different from those for the SAR; however, it does not appear likely that the measures will require drastically different approaches than those used for the SAR.

\subsubsection{Surrogate Performance Measures}

Performance measures other than those in Table 3-1 have been used in past performance assessments. For example, this was the case in analyses conducted for the environmental assessment (DOE, 1986b) and for the decision-aiding methodology used to recommend sites for characterization (DOE, 1986c). At the early stage of the program in which these assessments were conducted, all the site data needed to calculate the performance measures listed in Table 3-1 were not available. In these cases performance measures that could be evaluated with the available data and that could serve as effective surrogates for the true performance measures were defined. For example, the radionuclide-travel time was used as a surrogate performance measure to bound 
releases to the accessible environment in the analysis performed for the decision-aiding methodology. The use of surrogate performance measures may be continued in some of the future performance assessments, particularly where knowledge regarding a part of the system is absent or very uncertain; however, in such cases any such surrogate measures will in general be directly related to the performance measures in Table $3-1$.

\subsection{CONCEPTUAL MODELS}

Once the performance measures to be evaluated in the performance assessments are specified, the models needed to evaluate these variables can be defined. These models include the conceptual models of the site, models used to represent and evaluate scenarios, and process and constitutive models. The site conceptual models include representations of the geologic features, the geohydrology, the geochemistry, the tectonic regime, and other aspects of the site needed for the performance assessments. Scenarios are the sequences of processes and events that could affect the performance measures.

These conceptual models depend on the characteristics of the natural and the engineered barriers. In many cases these characteristics are determined during the development of the model itself. For example, the geohydrologic characteristics of the site are often determined as part of the development and use of geohydrologic conceptual models and flow models to interpret information about the site. In these and other analyses of the characteristics of the natural and the engineered barriers, the process of specifying the characteristics is of ten indistinguishable from the process of defining the needed models.

\subsection{COMPUTATIONAL MODELS}

Computational models are needed for the quantitative evaluation of the performance measures. Computational models generally mean computer codes but other techniques are also possible, e.g. evaluation using analytic solutions. Some of these computational models must be extremely complex because they must represent details of complex processes; computer codes of this type may take many hours for a single run on a high-speed computer. Other must be, by comparison, simple and fast running, because they may be run many times to evaluate performance measures. In discussing the strategies for evaluating performance measures (as in Section 3.6), it is convenient to describe the computational models in terms of three levels of complexity; process-level codes, subsystem-level codes, and total-system-level codes. The boundaries between these levels of complexity are not well defined and some codes may, in fact, fit into more than one level, depending on how they are used in a particular evaluation. Describing the levels, however, helps to explain the code-development needs of performance assessment and the levels of effort that the strategies require.

At the most complex leve1, process-level codes calculate details of physical phenomena. These codes are typically long (perhaps thousands of lines of code), require runtimes as long as several hours on supercomputers, 
and model the basic phenomena that underlie the overall behavior of a repository. Such codes are useful for understanding fundamental physical and chemical processes; for this reason they are sometimes called "research" codes. They produce the results that must be combined to describe the overall behavior of repository components. Modeling at this level is not appropriate for the direct evaluation of performance measures.

At the subsystem-level, the models of phenomena are less complex because such codes must generally represent many processes and detailed treatment of every process is of ten not practical nor necessary. These computational models are referred to here as subsystem codes because they explicitly evaluate specific components or subsystems of the total repository system. For example, a study of waste-package lifetime would probably use a subsystem-level code that combines the modes of container degradation with processes that determine the environments in the vicinity of the waste package. The fundamental information about the degradation processes would have been developed with process-level codes and might appear as submodels in the subsystem-level formulation. A subsystem-level code may, in fact, represent the entire system, providing a detailed representation of each of the subsystems. Subsystem-level codes may be appropriate for the direct evaluation of some performance measures.

Total-system-level codes are used to represent using more simple representations of the elements of the system more simply than the subsystem-leve1 codes. They use simpler mode1s for the subsystems and they use simpler mathematical descriptions of the processes and constitutive relations. They may actually omit elements that the modeling at the subsystem or process level have shown to be unimportant. Such simplified codes are needed at the total system level because it may not be practical to couple all the detailed models of phenomena that might occur in a single code used for calculating probability distributions or for other repetitive analyses. A total-system-level code therefore incorporates all the phenomena that are significant to the performance measures, but does so simply enough to make practical evaluations possible.

The codes at all three levels will need to be verified. Verification, according to the guidelines in NUREG-0856 [Silling, 1982], is the provision of assurance that a code correctly performs the operations it specifies. A common method of verification is the comparison of a code's results with solutions obtained analytically. Analytic solutions are usually possible only for problems that, in comparison with the problems that computer codes will solve, have simple boundary and initial conditions and simple material properties. Verification of all the parts of a single code may therefore require comparison with several analytic solutions. In some cases verification of all the parts of a single code using analytic solutions simply may not be possible.

Other verification methods are possible. Benchmarking is a useful method that consists of using two or more codes to solve related problems and then comparing the results. When the participants in a benchmarking exercise can discover the reasons for discrepancies among their results, they can usually find coding errors that caused the discrepancies. Benchmarking is most useful 
for codes whose development is nearly complete. It is time-consuming and requires that the problems be careful1y defined, that the results be compared in great detail, and that the reasons for discrepancies be understood. Not all discrepancies are due to errors: the differences in numerical techniques among codes frequently make it difficult for benchmarking calculations to be truly identical, and the participants must diligently separate differences due to errors from legitimate differences. Experience has shown that benchmarking can produce many valuable insights in addition to the correction of coding mistakes.

\subsection{QUANTITATIVE ANALYSIS OF PERFORMANCE MEASURES}

Once subsystem-1evel or total-system-level computational models have been developed and parameters are available as input for analyses, the performance measures can be calculated. A complete assessment requires not only the application of a computational model, but careful attention to the uncertainties in the p.3rameters and the conceptual models. Both qualitative and quantitative sensitivity and uncertainty analyses are needed to provide proper perspective for the assessment.

\subsubsection{Use of Deterministic and Rrobabilistic Calculations}

In deterministic calculations, single values of input parameters are used to calculate single values of the performance measures. Probabilistic analyses involve the analysis of input-paraneter probability distributions to calculate probability distributions for the performance measures. Several of the-performance measures are probabilistic and will require such probabilistic calculations; an example is the probability distribution for cumulative radionuclide releases and the time of ground-water travel. However, even the deterministic performance measures can be evaluated probabilistically to address uncertainties in the parameters.

There are several techniques for performing probabilistic analyses, such as the Monte Carlo techniques that rely on sampling from input parameter probability distributions. Efficient variance-reduction techniques have been developed to optimize sampling in such techniques. Furthermore, where appropriate, simplifications in the calculational models (e.g., neglecting inconsequential processes or components) can be made to simplify the calculation.

\subsubsection{Conservatism in the Analyses}

The calculations of the performance measures should be conservative; that is, the values of the parameters and the assumptions in the calculational models should be chosen in such a way that impacts and consequences are not under-predicted. There are many types of sonservative analyses, ranging from realistically conservative to bounding analyses. Realistically conservative analyses use values for parameters that are conservative but close to the expected values; for example, where a probability-density function for an 
input parameter is known, the realistically conservative analyses might use a conservative value that is within one standard deviation of the mean value. Where the expected value is not known precisely, the parameter values that are used should be reasonable values--that is, values that are in a direction to ensure conservative results, but not so extreme as to provide unrealistic results.

Bounding analyses are conservative analyses in which extreme assumptions are used to ensure that the impacts are overestimated. Several types of bounding approximations are possible: (1) where several alternate conceptual models exist, the most conservative of these can be used to represent the system; (2) where a particular process is not we11 understood, representations for mass, momentum, or energy transfer that bound the process can be used to substitute for the actual process; (3) where parameter values are uncertain, extreme values, well outside the range of uncertainty, can be used; or (4) a favorable process or effect can be neglected altogether.

Such bounding approximations are useful for addressing uncertainty in comparisons between model predictions and regulatory standards. Such an approach is also useful in decreasing effort and resource expenditures when there is confidence that an explicit treatment of some process can safely be omitted from the analysis.

\subsection{SENSITIVITY AND UNCERTAINTY ANALYSES}

A significant element of any performance assessment is the analysis of sensitivities and uncertainties in the assessment. Sensitivity analyses are conducted to identify important elements and parameters of the system and involve estimates of changes in performance measures produced by changes in the variables of the system. Uncertainties are analyzed to identify those associated with the important elements and parameters of the system and to understand the impacts of these uncertainties on the conclusions that might be drawn from the calculations of the performance measures.

\subsubsection{Types of Uncertainty In The Assessments}

Uncertainties in the assessments arise from uncertainties in parameters, uncertainties in the conceptual models of the site and of the processes and events anticipated to occur at the site, and uncertainties associated with potential evolution of the system due to unanticipated processes or events.

Parameter uncertainty is the uncertainty in the variables of the mode1s used in the analysis. Such uncertainties can arise from insufficient measurement or variability in the system that cannot be explicitly taken into account. For example, variability in site characteristics due to heterogeneity in the site may lead to such uncertainties. In some cases, such uncertainties can be addressed through development of probability density functions for these characteristics or by conducting analyses using values believed to bound the uncertainty. 
Uncertainty in the conceptual models is, more general than parameter uncertainty and arises from incomplete knowledge about the characteristics of the natural and engineered barriers. In some cases, significant uncertainties in the these characteristics may remain even after site characterization. Efforts to address such uncertainties include the development of alternate conceptual models, testing of alternate hypotheses, and analyses that attempt to bound the uncertainties in the models.

Uncertainties in the evolution of the system are addressed through the development of a comprehensive set of scenarios that take into account unanticipated processes and events and possible disturbances to the system arising from these processes and events.

\subsubsection{Sensitivity Ana1yses}

Sensitivity analyses are conducted to identify the elements of the system, the conceptual models, and the parameters that affect performance significantly. Such analyses are used, for example, to identify areas in which simplifications in the computational models can be safely made. Such analyses are also used for the testing and design programs to determine areas that should be emphasized and to identify priorities for the allocation of resources; they are used to identify areas where uncertainties may be particularly important, for example, and where additional testing may be needed.

In the development of any model, some factors are ignored on the basis of subjective understanding about the sensitivities in the system. For example, processes that occur very far from the repository site of ten are assumed to be negligible without detailed analyses because good judgment concludes that they are not likely to affect the repository. Likewise, it may be concluded that a process or component is important to a performance measure on the basis of conservative assumptions. In most cases, however, explicit analyses are conducted to identify sensitive areas. Sensitivity to a model may be identified by repeated analyses that explore the dependence of the results on changes in the model. In formal, quantitative analyses, sensitivities are expressed in terms of derivatives by calculating the change in the performance measure with respect to unit changes in the model parameters of interest. In such cases, the derivatives are evaluated directly through multiple applications of the calculational models or by more sophisticated techniques. For example, where nonlinearities in the system are not strong, adjoint methods can be used to generate response functions that describe the sensitivities of system.

\subsubsection{Uncertainty Analyses}

Uncertainty analyses are used to identify areas of uncertainty and to evaluate the importance of these uncertainties to the calculated performance measures. Both qualitative and quantitative analyses are used in the evaluation of uncertainties. Parameter uncertainties are generally amenable 
to quantitative analyses. Standard techniques 1ike Monte Car1o or error-propagation techniques can be used in these cases. In Monte Carlo analyses the uncertainties in the parameters are quantified in terms of probability-density functions, and these are sampled to derive probability distributions for the performance measures. These distributions can be compared with the sensitivities to these parameters to estimate the importance of the uncertainties. In error-propagation techniques, expressions for the uncertainties are derived directly from the expressions for the dependence of the performance measures on the parameters.

In many cases uncertainties in the physical models are not amenable to numerical analysis, and qualitative evaluations must be made. Such analyses are made in terms of objective and subjective judgement and reliance on statistical analyses, analyses of trends, and other information.

\subsubsection{Mode1 Validation}

Validation, according to the guidelines of NUREG-0856 (Silling, 1982), is a demonstration that a model as embodied in a computer code is an adequate representation of the process or system for which it is intended. The most common method of validation involves a comparison of the measured response from in-situ testing, laboratory testing, or natural analogs with results of computational models that embody the model assumptions that are being tested. Validation is therefore a process that uses data from site characterization, accelerated in situ and laboratory testing, and performance confirmation to increase the level of confidence in the performance predictions.

Natural analogs may play a role in the mode1-validation process by providing data for comparison with performance predictions involving the processes active in the natural analog. The main benefit of natural analogs is the potential for showing that complex natural systems can be modeled with some degree of confidence. If the natural analogs can be shown to be the result of processes comparable to those operating in the repository, they may be useful in providing data on the response of appropriate geologic environments over a time scale that is much longer than the period for site characterization and performance confirmation.

Laboratory validation testing can provide data from a highly controlled environment and can provide data from accelerated testing experiments that indicate the long-term performance of materials and components. Laboratory validation tests may be useful for augmenting the data from in-situ testing.

Even with data from natural analogs, laboratory testing, and in-situ testing, it may not be possible to validate all aspects of performanceassessment codes and conceptual models. For example, al1 uncertainty in the evolution of processes over the long time scales needed to represent the performance objectives will not be eliminated by laboratory or even field testing. Nevertheless, the basis for the use of a given model in the performance assessment can be stated and subjected to review by competent analysts. 


\subsubsection{Performance Confirmation}

After site characterization and the submittal of the License Application to the NRC, testing will continue during the period of "performance confirmation." This period is expected to provide information that will help to reduce uncertainties in the performance assessments conducted for the License Application.

The objective of the performance-confirmation program is to meet the requirements of Subpart $F$ of 10 CFR Part 60 which requires that the performance-confirmation program provide data that indicate, where practicable, whether(1) the actual underground conditions encountered and any changes in those conditions as a result of construction activities or waste-emplacement operations are within the 1 imits assumed in the licensing review and (2) the natural and engineered systems and components required for repository operation or designed or assumed to operate as barriers after permanent closure are functioning as intended and anticipated.

Although the general approach to performance confirmation is dictated by Subpart $F$ of 10 CFR Part 60 , most of the tests will be those dictated by performance assessments conducted during the site characterization period.

\subsection{PERFORMANCE ASSESSMENT STRATEGIES}

As shown in Table 3-1, each of the performance measures for the repository system falls into one of four performance assessment areas: postclosure performance of the total system, postclosure performance of the engineered-barrier system, postclosure performance of the natural barriers and preclosure safety. The general strategies for each of these areas are described in this section.

\subsubsection{General Strategy for Assessment of the Postclosure Performance of the Tota1 System}

The general strategy for the total system performance assessments has been developed as part of the issue resolution strategies for the performance issues related to total system performance, namely issues $1.1,1.2,1.3,1.8$, and 1.9 (see Section 2.2). Details of the general strategy are presented in Sections 8.3.5.8, 8.3.5.13,8.3.5.14, 8.3.5.15,8.3.5.17, and 8.3.5.18 of the Site Characterization P1an (1988a).

\subsubsection{Summary of the strategy}

The general strategy for the postclosure total system performance assessment must address three postclosure performance measures: the probability distribution for cumulative releases to the accessible environment, the doses received by individual members of the general public from postclosure releases, and the concentrations of radionuclides in special 
sources of ground water. The evaluation of these performance measures must consider significant processes and events--that is, the credible processes and events which, if realized, could have a significant effect on the performance measures. The general approach to the evaluation is to identify the significant processes and events, develop a set of scenarios that describe the ways that these processes and events could affect the performance measures, evaluate the performance measures for these scenarios, and combine the results for the scenarios into a comprehensive evaluation of the performance of the repository system. The general strategy for each of these steps is discussed below.

\section{Strategy for the development of scenarios}

The first step in the development of a set of scenarios is the identification of the processes and events that could significantly affect the performance measures at the site. Generally, categories of processes or events that have a small probability of occurrence at the site will be eliminated from consideration. The current criterion used for such screening is a probability of one chance in 10,000 of occurring during the period of interest (e.g., in 10,000 years after closure). The next step is to assemble these processes and events into combinations that could affect the performance measures. This will be done from two points of view. First, starting from an initiating process or event, sequences of processes and events that could lead to an effect on the performance measures are specified; this is analogous to an event-tree approach. Second, a fault tree approach is used; starting from a potential effect on a performance measure, sequences of events and processes that could lead to that specific effect are defined. This systematic, two-pronged approach will identify a candidate set of scenarios.

In theory, a large set of scenarios could be defined. Multiplicity in combinations of processes and events, variations in sequence and time, and variations in intensity of the contributing processes and events can lead to very large numbers of such scenarios. In practice, categories of scenarios with common processes and events are developed. These categories, or "scenario classes," are usually labeled by the initiating event and the effect on the performance measure. Each scenario class is then represented by a small number of scenarios within the class that are considered to bound the effects of all scenarios in the class. The scenario classes must be comprehensive, and it is useful if they are mutually exclusive. In defining them, these properties should be considered.

In the following discussion, the treatment of expected-performance scenario classes and disturbed-performance scenario classes is described. Expected-performance scenario classes generally refer to conditions that have a high likelihood of occurrence and disturbed-performance scenario classes are those involving conditions that are significantly different from the expected conditions and, therefore, have small probability of occurrence.

Because of the large uncertainties that currently exist at the site, the distinction between "expected performance" and "disturbed performance" is somewhat arbitrary at present. Nevertheless, because of the nature of the 
expected conditions and disturbances to these conditions, it makes sense to make the distinction. In addition, the regulations make the distinction between "undisturbed" performance and disturbed performance. For example, some of the performance measures, notably those related to individual protection and ground-water protection, refer only to undisturbed performance. In this case, the set of expected performance scenario classes are those to be evaluated with regard to undisturbed performance and the disturbed performance scenario classes circumscribe disturbed performance.

There is, of course, a third category of scenario classes. These scenario classes are those involving conditions that are not credible at the site. In general, the rule of thumb is that scenario classes in which combinations of processes and events have less than one chance in 10,000 of occurring during the period of interest are generally excluded from further consideration. Where there is large uncertainty as to whether this criterion is met or where the probability cannot be defined, the scenario is retained.

With regard to scenarios involving human interference activities, the regulations note that such activities are always to be considered as disturbances to the system; consequent1y, such scenarios will be classed as disturbed performance scenarios. The regulations also note that such scenarios can be considered to be credible only if the following factors are taken into account: (1) monuments constructed at the site are sufficiently permanent to serve their intended purpose; (2) the value to future generations of potential resources within the site will be known before construction of the geologic repository; (3) an understanding of the nature of radioactivity and an appreciation of its hazards will be retained; (4) institutions are able to assess risk and to take remedial action as needed; and (5) relevant records are preserved, and remain accessible, for several hundred years af ter permanent closure.

\section{Strategy for evaluating the consequences of expected-performance scenarios}

Appropriate scenario classes will be developed for the expected performance of the repository system. There may be more than one scenario in this class because credible alternate conceptual models may exist to explain the available measured data. For each of these expected-performance scenarios models must be developed for the radionuclide source term; for the transport of radionuclides to special sources of ground water and to the accessible environment; and, for the calculation of doses, for transport in the accessible environment and uptake by people.

The current strategy for determining the source term is to evaluate the radionuclide release from the system of waste packages. This evaluation will involve the analysis of a single waste package for the range of conditions expected in the underground facility. In addition, the source-term evaluation will take into account the distribution of waste packages throughout the underground facility and the variation in performance of different waste packages with time. 
The evaluation will take into account transport of radionuclides by ground water. The evaluation will involve determination of the ground-water flux and velocity, chemical retardation factors appropriate for matrix flow and for fracture flow, non-chemical retardation factors--for example, due to matrix diffusion--for saturated flow in fractures, and the combination of these quantities in appropriate transport models. Transport in both the vadose and phreatric zones will be considered.

The evaluation will take into account the possible release of gas-phase radionuclides (e.g., carbon-14 dioxide) from the waste packages and their subsequent transport through the unsaturated fractures or pore spaces of the rock. The evaluation will involve the determination of potential release rates of gas-phase radionuclides from the waste packages, the flow velocities of the gases through the pore spaces, and the efforts of chemical retardation and dilution upon the gas-phase concentrations. The transport of the dissolved gases in ground water will be evaluated separately.

The consideration of transport in the accessible environment and uptake by people is not required to evaluate the cumulative-release performance measure or the radionuclide concentration in special sources of ground water since both of these are calculated within, or at the boundary of, the controlled area.

Types of biosphere pathways which could be evaluated for the calculation of individual dose include: (1) a pathway with a well at the boundary of the accessible environment in which drinking water is obtained for use by an individual; (2) the well pathway in which the water is used for bathing, for irrigating a garden, and for watering livestock; (3) discharge to a spring; and (4) pathways in which gaseous-phase radionuclides are deposited on garden and farm crops.

Strategy for evaluating the consequences of disturbed-performance scenarios

Scenarios classes will also be developed for the conditions that arise from unanticipated processes or events. Two kinds of such disturbedperformance scenario classes will be evaluated, each involving a different type of strategy. The first kind of disturbed-performance scenario class is that in which the characteristics of the system have values outside the range considered in the expected-performance scenarios. In this case the strategy is similar to that for the expected-performance scenarios. Different conceptual models may be involved in the evaluations. The second type of disturbed-performance scenario class arises from a major disruption of the system resulting in new pathways for the release of radionuclides. In these cases new models may be needed for the source term and for the ground-water or gaseous-pathway transport barriers. New models for biosphere transport and exposure at the surface may be needed. 
The strategy for combining the results for different scenario classes depends upon the nature of the scenarios which must be considered. In the evaluations of performance measures for expected conditions and for which several, equally likely, expected-performance scenarios have been developed, the strategy is very simple. In this case, each of the various expectedperformance scenarios is examined separately. In some cases, the expected-performance scenarios may not be distinct with respect to the performance measure being evaluated; that is, the consequence models and the particular parameters needed to evaluate the performance measure may be the same. However, in other cases, the consequence models for the different scenarios may be different; in these cases,-the most conservative (unfavorable) values calculated among the scenarios will be chosen to represent the expected-performance scenario class.

The strategy for the evaluation of performance measures in which expected-performance and disturbed-performance scenario classes are considered together is more complex. The first step is to determine which of the scenarios are to be explicitly taken into account. As in the previous case, the most conservative of the equally-1ikely expected-performance scenarios will be used to represent the expected performance scenario class. Likewise, for each of the disturbed-performance scenario classes, the disturbedperformance scenarios for the most conservative conceptual model is taken into account. It is assumed that there is no other basis for selecting the scenario.

The next step is to combine the scenarios that have been selected to represent each scenario class. Ideal1y, the consequences (performance measure values) for each of the representative scenarios would be weighted by the probability of its scenario class and added together to provide an estimate of the overall value of the performance measure. For example, the estimate of the overall complementary cumulative distribution function (CCDF) for release to the accessible environment could be estimated in this way from the CCDFs for each selected scenario. Representing the overall CCDF by $\operatorname{Pr}(M>m)$, the probability that the releases, $M$, exceed a specified value, $m$, and the conditional scenario $C C D F$ by $\operatorname{Pr}\left(M>m \mid S_{j}\right)$, where $S_{j}$ is the designator of the scenario class, the procedure gives:

$$
\operatorname{Pr}(M>m)=\sum_{j} \operatorname{Pr}\left(M>m \mid s_{j}\right) P\left(S_{j}\right)
$$

where $P\left(S_{j}\right)$ is the probability that only scenarios of the $j$ th class occur. In this case

$$
\sum_{j} P\left(s_{j}\right)=1
$$

This approach to combining the scenario classes can be accomplished if the scenario classes are independent and comprehensive, and if the scenario class probabilities are known. However, in practice it may be difficult to satisfy all of these conditions rigorously. The possibility of alternate conceptual mode1s, lack of data on past occurrences of phenomena, and incomplete models for processes and events will make estimates difficult and 
contribute to this difficulty. Without the benefit of adequate models to determine the probabilities it will be necessary to evaluate scenario classes individually. Where relative probabilities can be estimated, the scenario classes will be combined in a way analogous to that considered previously. That is, the results for these scenario classes will be weighted by their relative probabilities and added together to estimate the consequences for that set of scenario classes alone.

\subsubsection{Conceptual models for total system performance}

A number of conceptual, process, and constitutive models will be needed for total-system performance assessments. In some cases the conceptual models will be developed from information obtained for other areas. For example, conceptual models of the ground-water flow developed for assessing the performance of the natural barriers and the waste-package process models developed for assessing the performance of the engineered-barrier system will be useful for the natural and engineered-barrier components of the tota1-system mode1.

In other respects, however, the total-system performance models will need information that does not have an analog in the other areas and must be developed independently. For example, the models for the impacts due to disruptive processes acting on the barriers will have to be developed to support total-system performance assessments. Models for gas transport and for radionuclide transport by ground water through the natural barriers will also need to be developed. Models for transport through engineered barriers other than the waste package, such as the shaft, ramp, and borehole seals, may need to be developed. Finally, models for transport in the biosphere will also need to be defined.

It is likely that simplifications can be made to the subsystem models when constructing a model for the total system because many of the variables are likely to be relatively unimportant for system performance. Such simplifications will be useful and necessary because of computational complexities and associated limitations. The simplifications for total system codes is discussed in Section 3.3.

\section{Scenario models}

Madels associated with various scenarios will be developed to define a framework to evaluate consequences and for determining scenario probabilities. Models will be developed for several types of scenarios: scenarios for expected or undisturbed conditions, scenarios for extreme conditions (i.e., conditions outside the ranges of those considered for the expected cases), scenarios for natural disturbances of the repository system, and scenarios for human interference with the repository system.

The general approach to the development of these scenarios is first to identify the various credible alternate conceptual models for the repository system, including the natural and the engineered barriers. For example, 
alternate conceptual models can arise from features of the site that have not yet been discovered but cannot be ruled out. Then, for each conceptual model it will be necessary to identify the set of processes and events that would play a role in performance (i.e., that would directly or indirectly affect the performance measures). The specification of these various possibilities defines a set of scenario classes for expected conditions.

The scenarios for extreme conditions are simply variations of the expected, scenarios in which parameters take values outside the ranges considered in the expected-performance scenarios classes. For example, values of saturated hydraulic conductivity much larger than those considered for the expected-performance scenarios may be taken into account in these scenarios.

Models for scenarios involving natural disturbances to the repository system will be developed to account for tectonic activity (e.g., fault movement), volcanism (e.g., igneous intrusion), and extreme climatic change. In addition to direct disruptions to the underground facility, these processes and events can disturb the conditions at the site (e.g., ground-water flux through the unsaturated zone) and create new ground-water and radionuclidetransport pathways. The models that will be developed will consider the ways the natural disturbances can affect each of the expected-case scenarios.

Models will also be developed for scenarios involving inadvertent human interference with the repository system. Because of the plans to mark the site and to use other passive means to prevent human intrusion into the repository, and because of the intention to ensure that the site will have little value in unique resources, large-scale human activities that would inadvertently affect the repository are not likely to take place at the site. According1y, the only scenarios currently considered for this case are those involving occasional, random exploratory drilling at the site. Models for two kinds of events will be developed: (1) the interception of a waste package by the exploratory borehole, allowing the waste to be brought to the surface with the drilling fluid, and (2) boreholes that pass through the repository and create special pathways for radionuclide migration to the accessible environment.

These models will be used to estimate probabilities for the scenarios. The probabilities for scenarios involving natural disturbances will be estimated from the probability of the disturbing process or event. The probability for the human-intrusion scenarios is more problematic since it is difficult to predict the probability of a particular human activity far into the future. Bounds on these probabilities will be estimated by considering historical information about exploratory drilling in formations similar to that of the repository site. It will be difficult to estimate the relative scenario probabilities associated with the different conceptual models of the site. In some cases estimates can be made in terms of the likelihood of certain conceptual models based on the exploration of the site that has occurred and the characteristics typical of the formation. 


\section{Waste-package models}

Physical models for the waste packages will be developed as a part of the performance assessments for the engineered-barrier system. The models for the undisturbed performance of a single package and for the ensemble of waste packages in the repository are discussed in Section 3.6.2.1. These models will serve as the basis for those to be developed for the total-system mode1.

Two kinds of models will be developed. The first is a comprehensive model that involves virtually all of the processes taken into account in assessing engineered-barrier performance. This model will be used in the total-system analysis to identify the key parameters and factors that need to be considered. The second is a simplified model that represents only the critical elements and processes of the waste package. This model will include a representation for the time of failure of the disposal container and for the rate of release from the waste packages.

\section{Models for other engineered barriers}

In general the models for transport through the shaft, ramp, and borehole seals will involve one-dimensional pathways and simple representations for the transport characteristics along these pathways. Both gas transport and dissolved-contaminant transport will be evaluated. The models will be simplifications of the more general models for transport described below.

Models for the ground-water transport of radionuclides

On the basis of current information, three different representations will be evaluated to represent the transport of radionuclides by ground water:

1. Transport through the rock matrix in the unsaturated zone. In this case the flow may be slow (e.g., because the matrix hydraulic conductivity is small) and chemical retardation effects may be very large. This situation appears to represent the transport through the unsaturated zone.

2. Transport through fractures with weak coupling to the rock matrix. In this case the flows could be rapid and the retardation factors small, both because of the rapid advective component and because the fractures may contain weakly sorbing minerals or be coated to inhibit transfer into the rock-matrix pores. This situation may apply, in some cases, to discharge through a structural feature, such as a fault zone.

3. Transport through fractures with strong coupling to the rock matrix. Under equilibrium conditions, the effective radionuclide transport velocity is the same as that through the rock matrix, and the situation can be represented as transport through an equivalent porous medium. This situation may apply to transport along pathways in the saturated zone. 
Mode?s of the advective, dispersive and diffusive components of transport will be developed for each of the three representations listed above. Knowledge of the advective component requires models of the ground-water flow system to evaluate the mean speciicic discharge; such models are discussed in Section 3.6.3. The conceptuai models in Section 3.6 .3 blso provide a focus for the analysis of total system performance.

The dispersive component of transport requires a statistical characterization of the inhomogeneities in the rock-hydrologic and geochemical properties (including the hydrologic properties of fracture systems); in turn, such a characterization leads to a statistical characterization of the effective transport velocity as a random field. In addition, a characterization of the inhomogeneities in hydraulic conductivity and porosity is necessary for modeling the advective coupling of mass concentrations in the fracture and matrix pore spaces.

The diffusive component requires knowledge of effective diffusion coefficients for various solutes in the rock matrix, the fracture pore space, and at the Interface between the matrix and fracture pore spaces; the last quantity is needed to model diffusive coupling of mass concentrations in the fracture and matrix pore spaces.

The prediction of geochemical retardation factors in transport processes requires models of sorption and precipitation of contaminants under a wide range of physical and chemical conditions in tine rock-water system. The current model assumes that chemical retardation factors can be predicted from chemical equilibrium distribution coefficients and from explicit consideration of precipitation effects through the use of geochemical equilibrium models. The physical retardation that arises through advective and diffusive coupling of solute concentrations may aiso be important, particularly in the saturated zone and locally saturated areas of the unsaturated zone; in this case, exchange of contaminants between fracture and matrix pore spaces may provide significant retardation of the flow of contaminants and will be taken into account. However, sorption and precipitation kinetics may in some cases be important and rieed to be taken into account. Similarly, the formation and transport of colloids need to be addressed.

The radioactive decay of nuclides and ingrowth of daughter products are effects that are easily accounted for in transport models. These effects are incorporated in the transport equations by including terms similar to the terms in the Bateman equations for the dynamics of radionuclide decay chains; the decay constants appearing in these terms are well known fundamental nuclear constants.

The ground-water radionuclide transport will be formulated to take into account potential changes in the flow system and in geochemical conditions that may arise due to the action of disruptive processes and events such as climate change and fault motion. In addition, a model may be needed for the change in flow conditions from the unsaturated zone to the saturated zone in order to transfer the radionuclides concentration in the flow above the water table to that below the water table. 
A few radionuclides, e.g., tritium, carbon-14, krypton-85 and iodine-129, may be transported as gases through the void spaces in the unsaturated-zone rock. The half lives of tritium and krypton-85 are of the order of ten years; because the travel time for gases is expected to be longer that this, these nuclide species are not expected to make a significant contribution to releases of radioactivity during the period of performance. Iodine-129 has a long half life, but gaseous compounds of iodine are highly reactive and are likely to be transformed into a liquid or solid phase. Transport of carbon-14 dioxide is the major concern.

Mode1s of the advection and diffusion of carbon-14 dioxide through the void spaces of the repository overburden are needed, particularly ones that account for thermally driven air flows, the isotopic exchange of carbon-14 with carbon-12 in the carbonate minerals of the rock mass, and the precipitation of carbon-14 as calcite. A prerequisite to a model of gas-phass? transport in the repository overburden is a realistic model of the air currents in the unsaturated zone, particularly one which can account for the internal heating and thermally-driven convection due to the presence of the repository.

\section{Models for biosphere transport and human uptake}

The EPA's Containment Requirements (para. 191.13 of Subpart B of 40 CFR Part 191) do not require development of models for biosphere transport of radionuclides; these requirements apply only to cumulative releases of radionuclides at the boundary of the accessible environment. However, the Individual Protection Requirements (para. 191.15) do require analysis of doses to members of the public in the accessible environment along a11 potential undisturbed pathways. In addition, the Ground-Water Protection Requirements (para. 191.16) require a prediction of the concentrations of radionuclides in any special sources of ground water (which could be located in the accessible environment). In either case, models of the airborne radionuclide concentrations and concentrations of radionuclides in ground water are needed.

The biospheric transport model for computing ingestion doses to members of the public will probably be similar to that specified in paragraph 191.15 of 40 CFR Part 191 involving a well located at the boundary of the controlled area. It will probably be assumed that this well also provides water for bathing and water to irrigate gardens and water 1ivestock. Transport of radionuclides to a spring may also be evaluated, and models will be needed to evaluate ingestion and immersion doses in a manner similar to the scheme used for the well.

Doses from the inhalation and ingestion of gaseous carbon-14 near the boundary of the controlled area will also have to be evaluated; this evaluation will require models of the atmospheric transport and deposition of carbon-14, as we11 as models for uptake by plants and livestock.

Models of critical human populations near the site over the next 1000 years may also be needed to evaluate the Individual Protection Requirements and the Ground Water Protection Requirements. However, population models are not needed for the analysis of the Containment Requirements, since the latter requires only an analysis of cumulative releases to the accessible environment. 


\subsubsection{Computationa1 models}

Process-level computational models needed for the total-system performance analyses have been developed in many cases. For example, the calculational mode1s described in Section 3.6.2 for waste-package performance can be used to represent source terms. Models for ground-water flow and transport in the saturated zone and the unsaturated zone have been developed. These include the PORFLO, NORIA, and TRACR3D codes. Codes for gas-phase transport also exist. For example, the TOUGH code can evaluate these efferts as well as 1iquid-phase and multiphase flows. Biosphere-transport codes are also available. For example, PABLM can be used for the biosphere transport and uptake associated with internal doses, and AIRDOS-EPA can be used for thle immersion-dose estimates.

Three subsystem-level computational models relevant to total system performance are under development. One is AREST, which is used to evaluc. te engineered-barrier system performance and to provide the source term for total system performance. Another is SUMO, which uses major calculational modlels as subelements (eg. the AREST code and PORFLO for the flow and transport); the third is TOSPAC, which provides a somewhat simpler representation for the flow and source term than does SUMO. This model currently solves a one-dinionsional Richards' equation for flow in the unsaturated zone (or a network of one-dimensional equations for different pathways in the unsaturated ibne) and can use nonlinear formulations of the hydrologic properties for the calculation. Transport is solved separately using the results of tire flow calculation. The source term for the transport calculation is currently an input to the code rather than a solution that is calculated within the code. The strategy in this case is to use both models to provide comparisons for evaluating critical elements and models.

A simple, total-system-level computational model has not yet been developed, and this is a critical element of the strategy. One such code, currently called the "Total System Simulator," will be capable of addressin:s the various scenario-class conceptual models and of calculating the probability distribution (the complementary cumulative distribution functidn (CCDF)) for the cumulative release to the accessible environment.

\subsubsection{Analyses}

The computational models will be used to evaluate the performance measures and to evaluate sensitivities and uncertainties quantitativel . For example, a CCDF for the cumulative release of radionuclides to the aciessible environment will be calculated for each of the scenario classes. The CCDF for the scenario class is defined by:

$$
\operatorname{Pr}\left(M>m \mid s_{j}\right)=\int_{\vec{v}} d \vec{v} U[M(\vec{v})-m] f\left(\vec{v} \mid s_{j}\right)
$$

where $M$ is the measure of the cumulative release, $\vec{v}$ is the vector of parameters of the system needed to calculate $M, U(x)$ is a step function, ard $f\left(\vec{v} \mid S_{j}\right)$ is the conditional probability-density function for the vector $\vec{v}$ given that only members of scenario class $S_{j}$ occur. As discussed in Section 3.6.2.1, the total CCDF is then 


$$
\operatorname{Pr}(M>m)=\sum_{j} \operatorname{Pr}\left(M>m \mid s_{j}\right) P\left(S_{j}\right)
$$

where $P\left(S_{j}\right)$ is the probability of occurrence of the $j$ th scenario class.

The subsystem-1evel computational models will be used for sensitivity analyses to identify the critical elements that must be taken into explicit account in order to evaluate the performance measures. The Total system Simulator will be used to obtain the CCDF for the cumulative release.

\subsubsection{General Strategy for Assessing the Postclosure Performance of the Engineered-Barrier System}

The general strategy for the engineered-barrier system performance assessments has been developed as part of the issue resolution strategies for the performance issues related to engineered-barrier system performance, namely issues 1.4 and 1.5 (see Section 2.2). Details of the general strategy are presented in Sections 8.3.5.9 and 8.3.5.10 of the Site Characterization Plan (1988a).

In this strategy, two performance measures will be calculated for the engineered-barrier system: the time of waste containment within the waste packages and the rate of radionuclide release from the waste package. Both of these performance measures will be evaluated for anticipated processes and events. The first of these performance measures requires the evaluation of two factors: (1) the time to the rupture or degradation of the disposal containers and (2) the time to the release of some fraction of the waste from the waste packages given that the containers are breached. Therefore, two quantities will be analyzed to calculate these performance measures: the first is the rate at which the containers are breached (i.e., the rate at which the container develops openings large enough to allow any radionuclides to be released), and the second is the rate of radionuclide release from the waste package through these openings. The information that is used to develop the container-breach rate and the rate of radionuclide release from the containers for anticipated processes and events will also be used to develop the source term for the total-system performance assessment.

The strategy for evaluating engineered-barrier system performance has four steps. The first step in the strategy is to evaluate the expected environments that will affect the performance of the engineered-barrier system. These include the time-dependent temperatures in the vicinity of the waste packages; the multiphase fluid, air, and vapor conditions; the chemical conditions; the thermomechanical stresses both in the host rock and in the waste-package components; and the radiation fields. The second step is to predict the breach rate for containers subjected to these environments. The principal role of the performance assessments in this regard will be to extrapolate the results from short-term accelerated tests of container degradation and rupture to representations of expected performance taking into account anticipated processes and events over long times into the future. The performance assessment approach to such extrapolations will be to use the 
available understanding of the basic physical processes. The third step in the strategy is to predict the rate of radionuclide release from a breached container. Using an approach similar to that in the second step, the development of conceptual models for release will rely on understanding gained from tests and an understanding of the constraints that the repository conditions place on possible physical procesess affecting radionuclide release. The fourth step is to consider this information to estimate the performance measures for the ensemble of waste packages. This step must consider not only the uncertainty in performance for a given environment, but the spatial variation of environments throughout the repository.

The strategy must consider radionuclides in several categories: the gaseous radionuclides, some of which could be released immediately after the containers are breached; the soluble species in the fue1-to-cladding gap, in the spent-fuel plenum, or in the $g r$ in boundaries of the waste-form matrix; the radionuclides in the waste-form matrix; and the radionuclides in the cladding of the spent fuel or in the hardware within the waste package. The analyses will entail evaluations of waste-form dissolution and analyses of radionuclides that are released to liquid water both congruently and incongruently with the waste-form matrix.

Other factors may be taken into account in the analysis of the release rate. For spent fuel, the degradation and failure of the cladding may be taken into account. Analysis of radionuclide transport from the waste form or other components to the wall of the contatner, through the breaches in the container wall, and from the container into the host rock may also be taken into account.

\subsubsection{Conceptual models}

The conceptual models needed for evaluating performance measures for the engineered-barrier system depend on the anticipated conditions in the vicinity of the waste packages and the ability to model them. Since the waste will be emplaced over large areas and because of the spatial variation of rock characteristics throughout these areas, a range of conditions is expected for the emplaced waste packages. The current information indicates that the host rock is not saturated and has a low flux of water down through the repository horizon. Gases can flow through the unsaturated pores in the matrix and through fractures. After waste emplacement in the repository, the heat from the waste will increase the temperature of the surrounding rock, possibly to more than $200^{\circ} \mathrm{C}$ in a few decades. The temperatures near most of the waste packages are expected to remain above the boiling point of water for 300 or more years and then decrease with time as the fission products in the waste decay. The increased temperatures are likely to change the chemistry of the water, change the fluid conditions, and possibly lead to thermomechanical effects that could affect the performance of the engineered-barrier system.

These changes and the uncertainties in the characteristics of the engineered-barrier system lead to a range of possible conditions that must be evaluated in the performance assessments. These ranges are addressed by three different modes of release. Each mode of release can lead to a different scenario. 
The first mode is the "dry" release mode, in which no liquid water comes into contact with the waste package. This condition is possible because of the matric potential that holds the water in the host rock (and therefore away from the waste packages) in the unsaturated zone and because of the high temperatures in the vicinity of the waste packages, which will vaporize water and dry out the host rock near the waste packages. In this case, the only radionuclides that could be released from breached waste packages are those that are in gaseous form for example, the volatile radionuclides that may have migrated from the waste form to void spaces in the waste packages or to gaps in the spent fuel. However, under these conditions moisture is likely to be present as vapor and available to affect corrosion of the container and degradation of the waste form. These effects need to be taken into account in the evaluation of this release mode.

The second release mode is the "wet-drip" case, in which a waste package comes into contact with a limited quantity of liquid water, for example, from water dripping from the rock above the waste package. In this case, not only gaseous radionuclides but also soluble species can be released, by way of discontinuous flow from the waste package. These radionuclides include the soluble species that have migrated to spent-fuel gaps or to waste-form grain boundaries, those that may be formed in the spent-fuel cladding, and those in the waste-form matrix.

The third mode of release is the "wet-continuous flow" case in which the waste package is treated as if it were immersed in a continuous flow of 1 iquid water. This representation provides a bounding case for the mass transfer of radionuclides by this pathway.

Conceptual models of the processes that might play a role in each of these cases must be defined. These include models that define the waste-package environments, the models needed to predict container breach, and the models of processes affecting the mass transfer of radionuclides in the waste package for each of these scenarios. The processes that affect the waste-package environment are heat transfer, thermomechanical processes, multiphase-fluid-flow processes, geochemical processes, and radiation.

The models needed to predict container breach include those that describe the response of the rock in the vicinity of the waste package to the residual thermomechanical stresses and models of thermomechanical stresses within the waste package itself. Models for container-degradation processes are needed, including models of oxidation, general corrosion, stress-corrosion cracking, hydrogen embrittlement, localized attack, intergranular attack, and other corrosion processes, as well as the dependence of these processes on the thermal, chemical, mechanical stress, fluid, and radiation environments. The container-degradation processes may be simply modeled as statistical correlations in terms of the important parameters of the system (e.g., temperature, residual stress, $\mathrm{pH}$, oxidation-reduction potential). Data available to define these correlations will not always span the range of interest in the analyses so extrapolations to the ranges of interest will have to be done. 
Models needed for the mass-transfer analyses include those that define the generation and transport of radionuclide gases in the waste package. Also needed are models for release from the waste form. For high-level waste, models are needed for the dissolution of the glass matrix and for the dissolution of radionuclides that are released congruently or noncongruently with the matrix dissolution. Analogous models are needed for the mass transfer from the spent-fuel waste packages. In addition, if the cladding is to be taken into account, models are needed for cladding failure. Finally, models for the mass transfer away from the waste form, through the breaches, and to the host rock must be defined if the contributions of these processes are to be taken into account in evaluating the release rate.

Models are also needed for the release of radionuclides in the cladding, on the hardware, or on the crust in the surface of the spent fuel. The models for these are likely to be crudely represented in terms of a dissolution process.

\subsubsection{Computational models}

A variety of analytical techniques that have been developed over the years are applicable to the analysis of the waste-package environments. For example, ANSYS has been used to calculate heat conduction and thermomechanical stresses in the vicinity of the waste package. The TOUGH and NORIA codes have been applied to the problem of multiphase fluid flow near the waste package and to calculate heat transfer and fluid flow for boiling, convective flow, and heat-pipe effects. - The EQ3/EQ6 codes have been used to predict ground-water chemistry, the formation of stable phases, the dissolution of the constituents of the waste-form matrix, and the solubility limit for the radionuclides in the waste. This code has also been used to calculate the progress of reactions near the waste package, including those associated with radionuclides that are released from the waste form incongruently with the waste-matrix dissolution.

Analytic solutions have been developed for many aspects of the mass-transfer problem for glass waste and spent fuel, but a complete subsystem-level computational model for waste-package performance has not yet been developed. However, simplified system models have been developed and applied to the wet-drip and wet-continuous-flow scenarios. These models include the PANDORA code, which has been applied to a simplified representation for the wet-drip scenario, and the AREST code, which has been used in a general study of spent-fuel performance and tested against other waste-package codes for saturated-flow conditions. Both the PANDORA and the AREST codes are capable of probabilistic analysis to address uncertainties in parameters and to generalize the simple waste-package results to an ensemble of waste packages. However, considerable work is still needed to test and integrate the full suite of models that may be needed for the evaluation of waste-package performance. 
The computational model for the breach rate of the container or the cumulative number of container breaches has not yet been developed. The calculational model will be developed in terms of correlations of breaches with important environmental parameters and container characteristics obtained from accelerated tests of container-material corrosion. A reference case will be defined for the containers, and the response of containers to extreme changes in a small number of variables from the reference conditions will be parameterized in terms of applicable correlation functions. These functions can then be used for predictions of the container-breach rate for approximate ranges of the parameters.

\subsubsection{Calculation of the performance measures}

Three types of calculation will be performed: (1) calculations of waste-package environments, (2) calculations of cumulative breaches of containers, and (3) calculations of mass transfer from breached waste packages. The prediction of environments will use information about the characteristics of the site, including variations in these characteristics across the site. These analyses will result in estimates of ranges of conditions for the other two types of analyses.

The cumulative number of breached containers will be calculated after developing correlations of breaches with important waste-package-environment parameters and container characteristics obtained from the accelerated container-corrosion tests. These correlations will be used to develop predictions for the ranges of waste-package environments throughout the repository.

The rate of radionuclide release from the breached containers will be evaluated for each of the three modes of release. The rate at which gaseous radionuclides are released from a single waste package will be estimated from the inventory of the gaseous radionuclides that are available for release and from models for the mass transfer of the gases from the containers. Likewise, the rate at which soluble radionuclides are released from a single waste package for the wet release mode will be evaluated for the ranges of characteristics and for the mass-transfer models appropriate to the release mode. The rate of release from the ensemble of waste packages will be evaluated by convolving the single-package release rates with the container-breach rate and by taking into account the variations in conditions throughout the repository.

The analyses will be conservative. For example, for cases where temperature increases lead to adverse or extreme conditions (e.g., modifications to geochemical conditions) temperatures will be overpredicted. On the other hand, for the evaluation of water vaporization and the drying of the repository environment, temperatures will be underestimated. Furthermore, care will be taken to ensure that an effect considered to be adverse is not, in fact, favorable. At the same time, care will be taken to ensure that the conservative values chosen for one part of a given calculation are within the correlation range of those used on another. 


\subsubsection{Sensitivity and uncertainty analyses}

The strategy for sensitivity and uncertainty analyses will be to focus on the conservatism in the scenarios. The scenarios will be investigated to understand the levels of conservatism in each one. Sufficient conservatism in the scenarios will obviate the need for extensive sensitivity and uncertainty analyses.

Nevertheless, critical process models and model parameters will be evaluated in general sensitivity and uncertainty analyses. These analyses will identify the areas where uncertainty in parameter values will have the greatest effect on conservatism and in the predictions.

\subsubsection{General Strategy for Assessing the Performance of the Natural Barriers}

The general strategy for the natural barriers performance assessments has been developed as part of the issue resolution strategy for the performance issue related to natural barriers performance, namely issue 1.6 (see Section 2.2). Details of the general strategy are presented in Section 8.3.5.12 of the Site Characterization Plan (1988).

The performance measure for the natural barriers is the pre-wasteemplacement time of ground-water travel from the disturbed zone to the accessible environment along the fastest path of 1 ikely radionuclide travel. The general strategy for evaluating this performance measure has three steps: (1) determine the extent of the disturbed zone, (2) identify paths of likely radionuclide travel, and (3) calculate the time of ground-water travel along these pathways and determine the fastest path.

The disturbed zone is the zone in which the effects due to the construction of the repository and the emplacement of waste lead to large uncertainties in performance and, in particular, the time of ground-water travel. It is expected that such effects would be important within the engineered-barrier system where thermal gradients may be large; but there may also be a portion of the host rock outside the engineered-barrier system in which hydrologic characteristics are sufficiently affected that they should also be considered part of the disturbed zone. The strategy to determine the extent of the disturbed zone is to assume that this zone is defined by the engineered-barrier system and the portion of the host rock in which the rock characteristics affecting the time of ground-water travel would be significantly disturbed. The determination will therefore require an evaluation of the ranges of hydrologic characteristics of the undisturbed host rock and an estimate of the potential changes in these characteristics from the stresses induced by the excavation of the repository and the heat generated in the repository by the emplaced wastes.

The strategy for identifying the pathways of 1ikely radionuclide travel focuses on two different types of pathway. The first type of pathway is that involving discrete, identifiable features of the site. For example, features like faults, fracture zones in the vicinity of faults, contacts between 
geologic units with significantly different hydrologic properties, or other discrete features may provide pathways for radionuclide travel. The approach for identifying such pathways is to examine the site conceptual model that is developed to interpret the site data and to propose pathways on the basis of this information.

The second type of pathway is that which cannot be identified with discrete features. For example, there may be zones in the heterogeneous rock in which the hydrologic and transport properties are correlated in such a way as to lead to preferred pathways for radionuclide travel. The approach to identifying such pathways is to model the transport through the natural barriers. The preferred pathways can be identified by examining the probability distributions calculated for travel time and noting the statistical correlations of the travel time with the hydrologic and transport characteristics.

The strategy for evaluating the pre-waste-emplacement time of ground-water trave1 is then to model each of these identified pathways individually, calculating the travel time of inert particles in the ground water along those pathways. The analyses will be probabilistic to take into account the probability distributions for the hydrologic characteristics along these pathways. These probability distributions arise from uncertainties in rock characteristics, as well as the heterogeneity in these properties. The results of the calculation will be cumulative distributions of the travel time for the various pathways. These distributions will be compared with the regulatory criteria of 10 CFR 60.113 .

\subsubsection{Conceptua1 models}

Process models and constitutive relations are needed to evaluate the extent of the disturbed zone. For example, models are needed for the thermomechanical analysis of the response of the host rock to the excavation and the effects of the heat from the emplaced waste. Models of other effects may also be needed. For example, if the minerals filling fractures are sufficiently altered by the elevated temperatures near the repository that the hydrologic characteristics of the host rock are significantly affected, then models of the alterations and the subsequent effects on flow would be needed.

For modeling ground-water and radionuclide travel, several types of conceptual models are needed. First, site conceptual models for flow in the unsaturated and saturated zones are needed. The conceptual models must include specifications of bounding and initial conditions; the geometric configuration of the features of the site, including the geohydrologic units and other features like fault zones, and the hydrologic characteristics of these features.

Also needed are models for the flow processes, particularly those in the unsaturated units between the disturbed zone and the water table. The nature of flow in the rock matrix and in fractures and the interaction between the matrix and fractures in each of these units should be represented in order to evaluate flow velocities in these units. In addition, models for lateral 
diversions of flow at unit contacts, for the diversion of flow at faults, and for the characteristics of the flow within faults should be represented. In the saturated zone beneath the water table, the flow is probably dominated by flow in the fractures, and appropriate representation for this flow should be developed.

For the identification of the paths of 1 ikely radionuclide travel, models for the transport of radionuclides are needed. These models include representations for the chemical retardation of radionuclides as well as matrix diffusion and other dispersion processes.

The strategy for obtaining the characteristics needed to develop these models is described in the SCP. It follows from strategy to resolve issue 1.6, which addresses the question of the time of ground-water travel. The studies and investigations dictated by this strategy are described in Section 8.3.5.12 of the SCP.

\subsubsection{Computationa1 mode1s}

Although development will be needed to accommodate the evolution of the physical models as site information is obtained, a number of available codes can be applied to this problem. Computational tools exist for the thermal and thermomechanical analyses to determine the extent of the disturbed zone, and there is considerable experience in using them. The EQ3/EQ6 codes are available for evaluating mineral alteration in this regard as well.

Computer codes at the process and subsystem levels are available for analyzing saturated- and unsaturated-flow systems. A process-leve1 code that has been used to explore multiphase fluid flow in the unsaturated zone is TOUGH. Codes for either process-level or subsystem-level modeling include TRACR3D (an isothermal flow and transport code for variably saturated media), NORIA and PORFLO (nonisothermal flow and transport codes for variably-saturated media and multiple phases). One-dimensional flow-and-transport studies have been accomplished with the subsystem-1evel code, TOSPAC. Some modifications of these codes will be needed to accommodate developments in the conceptual models of the system.

\subsubsection{Calculation of the ground-water travel time}

Preliminary analyses of the time of ground-water travel have already been conducted. For these calculations only a crude estimate of the extent of the disturbed zone was made. A distance of 50 meters from the repository was assumed to bound this zone, and the time of ground-water travel was calculated from this boundary to the water table. A simple one-dimensional vertical-flow model was used for these analyses, and the combined system of fractures and matrix in each unit was represented by an effective porous medium. In some analyses, lateral diversion at unit contacts and flow diversion at a vertical fault were permitted; these effects were represented by one-dimensional branches to the flow. Limited probabilistic analyses were conducted. 
Future analyses will refine these techniques for the credible conceptual models of the flow system. Two- and three-dimensional analyses will be conducted. The need for analyses that explicitly treat both fracture and matrix flow wil: be investigated, and, if necessary, analyses will be conducted for alternate conceptual models. The cumulative probability distribution for the time of ground-water trave1 will be calculated; therefore these analyses will be probabilistic.

\subsubsection{Sensitivity and uncertainty analyses}

Two types of sensitivity and uncertainty analyses will be conducted to evaluate the time of ground-water travel. First, the importance of the conceptual models for the flow will be investigated. These analyses will involve repeated calculations for different conceptual models and models of the flow processes. The results of these analyses will be reviewed to provide comparisons with site data and to provide insight into credible representations of the flow system.

Second, quantitative sensitivity analyses will be conducted to identify and understand the important parameters of the models. In addition, quantitative sensitivity and uncertainty analyses using statistical approaches will be conducted to evaluate data uncertainties and to understand the effects of these uncertainties on the travel-time estimates.

\subsubsection{General Strategy for the Preclosure Safety Assessment}

The general strategy for the preclosure radiological safety assessments has been developed as part of the issue resolution strategies for the performance issues related to preclosure safety, namely issues $2.1,2.2$, and 2.3 (see Section 2.2). Details of the general strategy are presented in Sections 8.3.5.1, 8.3.5.3, 8.3.5.4, and 8.3.5.5 of the Site Characterization P1an (1988a).

The assessment of preclosure radiological safety involves estimates of the doses and risks to which members of the public and the repository workers may be exposed as a result of repository operations before permanent closure. It requires estimates of individual and collective doses for both normal operations and accident conditions. The objective is to predict the probable radiological consequences of the operation of the repository, to compare the consequences with acceptability criteria, and to present the results for judgment by appropriate groups.

\subsubsection{Assessment for normal operations}

The assessment of radiation protection during normal operations will include evaluation of the doses received by members of the public and the occupational exposure of workers, including anticipated operational occurrences. The objective is to demonstrate that the regulatory dose limits are not exceeded and that the radiological exposures have been reduced to 
levels as low as reasonably achievable (ALARA). The ALARA provision implies an iterative process between design and radiological safety assessment, with the objective of modifying the design to minimize radiological exposures.

The dose calculations include evaluations of the design, the source term, radionuclide transport, and exposure to radionuclides.

The evaluation of design involves assessing the repository design features relevant to radiological safety, including the effectiveness of barriers and radiation shields, effluent-treatment systems, ventilation-system characteristics, and the distance between the point at which radioactive material is released and the boundary of the restricted area.

Source-term characterization consists of identifying and describing potential radiation and radionuclide sources in the repository. It includes information about the radionuclides (type, quantity, and concentration), the type and the energy of emitted radiation, and the physical and chemical forms of the radioactive materials that are released. These materials will consist of gaseous and particulate fission products released from any containers that breach during operations and naturally occurring radionuclides (i.e., radon and its daughters) released from the underground repository and from the mined rock stored at the surface.

The calculation of the source term also requires information on the design of the repository and operating procedures. Thus, the dose-assessment process requires knowledge of the quantity and characteristics of the radioactive materials that will be handled at the repository, their throughput rates and their locations in the repository, the characteristics of shielding materials, the locations and release rates of any radionuclides released into the repository air streams, and the characteristics of the ventilation system. The release of radionuclides into air depends on their inventory, their volatility, the temperature and pressure under which they are contained, and the aerodynamic properties of the release openings. The release of naturally occurring radionuclides (i.e., radon-220, radon-222, and their daughter products) into underground openings depends on the concentration of their precursors, the diffusion properties of the radionuclides in the host rock, temperatures reached during operations, and construction techniques.

The handling of radioactive materials may also result in the generation of contaminated liquids, including decontamination solutions, washdown solutions, and contaminated laundry waste. These liquids will be collected and treated to remove radioactivity and, possibly, discharged or recycled. The quantities of radioactive materials released in liquid effluents will depend on the design and operating characteristics of the liquid-radwaste treatment system. Liquid discharges must meet appropriate concentration and dose limits.

Radionuclides released in airborne effluents are subject to various removal processes (e.g., decay, filtration, deposition, chemical reaction, and agglomeration) and transport processes(e.g., entrainment, advection, and dispersion) that govern their concentration. The transport of airborne radionuclides within the repository depends on the design of the ventilation system, whereas the transport of radionuclides released from the repository depends on the atmospheric-dispersion characteristics of the site. 
The radionuclides released from the repository can deposit on the ground or in surface water and enter the terrestrial food chain. The resulting exposure modes include external irradiation from material suspended in the air or deposited on the ground and internal exposure from the inhalation and ingestion of radioactive material in air and foodstuffs. Resuspension of radionuclides can add to the long-term inhalation exposure, but it is significant only for those radionuclides that persist on the surface.

The calculation of doses from the above pathways requires quantitative descriptions of the pathways. The required information includes the atmospheric-dispersion characteristics of the site, the transport characteristics of the terrestrial pathway, the population distribution and the locations of the nearest individuals in the vicinity of the site, the characteristics of the exposed individuals, and dose-conversion factors for the various radionuclides.

Both individual and population doses should be calculated for members of the public. The individual doses will be based on the annual committed effective dose equivalent for the maximally exposed individual. The maximally exposed individual is a hypothetical person with the maximum food consumption, occupancy, and other usage in the vicinity of the repository. The population doses will be based on the annual collective committed effective dose equivalent for the population estimated to be present within 80 kilometers of the repository at the time the repository starts operating.

For repository workers, the radiological safety assessment is similar to that described above for members of the public but modified to account for the different environment that may exist for workers. The assessment will basically require the following: (1) characterization of the radiation environment in areas occupied by workers and (2) calculation of the doses received by workers on the basis of the duration of exposure in the various radiation areas.

The radiological environment is characterized primarily by the dose rate from penetrating gamma and neutron radiation and, if radioactive material is released into occupied areas, by radionuclide concentrations in air. It should be noted, however, that since nuclear facilities are designed to avoid occupationa1-exposure to airborne contaminants, occupational exposure assessments would seldom involve a radionuclide transport evaluation. The assessment of the design regarding the potential for exposure to airborne contaminants is part of the design process. If the design complies with the airborne-contaminant requirement, occupational exposure assessment during normal operations would primarily involve shielding calculations.

Once the gamma-dose rates, radionuclide concentrations, and the durations of exposure are estimated, the resultant doses to workers can be calculated. In practice, doses are not calculated for individual workers but for specific job categories (e.g., waste-handling operations, maintenance) that correspond to the specific operations a person in that job category is required to perform. The collective dose is then obtained by multiplying the dose for each job category by the number of workers in the category and by summing over the categories. 
This measure of collective dose is particularly useful in ALARA reviews because it facilitates identification of those operations that are the greatest contributors to the collective dose and thus have the greatest potential for dose reduction through a change in design (e.g., increase in shielding or automation) or in operating procedures (e.g., reduction of task duration through better training).

In order to calculate the individual and collective doses, it will be necessary to establish what operations will be performed at the repository, their durations, and which workers and how many will be involved in each operation. Thus, in addition to facility design, an operating plan that describes each waste-handling operation from the receipt of a waste shipment through emplacement underground is a prerequisite for the dose assessment.

Assessment of the doses received by the repository workers should be based on both individual and collective exposures from normal operations. The assessment should include an analysis of the annual effective dose equivalent that may be received by a worker in each job category to demonstrate that exposure limits will be met. It should also include an analysis of the collective annual effective dose equivalent to demonstrate that steps have been taken to ensure that exposures will be as low as reasonably achievable.

\subsubsection{Assessment for accident conditions}

The preclosure radiological assessment for accident conditions will consider accident sequences resulting from various initiating events, such as natural phenomena, equipment failure or malfunction, and human-induced events, including human error. Design-basis accidents will be established from a range of accident sequences, using probabilistic analyses to aid in the selection of the accidents. The structured evaluation process involved in probabilistic risk assessments provides a systematic, integrated assessment of safety that is useful for identifying design deficiencies and areas of uncertainty and for demonstrating the level of safety.

The general approach to the assessment includes identifying credible initiating events for accidents, developing detailed accident scenarios, and evaluating the probabilities and consequences of selected scenarios.

Two general groups of events will be investigated: events induced in the repository and externally induced events. Internal events would generally have consequences affecting limited portions of the repository (e.g., equipment malfunction), whereas external events would generally affect all or major portions of the repository (e.g., earthquakes). The scenarios developed will span the range of occurrence probabilities and potential consequences and address a spectrum of potential initiating mechanisms.

The radiological consequences to the public from various accident scenarios will be determined in terms of individual and collective doses. These analyses will consider both deterministic and probabilistic risk-assessment methods. Deterministic methods are used in current NRC licensing practice for nuclear power plants and other nuclear facilities for 
which conservative, regulatory-guide-type analyses have been historically performed. The steps in the probabilistic accident assessment for a repository will be similar to that for a light-water reactor, but the basic differences between the two facilities will need to be reflected in the repository assessment. For example, whereas a light-water reactor is a highly dynamic thermomechanical system with high energy sources that must be controlled by active systems, the repository will be a relatively passive, batch-type fuel-handling facility with few, if any, high-pressure/high-temperature sources of energy. And whereas in a light-water reactor most of the radioactive material is kept in the core and the spent-fuel pool, the repository will have large quantities of waste materials in different locations and different handling stages, and generally the spent-fuel-handling operations will be done under a dry environment. Another characteristic that distinguishes the repository from other nuclear facilities is underground operations. This may require the consideration of potential accident initiators (e.g., rock falls) not normally considered in the design of other nuclear facilities. The length and limited availability of modes of egress from the underground facilities are also unique features of the repository.

For the repository, the source term could range from a negligible, easily contained fission-product release from a dropped spent-fuel assembly to a significant release of fission products and transuranics from an unlikely fire affecting a number of unprotected fuel assemblies. The 1iterature discussing accidents of this type contains limited experimental data and a significant amount of judgmental extrapolation from source terms developed for other applications. In particular, information needs to be developed on particulate source terms for accidents involving the pulverization of spent fuel and on retention and removal factors for the repository under accident conditions.

For the public, both individual and collective doses from various accident scenarios will be calculated, and the results will be compared with applicable regulatory limits. The doses received by repository workers will also be calculated and assessed to determine whether they are acceptable.

The scope of accident assessment also includes the identification of structures, systems, and components important to safety and the demonstration of their adequacy for the prevention and mitigation of the consequences of accidents. The methodology required by the procedure has been applied to assess which structures, systems, and components of the exploratory-shaft facility are important to safety when the facility becomes part of the operating repository.

The procedure calls for separating the design configuration into components to facilitate a systematic assessment process. The analysis then proceeds in accordance with the general steps for accident assessment described above,starting with the identification of credible initiating events and leading to the evaluation of the probabilities and consequences of selected scenarios. 
The License Application for a geologic repository will include a Safety Analysis Report (SAR). The SAR will provide the information required by the Nuclear Regulatory Commission (NRC) to determine, with reasonable assurance, whether the repository will meet radiological safety requirements before closure and provide the required waste containment and isolation after closure. This section outlines the content of the SAR and describes the role of performance assessment in preparing the SAR.

\subsection{DESCRIPTION OF THE SAFETY ANALYSIS REPORT}

The SAR will summarize the DOE's knowledge about the design, operation, and performance of the geologic repository. The current plan is that it will be based on the License Application Designs (LADs) for the repository and the waste package, data from the surface-based drilling program, and laboratory tests, as well as in situ test data from the exploratory-shaft facility. It will utilize other information as well, such as results of tests conducted outside the controlled area.

The content requirements for the SAR are outlined in 10 CFR 60.21 (NRC, 1983) and will be used by the DOE to develop the SAR. The SAR will be modified if an amendment is needed to accommodate new information. The conditions that require modification of the SAR are defined in 10 CFR 60.24 (b) and 60.46 (NRC, 1986).

A preliminary 1ist of the SAR topics involving performance assessment is given in Table 4-1, which also shows where performance assessment is expected to play a direct or an indirect role. A direct role is one that requires quantitative analysis to predict the value of one or more performance measures. An indirect role is one in which performance assessment models or techniques are considered in the evaluation, but performance measures are not calculated. The direct activities that the DOE expects to perform for the preclosure and the postclosure SAR assessments are discussed in Section 4.2.

\subsection{PERFORMANCE ASSESSMENT ACTIVITIES FOR THE SAR}

\subsubsection{Preglasure Safety Assessment for the SAR}

The preclosure radiological safety analyses for the SAR will require the determination of radiation protection for the public and for the repository workers under normal operating conditions and radiation safety for accident conditions. The methods that can be used for these analyses are described in Section 3.7. 
TABLE 4-1. SAR Topics Involving Performance Assessment

\begin{tabular}{|c|c|c|}
\hline Preliminary Topic & $\frac{\text { Support }}{\text { Direct }^{2}}$ & $\frac{\text { Rale for PA }}{\text { Indirect }}$ \\
\hline $\begin{array}{l}\text { General description and assessment of the repository } \\
\text { system }\end{array}$ & & $\mathrm{X}$ \\
\hline $\begin{array}{l}\text { Anticipated response of the site to the maximum } \\
\text { design thermal loading }\end{array}$ & $\mathrm{X}$ & \\
\hline $\begin{array}{l}\text { Anticipated impact of favorable and potentially } \\
\text { adverse conditions on the ability of the site } \\
\text { to contain and isolate the waste }\end{array}$ & $\mathrm{X}$ & \\
\hline Postclosure performance of the repository system & $\mathrm{x}$ & \\
\hline Effectiveness of engineered and natural barriers & $\mathrm{x}$ & \\
\hline $\begin{array}{l}\text { Explanation of the measures used to support the } \\
\text { performance assessment models }\end{array}$ & $\mathrm{x}$ & \\
\hline Preclosure safety assessment & $\mathrm{X}$ & \\
\hline $\begin{array}{l}\text { Plans for retrieving and providing alternative } \\
\text { storage for the radioactive wastes }\end{array}$ & & $\mathrm{X}$ \\
\hline Plans for performance confirmation & & $\mathrm{X}$ \\
\hline Plans for permanent closure & & $\mathrm{X}$ \\
\hline $\begin{array}{l}\text { Plans for any uses of the repository site for } \\
\text { purposes other than the disposal of radioactive } \\
\text { waste }\end{array}$ & & $\mathrm{X}$ \\
\hline
\end{tabular}

${ }^{a}$ Direct role: requires a calculation of performance measures (e.g., release to the accessible environment).

'Indirect role: does not involve calculation of performance measures. 
The preclosure safety assessments for the SAR can be summarized as follows :

1. Analysis of radiological protection under normal operating conditions:

a. Assessment of offsite doses to members of the public.

b. Assessment of onsite doses to repository workers.

2. Analysis of radiological safety under accident conditions: a. Assessment of dose to members of the public and essential
repository workers.

b. Determination of systems, structures, and components important to safety.

The analysis of radiation protection in the SAR is required by $10 \mathrm{CFR}$ 60.21 (c)(7), which calls for a description of the radiation-protection program of the repository and methods for ensuring that the radiation exposures of the public and the workers meet applicable radiation-protection standards and are as low as reasonably achievable during normal operations and anticipated operational occurrences. The standards are specified both in the preclosure performance objectives of $10 \mathrm{CFR} 60.111$ (a) and the design criteria of $10 \mathrm{CFR}$ $60.131(a)$.

The analysis of postulated repository accidents is required by the NRC in 10 CFR $60.21(\mathrm{c})(1)(\mathrm{ii})(\mathrm{E})$, which requires an analysis of the performance of major design structures, systems, and components to identify those that are important to safety, and $10 \mathrm{CFR} 60.21(\mathrm{c})(3)$, which requires an analysis of the design and performance requirements for structures, systems, and components important to safety.

\subsubsection{Postalosure Performance Assessment for the SAR}

The regulations in 10 CFR 60.21 require assessments of five different types to be presented in the SAR: (1) an analysis of the characteristics of the site; (2) analyses of the effect of specified favorable and potentially adverse conditions on waste isolation; (3) an evaluation of postclosure performance of the total repository system, accounting for both anticipated and unanticipated processes and events; (4) analyses of the effectiveness of natural and engineered barriers with respect to the release of radioactive material to the accessible eqvironment; and (5) an analysis of the major design structures, systems, and components with respect to preclosure safety. In addition, measures used to support the models used in the postclosure performance assessments must be explained in the SAR. 
As part of these assessments, evaluations against the technical criteria of Subpart E of 10 CFR Part 60 will be conducted and presented in the SAR. These criteria include the EPA environmental standards of 40 CFR Part 191 implemented in $10 \mathrm{CFR} 60.112$. The regulation in $10 \mathrm{CFR} 60.113$ provides postclosure performance objectives for the effectiveness of the engineered barriers. Criteria are set for the containment of radionuclides by the waste packages and for the rate of release of radionuclides. The regulation in 10 CFR 60.113 also defines a criterion for the effectiveness of the natural barriers: namely, a requirement on the pre-waste-emplacement ground-water travel time for the fastest path of likely radionuclide travel from the disturbed zone around the repository to the accessible environment.

Subpart E also specifies preclosure performance objectives. It implements the standards of 40 CFR Part 191, Subpart A, for normal releases during the preclosure period. Although there are no criteria for accidental releases during this period, 10 CFR Part 60 does provide a quantitative definition for systems, components, and structures important to safety, and analyses will be used to identify these systems, components, and structures using this definition. Subpart $E$ also specifies design criteria in 10 CFR 60.130-135 and these criteria will be addressed in the design analyses. In many cases, these criteria reference the postclosure and preclosure performance objectives specified in Subpart $E$.

Subpart E does not explicitly specify criteria for the favorable or potentially adverse conditions. However, 10 CFR 60.122 which defines these conditions references the performance objectives related to waste isolation suggesting 10 CFR 60.112 and 10 CFR 60.113 are applicable.

The required SAR assessment areas specified by 10 CFR 60.21 and the technical criteria of Subpart $E$ therefore suggest that the following performance assessments will be conducted for the SAR: total system performance assessments; engineered barrier system performance assessments; natural barrier performance assessments; preclosure safety assessments; design assessments; site characteristics analyses; and model validation.

\subsection{MILESTONES AND SCHEDULE}

The performance assessments for the SAR will require a consistent set of calculations at the total-system and subsystem levels to calculate the performance measures for comparison with the technical criteria of Subpart $E$ of 10 CFR Part 60. These total-system-level and subsystem-level models must be supported by reliable process-level modeling based on the available laboratory, field, and in situ data, so that the NRC can make a judgment, with reasonable assurance, as to whether the repository will perform as required by the regulations.

The calculation of the performance measures for the SAR performance assessments requires conceptual and computational model development that is unprecedented. In order to have confidence in the conceptual and computational models that will be used in for the SAR performance assessments, this development must be underway at a very early stage. Particular areas of 
concern include: a Total System Simulator appropriate for addressing the total system performance performance objectives in 10 CFR 60.112, a waste package subsystem simulator capable of addressing the engineered-barrier system performance objectives of 10 CFR 60.113, and conceptual models to address fluid (1iquid and gas) movement in the unsaturated zone at the Yucca Mountain site. Developments in these areas are needed as a part of the preliminary preparations for the SAR even before the methodology is developed and the decision is made as to the conceptual and computational models that will be used for the SAR analyses.

It is assumed that the final specification of the methodology for the SAR performance assessments will not be completed until after construction of the Exploratory Shaft Facility (ESF) and completion of the geologic drifting associated with the ESF. It is also assumed that the final analysis will be based on data from the surface-pased drilling program and at least twelve months of in situ data from the ESF regarding percolation and bulk permeability, information from radial boreholes, testing of hydrologic properties of major faults, and at least nine months of in situ testing of waste package environments. In order for these assumptions to hold, the final stage of analyses could not begin until at least eighteen months after the start of in situ testing in the ESF.

It is also assumed that the analyses must be completed at least six months before the SAR to allow for final preparation and preparation and printing of the License Application. In fact, the analyses may need to be completed even sooner to allow for integration with the analyses of the LADs, the update of the EIS performance assessments for the FEIS, and any performance assessments to support the Site Recommendation Report.

To prepare for the SAR calculations, the performance assessment technology will be exercised during the early site investigation phase and during the EIS PA phase of performance assessment. These preliminary applications of the technology will allow the DOE to develop and apply computational techniques in an increasingly sophisticated environment, leading from preliminary calculations to the licensing analyses. Therefore the computational techniques and strategies can evolve, leading to a more comprehensive and complete SAR. This approach will also provide preliminary results that will form the basis for discussions with the NRC staff on key licensing issues and for setting priorities in developing models and codes.

The calculations during the early site investigation phase will employ available models based on the conceptual designs for the repository and the waste package, laboratory data, and data available from early site testing. The calculations during the EIS PA phase will be based on advanced conceptual designs for the repository and the waste package, additional data from laboratory tests and from the surface-based drilling program, and initial data gathered from the exploratory $\neg$ shaft facility. 
The performance assessments that will be reported in the SAR will use the LADs for the repository and waste package and data from the site testing programs gathered by the middle of 1998. Further, the assessments are to be conducted with certified computational models $\rightarrow$ that is, models that are validated, verified, and documented according to the appropriate quality assurance requirements.

With these constraints in mind, a focused effort of development and analyses has been defined to provide the performance assessments for the SAR. The sequence of performance assessment activities for the License Application is shown in Figure 4-1. The steps in this sequence include the preliminary preparations, methodology development, computational model development, code certification, calculations for the SAR performance assessments, and documentation of the performance assessments for the SAR. The preliminary preparations will continue until about the middle of 1996 when the final methodology, conceptual model, and computational model development will begin. The calculations for the SAR will be conducted from about october 1998 until about April 2001 when a draft SAR will need to be completed in order to issue the SAR in October 2001. From Apri1 through October 2001, performance assessments may be conducted in revising appropriate sections of the SAR and supporting documents for the SAR. 


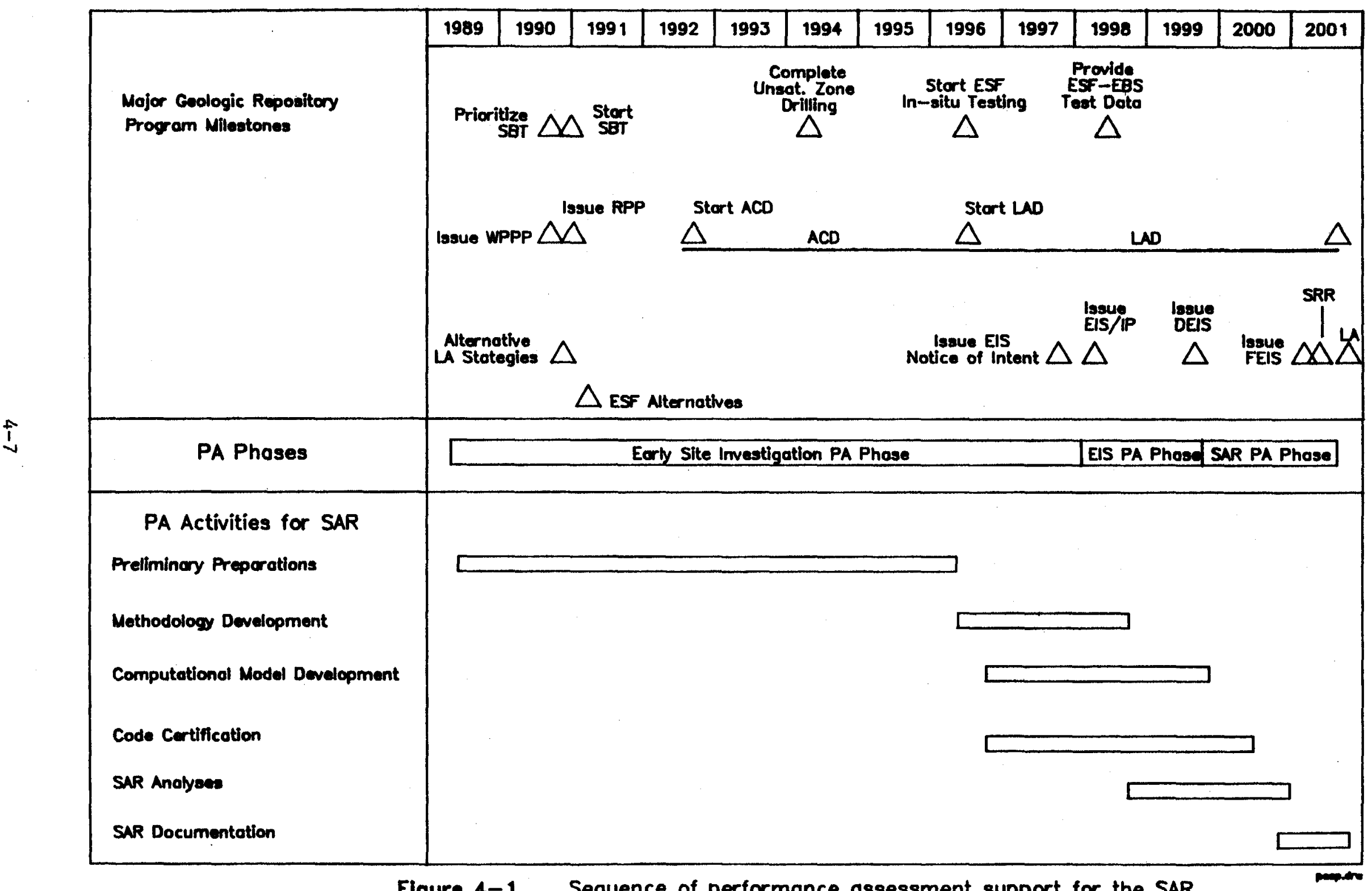

Figure 4-1. Sequence of performance assessment support for the SAR. 


\section{PERFORMANCE ASSESSMENT SUPPORT TO THE ENVIRONMENTAL IMPACT STATEMENT}

In accordance with the requirements of the National Environmental Policy Act of 1969 (NEPA) as amended and the Nuclear Waste Policy Act of 1982 (NWPA) as amended, the DOE will prepare an Environmental Impact Statement (EIS) for the repository. Since many of the impacts of the repository are associated with its preclosure safety and long-term performance, performance assessment will be a major contributor to the EIS. This section summarizes the statutory requirements for the repository EIS, describes the EIS requirements for performance assessment, and discusses the performance activities to be conducted in support of the EIS. It concludes with a brief discussion of milestones and schedules.

\subsection{DESCRIPTION OF THE ENVIRONMENTAL IMPACT STATEMENT}

Any DOE action that may significantly affect the environment is subject to the requirements of the NEPA of 1969 as amended; these requirements include the preparation of an EIS. The NEPA is implemented by the regulations of the Council on Environmental Quality (CEQ), codified in 40 CFR Parts 1500-1508. The DOE has formally adopted the CEQ regulations in its own regulations, 10 CFR Part 1021.

The NEPA and the CEQ regulations specify that any EIS is to include a statement of purpose and need; a discussion of alternatives to the proposed action; an analysis of the environmental impacts, including any adverse effects that cannot be avoided; and any irreversible and irretrievable commitments of resources. The analysis of environmental impacts usually includes effects on public health and safety. An EIS is to be developed in two stages: a draft EIS (DEIS) is to be prepared and submitted for public comment and then a final EIS (FEIS) is to be prepared, addressing the comments as appropriate.

An EIS for the repository is also required by Section 114 of NWPA as amended. This EIS is to accompany the DOE's recommendation to the President to approve a site for a repository (NWPA Section $114(\mathrm{a})(1)(D))$. The NWPA also modifies the NEPA requirements for the EIS by eliminating requirements to discuss the need for the repository, alternatives to geologic disposal, and alternative sites to Yucca Mountain.

In addition, the NWPA states that the EIS developed by the DOE is to be used by the NRC to the extent practicable. The NRC is establishing standards in 10 CFR Part 51 (currently in draft) to guide the development of the EIS that the NRC will use for licensing. If the DOE decides to develop an EIS that the NRC can use in its totality for licensing, the DOE will need to use the NRC standards.

The CEQ regulations require public participation in determining the scope of issues to be addressed in the EIS ( 40 CFR 1501.7). In 40 CFR 1508.25, the CEQ defines "scope" as the range of actions, alternatives, and impacts to be considered in an EIS." Final decisions on the scope, or decisions that 
foreclose options, cannot be made until the public has had an opportunity to participate in scoping. The performance assessments and information needed for the EIS will be derived from the scoping process.

\subsection{REQUIREMENTS FOR PERFORMANCE ASSESSMENT}

The protection of public health and safety during both the preclosure and the postclosure phases of the geologic repository will be a significant issue for the EIS. To address these public-health-and-safety issues, a systematic evaluation of repository performance and of potential health effects will have to be conducted. This assessment will need to consider the performance of the total repository system, to assess actual effects on human populations and the environment, and to consider the impacts in terms of health effects on future populations.

In the EIS, special performance assessments will be needed to establish a basis, in terms of environmental impacts, for making choices among various design alternatives, such as surface storage capacity, waste-package materials, and repository heat loading. The requirement to evaluate alternatives is found in $40 \mathrm{CFR} 1505.1(\mathrm{~d})$ and 1505.2(b).

A major purpose of the EIS is to provide estimates of environmental impacts for public information, review, and comment. The EIS needs to reflect the concerns expressed by the public.

These purposes are different from those for the SAR and dictate performance assessments that are somewhat different. That is, whereas in the SAR the performance assessments will be used to compare repository performance with regulatory criteria and to demonstrate that these criteria are met, the performance assessments for the EIS are intended to estimate the actual impacts and to compare alternatives. Significant differences between the EIS and SAR performance assessments include the following:

1. The focus of the EIS is on environmental impacts, not on meeting regulatory criteria.

2. The EIS will be expected to use realistic assumptions as practicable in order to provide realistic estimates of impacts.

3. At the same time, the EIS may consider a range of accidents for assessment, including some with consequences more severe than the design-basis accident, as well as lower-probability, higher-consequence scenarios than those considered in the SAR.

4. The postclosure assessments in the EIS may be required to address long time frames, perhaps as $10 n g$ a 100,000 years, in order to evaluate impacts.

5. Although the environmental regulations have no specific preclosure dose limits with which the EIS must demonstrate compliance, precedents established in the assessment of environmental impacts for nuclear power plants will have considerable influence on the types of preclosure safety assessments that will be needed in this EIS. 
The analyses for EIS need not wait until the completion of all site characterization. These analyses will consider all available data.

Previous regulatory actions have recognized that an EIS can use qualitative, rather than quantitative, data where necessary. In this regard, the CEQ regulations for NEPA implementation state, in 40 CFR 1502.22(b)(4), that, if necessary, impact assessments may contain "(1) a statement that such information is incomplete or unavailable, (2) a statement of the relevance of the incomplete or unavailable information to evaluating reasonably foreseeable significant adverse impacts on the human environment, (3) a summary of existing credible scientific evidence which is relevant to evaluating the reasonably foreseeable significantly adverse impacts on the human environment, and (4) the agency's evaluation of such impacts based upon theoretical approaches or research methods generally accepted in the scientific community."

\subsection{PERFORMANCE ASSESSMENT ACTIVITIES FOR THE EIS}

\subsubsection{Preclosure Safety Assessment for the EIS}

The preclosure radiological assessment for the EIS will consist principally of evaluations of the radiation exposures of workers at the repository and members of the public during normal operations and members of the public under accident conditions. Because the requirements in the NEPA and the CEQ regulations are directed toward evaluating and comparing impacts without regard to meeting any specific limiting values, the focus of the EIS will be on ensuring that the impact of the exposures is fully evaluated in terms of environmental pathways, the relative impacts of design alternatives, and the estimated effects on health and the environment.

\subsubsection{Assessment of radiological impacts}

In making realistic assessments of radiological impacts, the locations of the nearest existing or probable residences will be used (rather than the uninhabited site boundary) and existing or probable exposure pathways will be considered, using average values for the input parameters of the models. Both individual and collective health effects will be estimated, for both the repository workers and members of the public. These will be combined to define the total impact of the repository system.

The assessment of the preclosure radiological impacts under both normal conditions and accidents will require information about the design of the repository, the radionuclide source term, radionuclide transport in the environment, estimated population distributions, and pathways for human exposure. The evaluation of impacts under accident conditions will involve identifying initiating events, developing accident scenarios, and evaluating probabilities and consequences. The focus of the EIS will be on using probabilities and dose consequences to estimate the health effects that may result from these accidents. 


\subsubsection{Analysis of accidents beyond the design basis}

The CEQ regulations require in 40 CFR $1502.22(\mathrm{~b})(4)$ the evaluation of "reasonably foreseeable significantly adverse impacts, including impacts that have catastrophic consequences, even if their probability is $10 \mathrm{w}$, as long as the analysis is within the rule of reason.

The NRC implemented this regulation in its Statement of Interim Policy on 10 CFR Part's 50 and 51 (45 FR 40101) as follows:

It is the Commission's position that its Environmental Impact Statements sha11 include considerations of the site-specific environmental impacts attributable to accident sequences that lead, to releases of radiation and/or radioactive materials, including sequences that can result in an adequate cooling of reactor fuel, and to melting of the reactor core. In this regard, attention shall be given both to the probability of occurrence of such releases and to the environmental consequences of such releases.

In this statement, the phrase "result in inadequate cooling of reactor fuel and to the melting of the reactor core" is equivalent to "exceed the consequences of the design-basis accident (DBA)." Such an accident has been referred to as a "class 9" accident.

For the repository EIS, performance assessment may have to identify and evaluate one or more class 9 accidents that can be postulated to occur during both the preclosure and postclosure phases of the repository.

\subsubsection{Conversion of doses to health effects}

Health effects are common measures to define the environmental impacts of radiation and radionuclide exposure from a variety of accidents and exposure pathways. The guidance provided by the International Commission on Radiological Protection (ICRP, 1980) is particularly useful for converting a series of doses and probabilities from accidents into health effects, which then can be used as a measure of the total impact of the facility on the eqvironment. Health effects also provide convenient measure that combines the impacts on individuals with those for the public in general and for combining the impacts of continuous exposures from normal operations with the discrete probabilistic estimates of exposures from accidents. The EPA has been using total health effects as the measure of impact in most of its recent regulatory decisions. Hence, by using health effects, the impact from accidents can be added to that from normal operations to arrive at the total environmental impact of the repository. The use of health effects in the EIS will also facilitate the comparison of the impact of the repository with that of other facilities and the comparison of alternative designs for the repository. 


\subsubsection{Input-data requirements}

To perform the evaluations above, data will be required from the socioeconomic and environmental monitoring programs. These data include the joint frequency distribution of wind velocity and atmospheric stability, the population densities and distrioutions by distance from the repository, and data on agricultural production. In addition, data on radiation levels and the distribution and transport of radionuclides within the repository will be required to evaluate health effects in workers.

\subsubsection{Pastclosure Performance Assessment for the EIS}

The EIS, like the SAR, must assess the long-termi performance of the repository. However, there are differences between the SAR and the EIS assessments for the postclosure period relative to those for the preclosure period. For example, since the EIS is scheduled for completion before the end of the site'characterization, its assessments must be based on fewer data and less conclusive models than for the SAR. Other differences'include:

- The SAR will involve assessments of compliance with specific regulatory cumulative-radionuclide-release limits established for a defined Eoundary (the accessible environment) in 10 CFR Part 60 and 40 CFR Part-191. The EIS assessments will emphasize actual and potential impacts on health and safety and the environment.

- The SAR must address potential releases for 10,000 years, while the EIS release analysis extends for as long as the radionuclides in the waste may affect the environment, perhaps much longer than 10,000 years.

- The EIS may need to consider direct and indirect impacts at locations beyond the accessible environment specified for the SAR.

- The EIS may also need to consider scenarios with lower probabilities and higher consequences than those prescribed for the SAR.

\subsection{MILESTONES AND SCHEDULES}

The EIS process begins with preliminary planning by the DOE so that it can make available for public consideration during the scoping process a description of the action it proposes and some of the major biternatives and their likely impacts. When it is ready, the DOE files a notice of intent that an EIS will be prepared. After this, a meeting will be held for the public to determine the scope of the EIS. Since the scoping activity defines the assessments needed, 'performance assessment methodologies and tools will be developed to meet these needs. The activities will be conducted during the EIS PA phase of performance assessments.

After data collection and analyses required to address the issues determined during scoping, the DOE will issue a DEIS for public comment. At the end of the period for public comments, the DOE will prepare its responses to the comments received. This process may involve the addition of some analyses during the SAR PA phase for the final EIS. 
The schedule of performance assessment activities in support of the EIS is presented in Figure 5-1. There are certain assumptions implicit in this schedule. First, it is assumed that methodology and mode1 development activities are an integral part of DOE's planning process to prepare for scoping of the EIS. It is assumed that this process will begin about the middle of 1994 and the EIS scoping activity will begin in 1997. Furthermore, it is assumed that preliminary analyses conducted in the early site investigation phase will be used to assist in defining the scope of the EIS. Analyses conducted from about mid-1996 will help the preparation for the EIS analyses and assist in the scoping effort. It is assumed that the methodology and model development cannot be completed until after scoping in completed and the EISIP is issued. Therefore, the EIS PA phase includes sufficient time for these developments as well as the EIS calculations using them.

Several years of surface-based testing data will be available for the completion of model development and the analyses for the EIS. Some data from in situ testing at depth in the Exploratory Shaft Facility (ESF) will become available before the analyses for the DEIS are completed. It is anticipated that the analyses will be based on the Advanced Conceptual Designs for the repository and the waste package; however, some of the License Application Design (LAD) effort will be completed during the period when the DEIS analyses are being conducted and this information will allow the assessments to take into account some design changes associated with the IADs. 


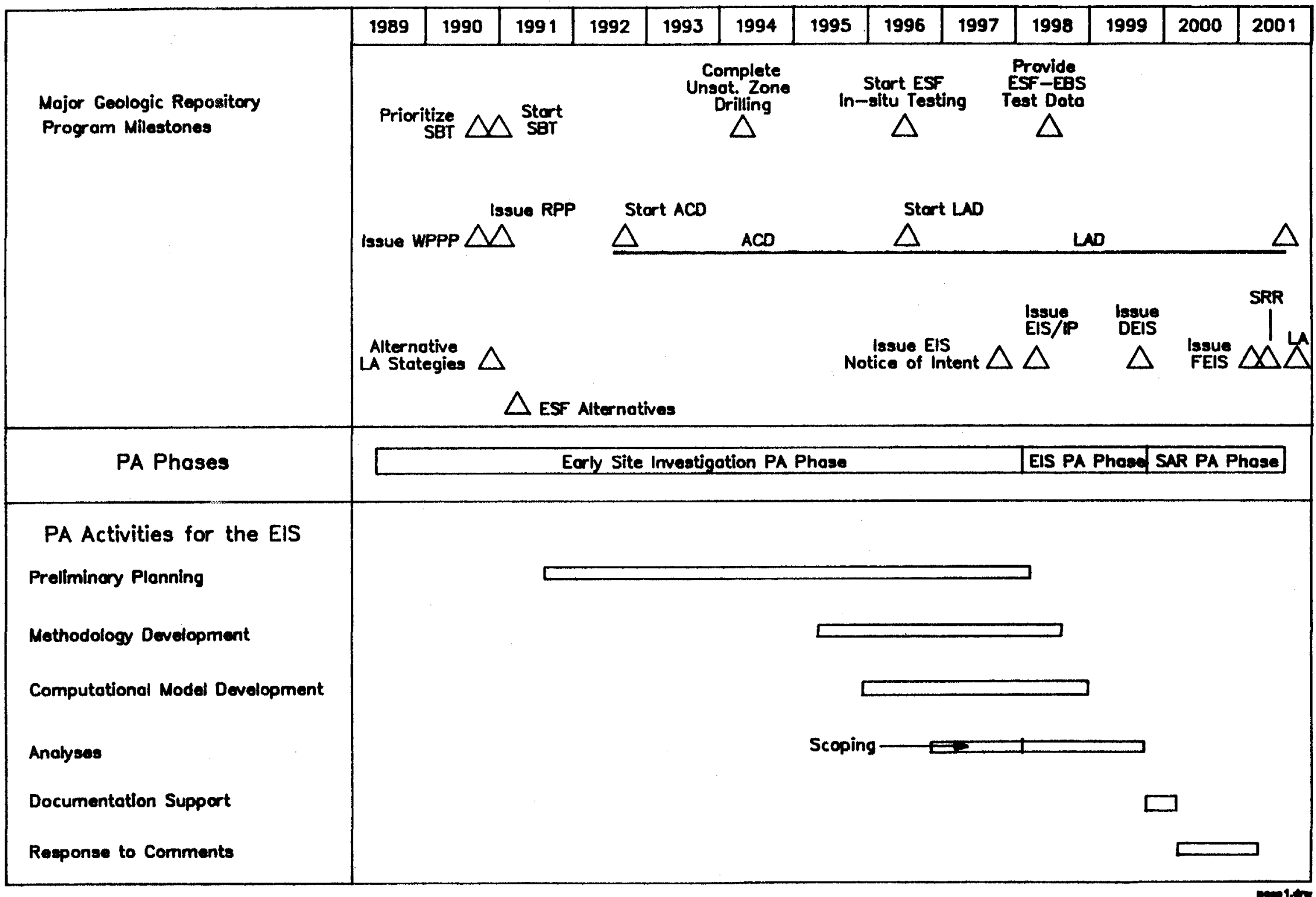

Flgure 5-1 Sequence of performance assessment support for the EIS. 


\section{PERFORMANCE ASSESSMENT SUPPORT TO SITE-SUITABILITY ANALYSES}

The purpose of the site characterization program is to determine the suitability of a site for a geologic repository. The program of testing described in the Site Characterization Plan (DOE, 1988a) is therefore focused on obtaining information to address performance objectives specified in the regulatory criteria related to safety and waste isolation, information to address the siting criteria in the regulations, and information to address specific site suitability concerns, such as potentially adverse features or conditions of the site. The testing program specified in the site Characterization Plan (SCP) is believed to be sufficiently comprehensive to be able to provide this information and this program will be continually reviewed as the testing progresses to ensure that new concerns can be investigated. In addition, the program is to be reviewed to emphasize an early focus on the potentially adverse features and conditions that could potentially disqualify. the site.

Performance assessments will play an important role in the evaluations of site suitability. Performance assessment sensitivity studies will be used to evaluate the importance of specific features or conditions with respect to safety and waste isolation during site characterization and comprehensive performance assessments will be conducted at the conclusion of site characterization as a part of DOE's effort to determine the suitability of the site.

If the site is found to be suitable, the comprehensive performance assessments will be presented in the Site Suitability Report and in the Safety Analysis Report (SAR). The Site Suitability Report will provide the basis for the recommendation of the site to the President. If this recommendation is accepted, the SAR will be submitted to the Nuclear Regulatory Commission (NRC) as a part of the License Application (IA). The arguments in the SAR will be considered by the NRC for the decision to authorize construction of the repository. These arguments will be reconsidered, along with those given in any amendments to the LA, in later decisions to grant a license to receive and possess radioactive material at the site and to close, decontaminate, and decommission the repository. This chapter discusses the requirements that apply to the site-suitability analyses and the performance assessments that are to be conducted as a part of these analyses.

\subsection{DESCRIPTION OF THE SITE-SUITABILITY ANALYSES}

A site-fsuitability analysis by the DOE is implied by the requirements of the Nuclear Waste Policy Act (NWPA) of 1982 as amended. The requirements for such an analysis arise from Section $114(\mathrm{~b})$ of the NWPA as amended. These requirements specify that the Secretary of Energy shall submit to the President a recomendation that the President approve the site for the development of a repository and that together with any recommendation of a site, the Secretary shall make available to the public, and submit to the President, a comprehensive statement of the basis of such recommendation. This basis is to include a discussion of the data obtained in site 
characterization activities relating to the safety of a repository at the site. This requirement calls for analyses of the suitability of the site with respect to the performance of the repository system. These analyses are to be conducted using the information obtained from the site characterization program. Siting guidelines developed for the site characterization program are given in 10 CFR Part 960. These guidelines are closely related to the siting criteria of $10 \mathrm{CFR}$ Part 60 ; that is, they require analyses of both individual favorable and potentially adverse conditions at the site and an evaluation of the performance of the repository system and its subsystems to show compliance with the performance objectives of 10 CFR $60.112-113$. The analyses of site suitability will be closely related to those that will therefore be conducted for the LA, i.e., the SAR analyses discussed in Chapter 4.

Analyses of particular conditions and features of the site will be conducted as the results of site characterization regarding them are obtained. The evaluations of these individual conditions and features of the site as early as possible during the site characterization program are referred to here as "early site evaluations." The analyses will involve determination of whether the conditions are present at the site or not and, if present, whether their presence could have a significant effect on safety or performance.

A comprehensive analysis of repository performance and safety will also be conducted at the conclusion of site characterization to ensure that the performance objectives of 10 CFR Part 60 can be met. This analysis must address individual potentially adverse conditions specified in 10 CFR 60.122 as well as the possibility that combinations of conditions and features may affect the suitability of the site.

\subsection{PERFORMANCE ASSESSMENTS FOR THE SITE-SUITABILITY ANALYSES}

\subsubsection{Early Site Evaluations}

In addition to the general geologic, geohydrologic, geochemical, tectonic, climatic, and other characteristics of the site, the site characterization program will provide information on specific potentially adverse conditions of the site. Sections 8.3.5.17 and 8.3.5.18 of the SCP discuss the current plans to address these conditions during site characterization. For those conditions found to be present at the site, performance assessments will be conducted as early as possible in the program to determine if performance could be significantly affected.

For a given potentially adverse condition or feature, scenarios will be developed for the various ways the condition or feature could affect performance of the repository system. Performance measures will be estimated for each of these scenarios to evaluate the importance of the condition or feature with regard to performance. The approach to the development of scenarios, the specification of what performance measures will be evaluated, and the approach to the estimation of values for the performance measures will 
be defined early in the program so that a consistent approach will be used for each of the potentially adverse conditions or features. The evaluations themselves will be conducted in conjunction with each of the studies that focuses on the potentially adverse conditions. The current set of these studies is identified in Sections 8.3.5.17 and 8.3.5.18 of the SCP. Table 6-1 summarizes these studies and their planned schedules. Site characterization may indicate that other studies may be needed with regard to particular features and conditions at the site. In this case, plans can be developed and additional early site evaluations can be undertaken.

The priorities of the site-characterization program are currently under review to ensure that the program provides an early focus on the potentially adverse features and conditions that may disqualify the site. Therefore, the studies and schedules specified in Table 6-1 may be changed. Nevertheless, the principle involved is the same. Performance assessment sensitivity studies will be conducted as a part of the planning of the studies and in the evaluation of the results of the studies to determine the significance of the features or conditions being investigated to safety and waste isolation. Therefore, the planning of the performance assessments must anticipate the particular investigations needed in order to provide relevant information. This requirement will be taken into account in implementing the performance assessment strategy for the early site evaluations.

\subsubsection{Comprehensive Site Evaluation}

At the conclusion of site characterization, a comprehensive site evaluation will be conducted in which the potentially adverse conditions and features will be taken into account together to ensure that the performance objectives of 10 CFR Part 60 can be met. This analysis will address both individual conditions and features of the site and the combination of these conditions and features as they affect the ability to meet the performance objectives. The comprehensive site evaluation will address the requirement of 10 CFR 60.21 (c)(1)(ii)(B) that calls for an analysis of the potentially adverse conditions of the site that are identified in the siting criteria of 10 CFR 60.122. The approach to this evaluation is discussed in Section 4.3.2. In general, these analyses will involve performance assessments in which the conditions and features are explicitly taken into account. For example, for the system performance objective, scenario classes based on the potentially adverse conditions and features will be evaluated and the results will be combined into the overall Complementary Cumulative Distribution Function for comparison with the EPA environmental standards.

\subsection{MILESTONES AND SCHEDULE}

The methodology development to support the early site evaluations will be completed early in the program. The initial development will take place as a part of a review to reprioritize the site characterization program to focus on potentially adverse features and conditions of the site. The milestones for this development are shown in Figure $6-1$. As shown in Figure $67^{1}$, the analyses of individual conditions and features will be conducted throughout the early site investigation phase on a schedule consistent with that for the site studies associated with them. 
TABLE 6-1. Studies that Address Potentia11y Adverse Conditions and Features of the Yucca Mountain Site

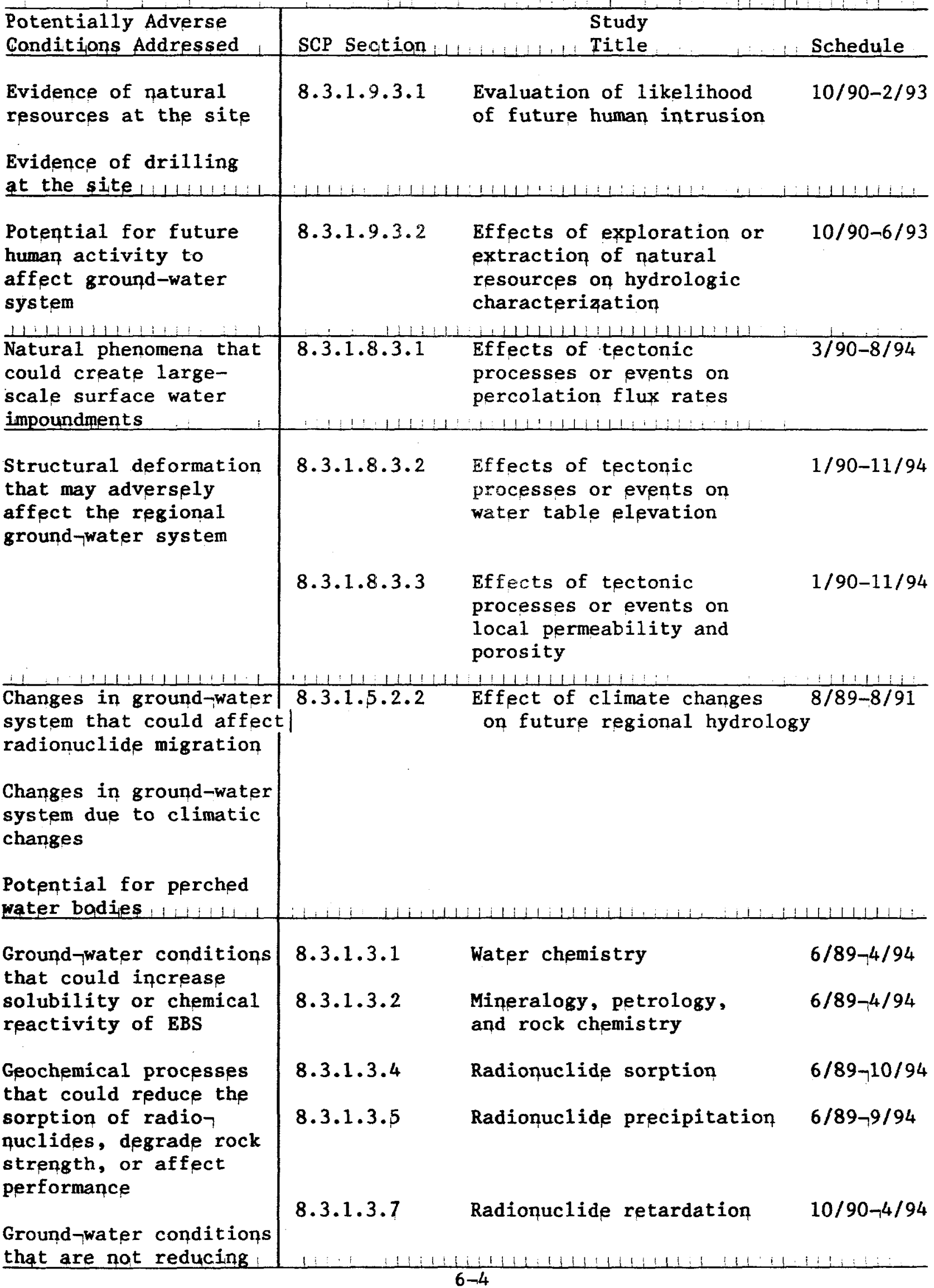


TABLE 6-1 (Continued)

\begin{tabular}{|c|c|c|c|}
\hline $\begin{array}{l}\text { Potentially Adverse } \\
\text { Conditions Addressed }\end{array}$ & SCP Section & $\begin{array}{l}\text { Study } \\
\text { Title }\end{array}$ & Schedule \\
\hline $\begin{array}{l}\text { Structural deformation } \\
\text { potential }\end{array}$ & $8.3 \cdot 1.8 \cdot 3 \cdot 1$ & $\begin{array}{l}\text { Effects of tectonic } \\
\text { processes on percolation } \\
\text { flux rates }\end{array}$ & $3 / 90-8 / 94$ \\
\hline arthquake potential & $8.3 .1 .8 \cdot 3.2$ & $\begin{array}{l}\text { Effects of tectonic } \\
\text { processes of water-table } \\
\text { elevation }\end{array}$ & $1 / 90-11 / 94$ \\
\hline & $8 \cdot 3 \cdot 1 \cdot 8 \cdot 3 \cdot 3$ & $\begin{array}{l}\text { Effects of tectonic } \\
\text { processes on local } \\
\text { permeability }\end{array}$ & $1 / 90-11 / 94$ \\
\hline & 8.3 .1 .8 .4 .1 & $\begin{array}{l}\text { Effects of tectonic } \\
\text { processes on geachemistry }\end{array}$ & $1 / 90-10 / 94$ \\
\hline Igneous activity & 8.3 .1 .8 .2 .1 & $\begin{array}{l}\text { Effects of igneous } \\
\text { intrusion on waste package }\end{array}$ & $12 / 89-4 / 94$ \\
\hline $11+1111: 11$ & $\begin{array}{l}8.3 .1 .8 .1 .2 \\
11: 11: 11\end{array}$ & $\begin{array}{l}\text { Effects of igneous } \\
\text { intrinsic on repasitory }\end{array}$ & $7 / 89-9 / 92$ \\
\hline $\begin{array}{l}\text { Potential for movement } \\
\text { of gaseous radionuclide } \\
\text { through air } \neg \text { filled pore } \\
\text { spaces }\end{array}$ & 8.3 .1 .3 .8 .1 & $\begin{array}{l}\text { Gaseous radionuclide tran } \\
\text { calculations and measurem }\end{array}$ & $9 / 90-3 / 92$ \\
\hline & 8.3 .1 .2 .2 .6 & $\begin{array}{l}\text { Gaseous phase movement in } \\
\text { the unsaturated zone }\end{array}$ & $6 / 89-10 / 91$ \\
\hline
\end{tabular}


The comprehensive site evaluation to be completed near the conclusion of site characterization will be used to support the Secretary of Energy's recommendation of the site to the President. This major milestone is currently scheduled for April of 2001. Preparations for these comprehensive evaluations will begin during the EIS PA phase, while the performance assessments to support this evaluation will be conducted during the SAR PA phase. The methodology development for these assessments will be completed along with that for the SAR performance assessments. The current assumption is that the analyses to support the site recommendation must be completed four months before that milestone date to allow for review and integration into the program decision base. 


\section{PERFORMANCE ASSESSMENT SUPPORT TO SITE CHARACTERIZATION AND CONFIRMATION TESTING}

The major source of site information for the performance assessments is the site investigations, including site characterization and confirmation testing. To ensure that data are provided for performance assessments and confirmation of performance predictions, performance assessment coordinates with the site programs during the development of the investigation plans and reviews of the results of the investigations. Performance assessment sensitivity studies help to establish levels of confidence expected to be needed in performance predictions; then as predictions are conducted, the level of confidence obtained in the investigations will assist in determining if enough data have been collected. Performance assessment also has the responsibility to review the test plans and the test programs as they progress to assess the potential impacts of the testing on repository performance. This section briefly describes the site characterization and confirmation testing programs and discusses the interfaces between the testing programs and discusses the interfaces between the testing programs and performance assessment.

\subsection{DESCRIPTION OF SITE INVESTIGATION PROGRAMS}

There are two major phases of site investigations: a site characterization phase which is to be conducted to provide the for the license Application and a confirmation testing phase data which is to continue after site characterization until permanent closure of the repository.

\subsubsection{Site Characterization Program}

The site characterization program is to investigate the geologic, hydrologic, geomechanical, and geochemical characteristics of the site to develop an understanding of the site that is sufficient to support repository and waste package design, the determination of site suitability, and the license application. The site characterization program is to supply the site data necessary for the conduct of performance assessments. The site characterization program will obtain the necessary data using a variety of techniques both at and near the site and in laboratories. Specific components of the testing program at the site include the surface-based drilling program and in situ testing at depth within the Exploratory Shaft Facility (ESF). In addition, tests outside the controlled area will be conducted.

A Site Characterization P1an (DOE, 1988a) has been published which describes the DOE's initial general plan to obtain these data for the Yucca Mountain site. The DOE expects to modify this plan as the repository program evolves and as more information about the repository system and the site becomes available. The Site Characterization Plan (SCP) was developed using an approach that starts with the regulatory requirements, identifies the performance and design information needed to address those requirements, and then defines specific site investigations to obtain the needed site information. Performance assessments were conducted in support of the 
development of this process. The process is described in Section 8.1 of the SCP. As the characterization proceeds, progress is to be documented in semi-annual progress reports to be issued by the DOE.

Before conducting an investigation, study plans are developed which describe the tests in more detail than that contained in the SCP. These study plans define the data to be collected, where and when they are to be collected, and equipment and procedures to be used. The study plans go through a review process which includes those who will use the data generated by the test. Approval of the plans leads to the conduct of the investigation. As data are obtained, processed and analyzed, conceptual models of the site and its behavior are developed. These data and conceptual models are distributed to the user community (design, performance assessment, and licensing activities) through a computerized, controlled data base system.

\subsubsection{Performance Confirmation Program}

The confirmation testing program will be responsible for obtaining data to test predictions made by the design and performance assessment calculations. This confirmation process is particularly important for predictions of postclosure performance because of the importance that predictions play in demonstrating compliance with the postclosure regulatory requirements in the licensing process. Recognizing this importance, the NRC (10 CFR 60.137) requires that the repository be designed to permit implementation of a performance confirmation program in accordance with Subpart $F$ of 10 CFR Part 60 . The requirements in Subpart F specify that the program be directed toward confirming that the actual subsurface conditions, including changes during construction and operations, are within the limits specified in the License Application, and that the natural and engineered barriers are functioning as intended and predicted.

To implement Subpart F of 10 CFR Part 60, the DOE has established a performance confirmation program consisting of two phases: a baseline phase and a confirmation phase. The baseline phase is conducted during site characterization and ends with the submittal of the License Application. During the baseline phase, data are identified which are needed to confirm performance predictions and, using a part of the data collected during the site-characterization phase, a baseline data base is established with which to compare data to be collected during the confirmation phase. The SCP describes the current program to obtain the baseline data. If a need for additional baseline data is identified during site characterization, the baseline phase will be appropriately expanded or otherwise modified. During the baseline phase, a Performance Confirmation Test Plan will be developed which defines the tests to be conducted during the confirmation phase. Some of these tests will be continuations of the tests conducted during the baseline phase.

\subsection{PERFORMANCE ASSESSMENT ACTIVITIES IN SUPPORT OF SITE INVESTIGATIONS}

The dependence of performance assessment on site data and the role of performance assessment in assuring that site characterization activities do 
not compromise the performance of the natural or engineered barriers place constraints on performance assessment and define interfaces between performance assessment and the site investigation programs. These constraints apply to both the site characterization phase and to the performance confirmation phase.

During site characterization, performance assessment sensitivity studies will be conducted to identify the site data and confidence leve1s important to the performance assessments needed for the License Application and other program milestones. Associated with assisting to establish the confidence levels needed for the data, performance assessment must assist in defining the criteria that will allow the site characterization program to determine when data are sufficient. An example of such interactions between performance assessment and site testing is presented in Section 8.2 of the SCP.

Although during the test-planning process, performance goals are established to allow the site characterization effort to determine when a test has collected sufficient data to allow likely demonstration of compliance with regulatory requirements, these are based on initial estimates of the needed confidence levels using existing knowledge and conceptual models of the site. It is not until predictions of performance are made using the full data set and a comparison is made with regulatory criteria that a final determination can be made whether sufficient data have in fact been collected. As the site data are obtained, conceptual models of the site can change and, in turn, data nefeded and the associated accuracy requirements can change.

The assessment of site characterization activities to assure that they will not adversely affect performance is conducted at the time that the site characterization and performance confirmation plans are being finalized as part of the approval process. However, if data collected during the test indicate effects of the testing outside the expected envelope defined in the test plan, the assessment of impacts will have to be revisited.

\subsection{MILESTONES AND SCHEDULE}

The schedule showing the key interactions between site characterization and performance assessment are shown in Figure $7-1$. The review of the surface-based testing program is scheduled to be completed in September 1990. It is assumed that performance assessment input to this review must be completed in July 1990. Similarly, since the draft ESF requirements are scheduled to be issued in June 1990, it is assumed that performance assessment evaluations needed for this purpose should be completed in April 1990.

Similar considerations will be made throughout the testing program. Performance assessment sensitivity studies will be planned in anticipation of planned tests in order to confirm the performance goals set for these tests in the SCP and to take into account the results of testing available at that time. As data are obtained from the surface-based testing and in situ testing at depth in the ESF, performance assessments will be conducted to review the results of the test program. Therefore, performance assessments to support the testing program will be conducted throughout the early site investigation phase and specific plans for these assessments will be developed on a year-by-year basis in the PAIPs. 


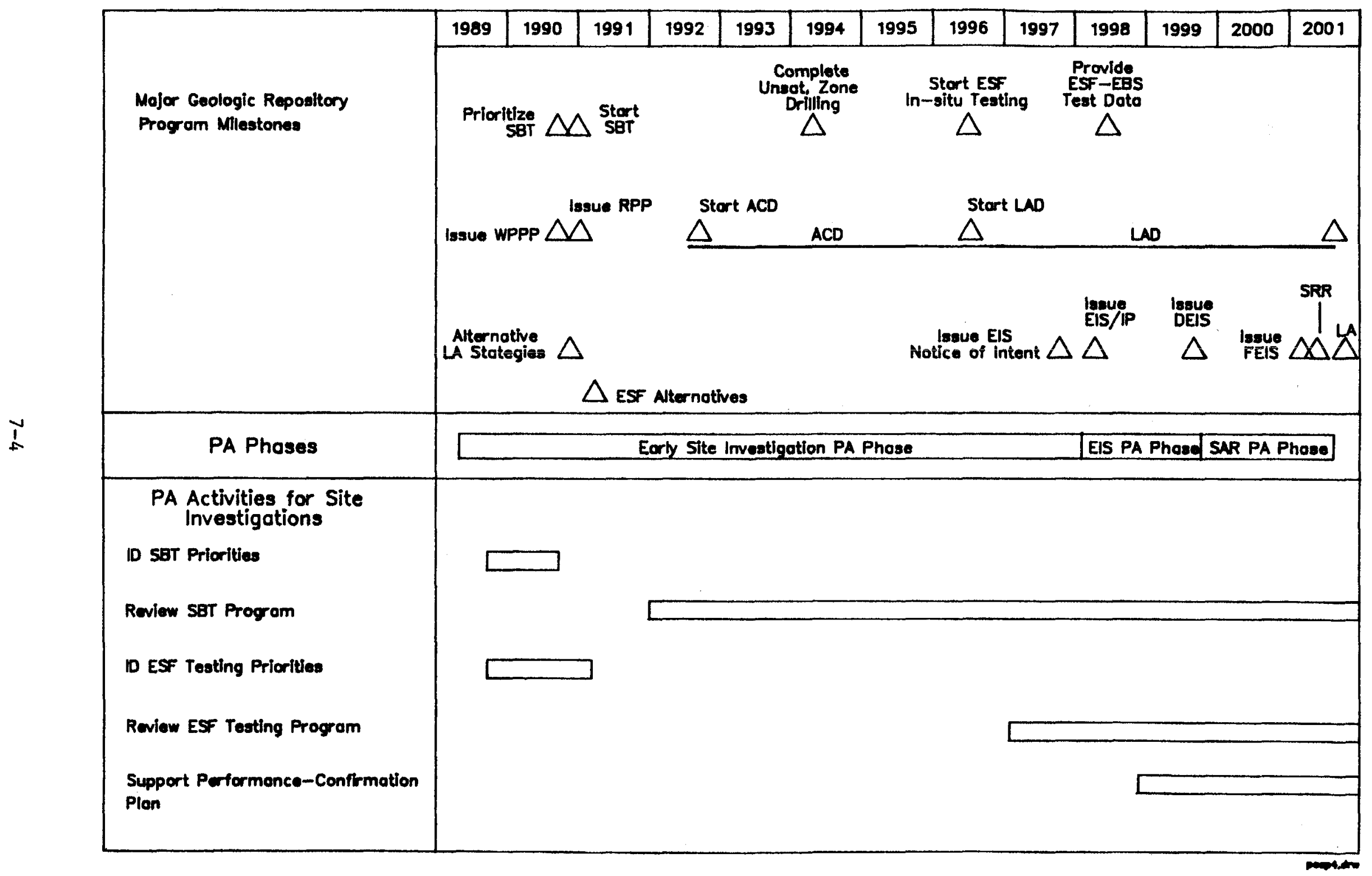

Flgure 7-1. Sequence of performance assessment support to site investigotions. 
One of the major roles of performance assessment is to assess the repository and waste-package designs to determine whether the assessments indicate that performance criteria will be met. Because design data are important to the assessments, the performance assessment program must provide guidance to the design programs regarding data needs. In addition, performance assessments are performed to derive from the more general performance criteria a set of detailed constraints that can be more directly implemented by the design effort.

Assessments of the design of the exploratory-shaft facility (ESF) will be performed to ensure that the design does not adversely affect repository performance. These assessments will investigate the effects of the facility and of the tests planned for the facility.

Performance assessments will use the current design and currently available site and materials data to evaluate the performance of the repository. For example, the conceptual design and data from surface-based tests will be used in the preliminary performance assessment exercises. Because only preliminary data are available for the preliminary exercise, the performance assessments will be limited to sensitivity studies, parameter ${ }_{7}$ variation analyses, bounding calculations, and limiting calculations. These studies will be used to update the design requirements. As the data base expands and more refined data become available, the performance assessments will become more predictive.

\subsection{DESCRIPTION OF DESIGN PHASES}

The designs of the repository and the waste package will be developed in several phases. The initial phase was the conceptual design (CD) developed for the site characterization plan; the CD was completed in 1987 and is described in the conceptual design report for the repository (MacDougall et at., 1987) and in Chapter 7 of the SCP for the waste package (DOE, 1988a). The remaining phases are the Advanced Conceptual Design (ACD) stage, the License Application Design (LAD) stage, and the final procurement and construction design stage. These design stages are briefly described below, with emphasis on the $A C D$ and the $L A D$, which have important interfaces with future performance assessment.

Included in the discussion that follows is the design of the exploratoryshaft facility (ESF). The ESF design is given special attention because the facility will be part of the repository.

\subsubsection{Design of the Exploratory-Shaft Facility}

The current design of the ESF includes two exploratory shafts, underground drifts and test chambers, and laboratories and other support facilities at the surface. Its purpose is to allow the DOE to conduct site characterization studies at the depth of the repository, and the results of these studies will provide site characterization data for performance assessments. If the site is found to be suitable, the two exploratory shafts will be used in the repository. 


\subsubsection{Advanced Conceptual Design}

The ACDs of the repository and the waste package will be used to explore design alternatives and provide a basis for establishing the design criteria and concepts that will be used in later design. The ACDs will assist in demonstrating the feasibility of the design, estimating the life-cycle cost, and preparing preliminary drawings. The objective of the ACDs is to develop appropriate solutions to design-related licensing issues through consultation with the NRC as established by the procedural agreement between the NRC and the DOE (NRC/DOE, 1983).

\subsubsection{License App1ication Design}

The LADs must satisfy the design criteria of 10 CFR Part 60 , and must support the resolution of issues related to design and licensing identified in earlier design phases. Sufficient design information will be developed during the LAD phase to meet the requirements of 10 CFR 60.21 for the License Application. Work on the LAD will start after the completion of the ACD. This stage will conclude with the submittal of the LAD report in support of the License Application.

\subsubsection{Final Procurement and Construction Design}

During this phase, the DOE will develop the final drawings and specifications for procurement and construction. This design phase will emphasize the completion of the design of ancillary support items, final design refinement for the items necessary to demonstrate compliance with the design criteria and performance objectives of 10 CFR Part 60 , the development of construction bid packages for all systems, and the development of final construction and procurement schedules.

\subsection{REQUIREMENTS FOR PERFORMANCE ASSESSMENT}

\subsubsection{Interfaces Between Performance Assessment and Design}

The waste package and the surface and underground facilities of the repository will be designed according to requirements that are determined, in part, from performance assessments, and these designs will be used to evaluate predicted performance against performance requirements. Generic design requirements are documented in a baselined document (DOE, 1986d). Design requirements for specific subsystem designs will be reported in requirement documents as they are developed. The performance assessments used to evaluate the designs will be documented in the design reports; however, these analyses will be conducted during the course of design itself. The analyses used to develop the requirements for a design stage will be based on analyses for earlier stages, using the site information available at the time the requirements are developed. For example, the LAD requirements will be based of the analyses of the CD and the ACD, using generic data, laboratory data, 
and some data from the surface-based drilling program. The design evaluations against these requirements will use the data available at that time; for example, the evaluation of the LAD against the LAD requirements will use the available data from the surface-based drilling and in situ test programs.

Performance assessments must be used to analyze whether the design is adequate to address the design and performance issues identified in the issues hierarchy. Numerous performance assessments will be conducted while designs are being developed. The results of these various assessments will be compiled into reports and recommendations that can be used to more formally guide design updates and issue-resolution activities.

\subsubsection{The Resalution af Design Issues}

Nine design issues have been defined in the DOE issues hierarchy for a geologic repository (Table 2-1). Performance assessments of the waste-package design for issue 1.10 will be conducted to address the design criteria of 10 CFR 60.135. Performance assessments of the repository and the seals subsystems for issues 1.11 and 1.12 will be conducted to address the design criteria of $10 \mathrm{CFR} 60.133$ and $10 \mathrm{CFR} 60.134$. With regard to preclosure radiological safety, risk assessments for the repository under accident conditions could identify accident sequences with insignificant dose consequences to members of the public but with a high potential for contaminating the repository facilities and thus disrupting repository operations. Appropriate measures or features to prevent such accidents or mitigate their consequences will be considered in the design of the repository. These assessments are similar in nature to those that will be conducted for the SAR. The analyses for these issues for the ACD will be conducted before those for the SAR, however, and thus will be based on fewer data and simpler site models. Since the LAD analyses are needed at the same time that the SAR analyses will be conducted, the analyses for the SAR will, in fact, be the analyses conducted for the LAD report.

\subsubsection{Assessment of the Exploratory-Shaft Facility Design}

The performance assessment support to the engineering and design of the ESF addresses two concerns. First, it is used to evaluate whether the ESF construction or site characterization activities in the facility will adversely affect the long-term performance of the geologic repository. Second, it is used to demonstrate that ESF activities will not affect the repository's ability to meet numerous additional related criteria that, if satisfied, are likely to help meet performance objectives.

The current plan is that the ESF will eventually be integrated into the repository itself; therefore, the design of this facility must meet design criteria related to those that will be established for the repository system. The analyses of the ESF are reported in Section 8.4 .3 of the SCP (DOE, 1988a) and in the ESF title I design report (DOE,1989). 


\subsection{MILESTONES AND SCHEDULE}

Performance assessments will be conducted throughout al1 three design phases. Each performance assessment phase will provide a series of reports that will identify the degree of confidence that can be placed in the performance of the total system and the barriers that have been identified by performance allocation. If data are not sufficient or the design requirements must be updated, these needs will be identified in reports at specific times during the preparation of the license application.

Figure 8-1 shows the schedule for providing the information for management decisions about design updates and issue resolution, and Table 8-1 shows the related milestones. As indicated in the figure, there is an effort before the start of each design stage (ACD and LAD) to assess the previous design in 1ight of the best data available from the site investigations to assist in the development of design requirements. Also scheduled is a review of each design which will be conducted between the freeze date for each design and the date of completion of the design documentation. Therefore, at the time of design release, an assessment of that design will be available. The specific dates to begin these assessments are tentative and depend on the finalization of the design schedule. 


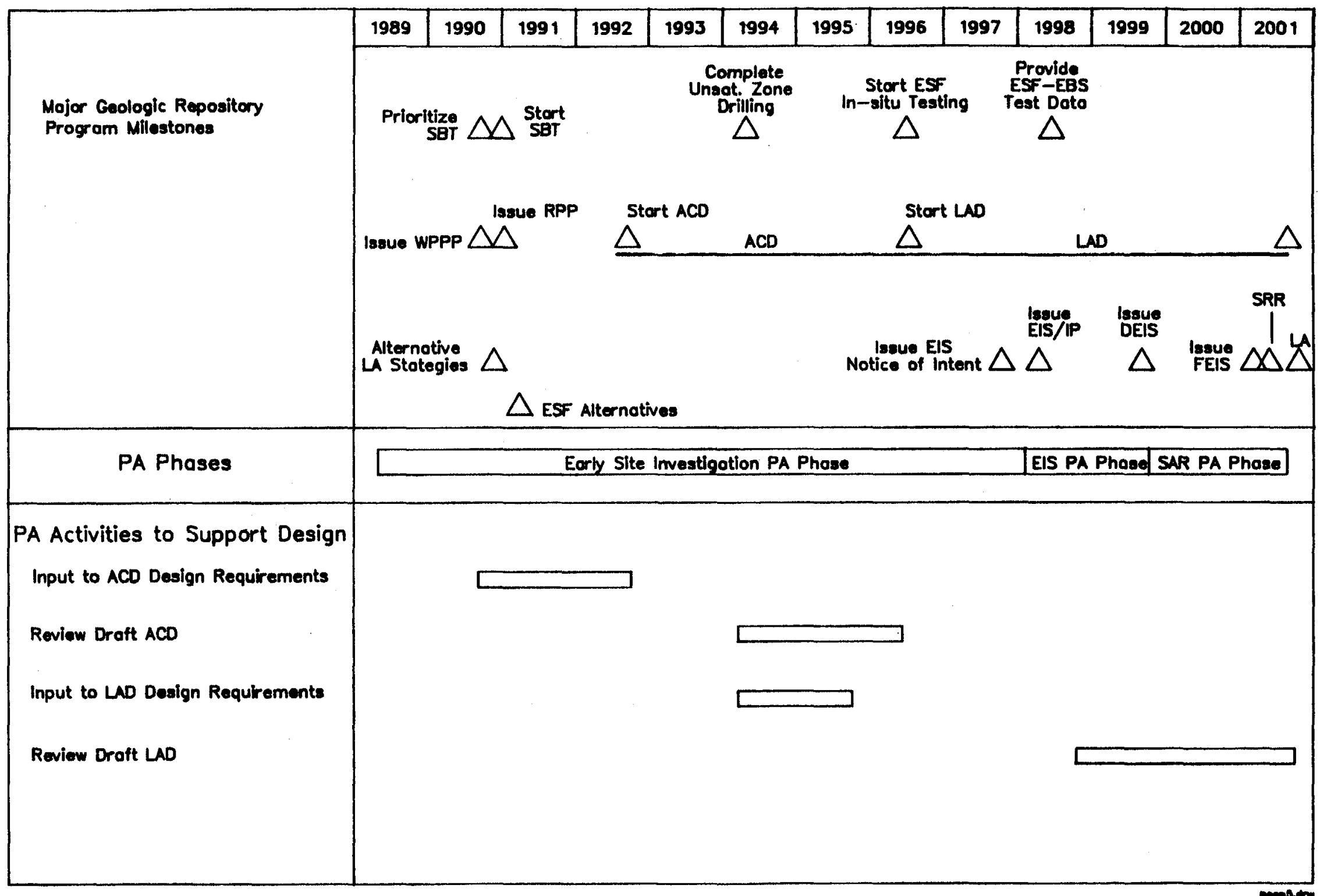

Figure 8-1. Sequence of performance ossessment activities to support design. 


\section{PERFORMANCE ASSESSMENT INTERFACES WITH OTHER WASTE-MANAGEMENT FACILITIES}

For several reasons, performance assessment participates in the interfaces between the geologic repository and other radioactive-wastemanagement facilities. First, understanding how the waste is handled at the other waste-management facilities is important to performance assessment since the condition of the waste upon arrival at the repository may affect wastepackage and waste-form performance. Second, to efficiently tackle issues whose scope spans several waste-management facilities, sometimes repository performance assessment resources are brought to bear on these broader issues. Third, it is the repository program's responsibility to assess potential risks to the health and safety of workers and the general public from operations at the physical interface between the waste $e_{7}$ ransportation system and the repository. This section discusses the performance assessment activities that address these interface concerns.

\subsection{DESCRIPTION OF INTERFACES}

The interfaces of the repository with the waste generators and the waste-transportation system and other aspects of the radioactive waste management program are not yet fully defined. These important interfaces will be determined by decisions on the specific waste-management operations to be carried out at a particular facility. In addition to such functional interfaces, there will be a direct physical interface between the waste-transportation system and the repository. of interest in preclosure safety assessments are those operational and procedural parameters at this interface that are pertinent to preclosure risks to the health and safety of workers and the public. Examples include requirements for the inspection and decontamination of shipping casks after their arrival at the repository site, procedures for unloading the casks in the receiving hot cell, cask-maintenance activities, and the need to control and protect the casks before unloading.

In addition to these direct interfaces, there will be significant indirect interfaces with waste generators, the transportation system, and other parts of the program. One example of an indirect interface is the evaluation of fuel burnup at reactors, which define such waste characteristics as radionuclide composition, neutron $f 1$ ux, and the decay temperature profile. Another example is evaluation of the set of conditions at temporary storage facilities (e.g., at reactor sites or at a Monitored Retrievable Storage facility) or during transportation; these could affect the temperature of the waste during storage or transportation, which in turn could affect the physical or chemical condition of the waste, the condition of the spent-fuel cladding, and the integrity of the waste package. Effects on the waste form or the disposal container could affect the behavior of the repository before and after closure. 
The interface with the postclosure performance of the repository is primarily indirect. It involves the need to establish the state of the engineered systems at the time of repository closure in order to assess postclosure performance. This includes establishing the state of the waste forms (including spent-fuel cladding) and disposal containers at the point at which they are physically transferred to the repository. Since some of the characteristics that are important to the long-term performance of the repository may be affected by the storage facility and by transportation, it is important to assess the effects of storage and transportation on these parameters.

The strategy that is being adopted is to establish interface controls between the various facilities (i.e., waste-acceptance requirements and operating procedures) to ensure that storage and transportation that are important to the long-term performance of the repository are well established and understood.

\subsection{PERFORMANCE ASSESSMENT SUPPORT}

Performance assessment will be important in defining controls on direct and indirect interfaces and the information-transfer needs for these interfaces. This will be accomplished by developing interface specifications for each type of waste form. Some of these specifications will be wasteacceptance criteria; others will be operating procedures at the physical interface between the repository and the transportation system.

The performance assessment support will involve the following steps:

1. Identifying parameters that are important to repository performance and may be significantly influenced by the waste generators, the transportation system, and/or other waste-system components.

2. Determining how the above parameters can and will be controlled at direct (physical) interfaces by, for example, acceptance specifications.

3. Identifying information-transfer requirements at the indirect interfaces.

The specific parameters for which acceptance specifications, other interface controls or information transfer may be required include the following:

1. Parameters associated with the waste form, such as thermal output; radionuclide content; cladding condition; age and origin of the waste; and the thermal, chemical, and mechanical history during storage, handling, and transport.

2. Parameters associated with the disposal containers, such as container damage, fill gases, and closure procedures. 
The information developed by performance assessment will be integrated with other efforts by the repository and waste-package design groups to define a DOE position on the interface requirements. Then discussions and negotiations will be held among the groups representing the various components of the waste-management system and the waste generators. Because of the possibility of conflicting requirements and objectives, it will be important to understand the importance of the parameters involved to repository performance and the sensitivity of performance to changes in those parameters.

\subsection{PERFORMANCE ASSESSMENT ACTIVITIES}

Before an assessment of the interfaces can be identified and scheduled, the functional design requirements and specifications for a potential Monitored Retrievable Storage (MRS) facility and the transportation system must be developed. Functional design requirements and specifications for the MRS facility are being developed. Some consideration is being given to the incorporation of functions associated with the transportation support system into the repository or the MRS facility. These support functions include routine cask maintenance, cask-seal replacement, cask decontamination, and annual inspections.

The only performance assessment activities scheduled at present to support interfaces with other waste-management facilities are preclosure and postclosure assessments to support the definition of functions. These activities are responsible for identifying significant functions for which location is a question and making a preliminary, qualitative determination of the function location on repository performance. The parameter-identification activities are responsible for a preliminary identification of parameters that are important to repository performance, before and after closure, that could also be significantly affected by an MRS facility or transportation and proposing preliminary interface controls for these parameters. 


\subsection{OVERVIEW}

The DOE actively supports international waste-management programs as provided for in the Nuclear Waste Policy Act (NWPA) and the Nuclear Waste Policy Amendments Act of 1987. In many cases it is advantageous for the DOE to share the costs of waste-management technology with foreign organizations conducting similar activities.

For the Civilian Radioactive Waste Management (CRWM) program, the DOE has bilateral agreements with the following national authorities:

- Commission for the European Communities (CEC).

- Nuclear Energy Research Center of Belgium.

- Atomic Energy of Canada, Limited (AECL).

- Atomic Energy Commission of France.

- Federal Ministry for Science and Technology of the Federal Republic of Germany (FRG).

- Power Reactor and Nuclear Fuel Development Corporation of Japan.

- Swedish Nuclear Fuel and Waste Management Company (SKB).

- National Cooperative for the Disposal of Radioactive Waste (NAGRA) of Switzerland.

- United Kingdom Atomic Energy Authority.

These bilateral agreements provide access to technical results produced by the respective programs, including information on performance assessment and related activities.

In addition, the United States is a member of the following international organizations that are active in nuclear activities, including evaluations of performance assessment technology:

- International Atomic Energy Commission (IAEA).

- Organisation for Cooperation and Development, including its Nuclear Energy Agency (OECD/NEA).

Through these organizations, the DOE is participating in international technical projects, information exchange, and symposia and in various steering, advisory, and working committees and groups.

This section briefly discusses the summary international cooperative activities in which the DOE is participating and which are relevant to performance assessment. More details and information, including specific technical tasks, can be found in the cited references and in additional progress and topical reports. 


\subsection{INTERNATIONAL CODE VERIFICATION AND MODEL VALIDATION}

The DOE has been participating in three international model and computer-code comparison projects sponsored by the OECD/NEA, with technical and administrative oversight assigned to a secretariat provided by Sweden's Statens Karnkraftinspektion (the Swedish Nuclear Power Inspectorate). These projects are, in chronological order, INTRACOIN (International Nuclide Transport Code Intercomparison), HYDROCOIN (Hydrologic Code Intercomparison), and INTRAVAL (International Transport Code Validation).

These international comparisons are designed to test the capabilities of the mathematical models and computer codes used for performance assessments by the participating nations. The comparisons are made with data sets representative of the conditions expected at participants' waste-management facilities. In addition, the comparisons provide a mechanism for evaluating the adequacy of field and laboratory data available for model testing and validation. Therefore, they are also invaluable in providing guidance for the planning and design of future laboratory, field, and natural-analog studies intended to provide data for model validation.

Participation in these projects provides independent assessment and peer review. Therefore, the results of the comparisons aid in determining the accuracy, applicability, flexibility, and acceptability of mathematical models and computer codes.

\subsubsection{INTRACOIN}

The INTRACOIN project, initiated in June 1981 and completed in 1986, was the first of the international model and code intercomparison projects (SKI, 1984 and 1986). Its objectives were the verification and validation of mathematical models and computer codes for radionuclide transport in saturated rocks. The participants were Canada, the Federal Republic of Germany (FRG), Finland, France, Sweden, Switzerland, the United Kingdom, and the United States (the DOE and the NRC). INTRACOIN consisted of three levels:

- Benchmarking and verification of computer codes.

o Validation of the underlying mathematical models.

- Uncertainty and sensitivity analyses for realistic problems.

In leve1 1, computer codes were verified and benchmarked against each other and against analytical solutions. In leve1 2, test data from laboratory and field studies were analyzed to evaluate (1) the validity of the underlying mathematical models, (2) the adequacy of the test data, and (3) the role of the modeler in interpreting test data (which are sometimes incomplete and inaccurate) for modeling purposes. In level 3, test cases that represent conditions expected at disposal facilities were analyzed; sensitivity and uncertainty analyses were performed to evaluate the adequacy of the models and data for realistic problems and to define the relative importance of various parameters and phenomena. 
The DOE and the NRC participated only in INTRACOIN level 1. For level 1, seven test cases were defined and 22 computer codes were tested; not all test cases, however, were analyzed with all computer codes. Summaries of the results of all three leve1s have been published (SKI, 1984, 1986), including references to more-detailed reports by the individual participants(see, for example, Cole, 1982; INTERA, 1982).

The principal benefits to the DOE in the leve1 1 participation were the verification of the radionuclide-transport codes GETOUT, LAYFLO, MMT1DPNL, and UCB $-\mathrm{NE}-\mathrm{X}$ and of the radionuclide-transport submodels imbedded in the computer codes FTRANS and SWENT (a version of SWIFT). The NRC participated in the verification of the radionuclide-transport submodels imbedded in the computer codes DPCT, NUTRAN, NWFT/DVM, PORFLO, and SWIFT $\neg$ II. Versions of GETOUT, MMT, and SWIFF were also verified by participants from other nations. Although the DOE and the NRC did not participate in levels 2 and 3, the SWIFT code was used in level 2 by the German participant.

\subsubsection{HYDROCOIN}

The HYDROCOIN project was initiated in May 1984 for the verification and validation of mathematical models and computer codes for ground-water flow (Cole, 1986; OECD/NEA, 1987). The participants were Canada, the FRG, Finland, France, Japan, the Netherlands, Sweden, Switzerland, the United Kingdom, and the United States (the DOE and the NRC). Test cases, mathematical models, and computer codes for ground-water flow in both saturated and unsaturated rock were included in the comparisons.

Like INTRACOIN, the HYDROCOIN project was divided into three levels, with the same objectives for each level. For this project, the DOE participated in a11 levels. For level 1, seven hypothetical test cases were defined and 29 ground-water-flow codes were tested; not all test cases, however, were analyzed with all computer codes. Several progress reports and a summary of the leve1 1 results have been published (OECD/NEA, 1988), with references to more-detailed reports (see, for example, Cole, 1986; Gureghian et al., 1987).

The principal benefits to the DOE from the level 1 participation were the verification of the ground-water flow codes FE3DGW, SAGUARO, and STOKES, of the ground-water flow submodel imbedded in the computer code CFEST, and of the ground-water particle-tracking code PARTICLE. The NRC participated in the verification of the ground-water flow codes FEMWATER, UNSAT2, and USGS3D and the ground 7 water flow submodel imbedded in the computer code SWIFT $\neg I I$.

Versions of FEMWATER, SWENT, and SWIFT were also verified by participants from other nations. Some of the test cases and codes (CFEST,SAGUARO, STOKES, and SWIFT-II among the participating U.S. codes) included coupling of ground-water flow with heat transport (i.e., the effects of temperature on ground-water flow). Some of the test cases and computer codes (CFEST,SWENT, and SWIFT-II among the participating U.S. codes) included the coupling of ground-water flow with solute transport (i.e., the effects of salinity on ground-water flow). The computer codes SAGUARO and UNSAT2 simulate ground-water flow through saturated and unsaturated rock, whereas the other computer codes listed above simulate ground-water flow through saturated rock only. 
Level 2 included five test cases, and level 3 included seven test cases; the number of computer codes tested for levels 2 and 3 is not yet known since analyses are still in progress and the final results have not yet been published. Draft summary reports for levels 2 and 3 were distributed to participants for review in 1989.

\subsubsection{INTRAVAL}

Only partial validation of radionuclide-transport models was achieved in INTRACOIN because of the preliminary nature of some radionuclide-transport models, the shortage of adequate test data, and the absence of an international validation of ground-water flow models as a prerequisite for INTRACOIN. Consequent1y, the INTRAVAL project was initiated in October 1987 with the objective of validating mathematical models for both ground-water flow and radionuclide transport, using better models and data than were available for INTRACOIN and HYDROCOIN (SKI, 1987, 1988a, b). The specific objectives of INTRAVAL are to demonstrate the adequacy of the models for flow and transport processes in both porous and fractured rocks and to evaluate the adequacy of the experiments and measurements with respect to providing reliable and sufficient data for model testing and validation. The participating nations are Australia, Canada, the FRG, Finland, France, Japan, the Netherlands, Spain, Sweden, Switzerland, the United Kingdom, and the United States (the DOE and the NRC).

The study is divided into two parts. Part $I$ is based on experiments and studies for which results are already available or will be available shortly, whereas part II is based on ongoing or planned experiments and studies for which results are to be available later. The results of the part I analyses will provide guidance to the design and conduct of the part II experiments and analyses.

By the end of 1989 , twelve test cases were adopted for INTRAVAL, three for part I and nine for part II. Some of the test cases consist of more than one experiment. The twelve test cases include laboratory experiments, field studies, and natural analog, covering both porous and fractured rocks. Some of the test cases are being provided by other international cooperative projects, such as the DOE/AECL, Pocos de Caldas, and Stripa Projects.

Nine of the twelve test cases are for saturated rocks; the remaining three are for unsaturated rocks and are therefore considered applicable to the validation of models of potential use to the DOE's repository project. Five of the twelve test cases are being provided by the U.S. participants, two by the NRC (both for unsaturated conditions) and three by the DOE (two for saturated and one for unsaturated conditions). Analyses of test cases have been initiated by some of the participants, including the DOE.

INTRAVAL is scheduled to last for three years (through early 1991), with an optional extension for another three-year period. A summary report is planned for early 1991, with an optional extension until early 1994. 


\subsection{INTERNATIONAL COOPERATION IN RESEARCH AND DEVELOPMENT}

The DOE is participating in field, laboratory, and mathematical-modeling studies at various research facilities in other nations to develop techniques for characterizing and evaluating a repository site. These studies are being conducted under agreements between the DOE and radioactive-waste-management authorities in Swituerland and Brazil or under the auspices of the Nuclear Energy Agency of the Organisation for Economic Cooperation and Development.

\subsubsection{Pacas de Caldas Praject, Brazil}

The Pocos de Caldas project is a wide-ranging natural-analog study with three years of data gathering and analysis. It is a joint venture of Brazil, Sweden, Switzerland, the United Kingdom, and the United States. The project duration is from May 1986 until March 1990; the DOE started participating in June 1987. Information on the sites under study has been presented by Smellie et a1. (1987).

Work is concentrated at two sites: the Osamu Utsumi open-pit uranium mine and the Morro do Ferro thorium/rare-earth element prospect, both in the Pocos de Caldas caldera, a Cretaceous alkaline volcanic complex, in Minas Gerais, Brazil. Drilling and other preparatory work at both sites has been completed to provide the necessary rock samples and reference sampling zones for deep and shallow ground waters along a principal direction of ground-water movement. The project has four principal objectives:

1. To assist in the validation of hydrogeochemical equilibrium thermodynamic conceptual models, computer codes, and data bases used to evaluate interactions between rock and water and to evaluate the solubilities and speciation of elements.

2. To determine the interactions of natural ground-water colloids, radionuclides, and mineral surfaces with respect to radionuclidetransport processes and colloid stability.

3. To produce a model of geochemical transport across redox fronts, with special attention to the understanding of long-term, large-scale movements of redox-sensitive natural-series radionuclides, including, if possible, natural plutonium and technetium.

4. To model the migration of radionuclides of the rare-earth-element and uranium-thorium ( $\mathrm{REE} / \mathrm{U} \rightarrow \mathrm{Th}$ ) series during hydrothermal activity similar to that expected in the immediate vicinity of the waste packages in some geologic-repository concepts.

These objectives are being pursued at the Osamu Utsumi mine, where three-dimensional hydrogeologic modeling has been completed. Work at Morro do Ferro focuses on objectives 1 and 2. Preliminary interpretations have been possible in most of the study areas related to the four objectives (Smellif et a1., 1988), and these have helped to guide the final data-gathering program. 


\subsubsection{Bilateral Cooperation With Canada}

In 1977, Canada and the United States signed a bilateral agreement for radioactive-waste management. In March 1986, the DOE and the AECL signed Subsidiary Agreement 1, for a 4-year program of cooperation on specific technical activities related to geologic disposal in crystalline rock. The AECL activities included a field program at the AECL's Underground Research Laboratory (URL) near Lac du Bonnet, north of Pinawa in Canada.

Subsidiary Agreement 1 covered the testing of hydrogeologic field techniques, a tracer-migration laboratory experiment, and an exchange of computer codes for performance assessment. Testing of hydrogeologic field techniques was conducted to compare surface geophysical techniques with downhole measurements and to develop and evaluate techniques for measuring geometric and hydraulic characteristics of fractured rocks. The tracer-migration laboratory experiment was accepted by INTRAVAL as a saturated-rock test case (Noronha et al., 1989). It was also used for a partial validation of the computer code FRACFLO, a code utilizing an analytical solution for the two-dimensional transport of a decaying species in a planar fracture with diffusion into the rock matrix (Gureghian, 1988; Noronha et a1., 1988). As part of the computer-code exchange, in 1987 the AECL provided to the DOE the total 7 system performance assessment code SYVAC. Shortly thereafter, the DOE transmitted to the AECL the computer codes CFEST (coupled ground-water flow, heat, and solute transport), MATLOC (thermomechanical rock stress), NUTRAN (radioactive-waste inventory, radionuclide transport, and radiation doses), STAFAN (coupled fluid flow and mechanical rock stress), and SWENT (coupled ground-water, heat, conservative solute, and radionuclide transport).

Subsidiary agreement 1 was set aside in June 1988 in compliance with the Nuclear Waste Policy Amendments Act. A new subsidiary agreement is being negotiated between the DOE and the AECL, with a proposed scope of work that is directly applicable to the Yucca Mountain project. Areas that appear to be potentially fruitful, and therefore potential subjects for the agreement, include waste package experimental work and modeling, in situ testing approaches, and the Cigar Lake analyses that may provide meaningful analogues of processes at the Yucca Mountain site.

\subsubsection{Bilatera1 Activities With SKB, Sweden}

Under a direct contract between SKB in Sweden and the DOE, a number of activities related to study plans for site characterization at Yucca Mountain are in progress and planned,including the exchange of performance assessment codes, data, and technologies. Information exchange has been identified in the following areas: chemistry, saturated flow, radionuclide transport, conceptual geologic and tectonic models, spent-fuel modeling, container materials, site mineral evolution, and total-system performance assessment. 


\subsubsection{OECD/NEA Stripa Project, Sweden}

The Stripa Project has been conducted under the auspices of the OECD/NEA since 1980 at an abandoned iron mine northwest of Stockholm, Sweden. The Stripa mine is located in a rock mass that has not been disturbed until the present activity and is approximately $360 \mathrm{~m}$ deep in granite. The dimensions of the test block are on the order or 125 by $125 \mathrm{~m}$ and $50 \mathrm{~m}$ high. Phases 1 and 2 of the project were conducted between 1980 and 1987. The participants in phase 3, to be completed in late 1991, are Canada, Finland, Japan, Sweden, Switzerland, the United Kingdom, and the United States. Phase 3 objectives are to integrate different tools and methods in order to predict and validate ground-water flow and transport in a specific volume of fractured granitic rock in the Stripa mine and to demonstrate and verify the use of different materials and techniques for sealing ground-water flow paths in fractured granitic rock in the Stripa mine.

The model validation objective involves an evaluation of the current ability to predict ground-water flow and radionuclide migration in fractured crystalline rock on the basis of data obtained from an optimized characterization program. The model validation program consists of five consecutive stages that involve characterization, prediction, and evaluation. Stage 1 involves preliminary site characterization with the intent to define rock properties with a few boreholes. Stage 2 consists of the formulation of a preliminary conceptual model and of preliminary mathematical modeling of fracture network geometry and ground-water flow, based on the limited data base from stage 1. Stage 3 consists of the drilling of additional boreholes for more detailed characterization and of evaluations of the accuracy of the preliminary conceptual model and mathematical modeling on the basis of the new data. In stage 4, a more detailed conceptual model will be formulated and more-detailed mathematical modeling of ground-water flow and tracer transport performed, using the new data and understanding derived in stage 3 . This includes the prediction of ground-water inflow into a drift to be excavated later. In stage 5, a drift will be excavated and the ground-water inflow will be measured. Tracers will be injected from the drift into the rock at selected intervals. The final evaluation will compare the accuracy of the detailed modeling predictions with the measured flow and tracer rates to assess both the validity of the mathematical models and the adequacy of the characterization techniques.

The program plan for phase 3 was developed by representatives of Sweden, Switzerland, and the United States, with input by representatives of Canada, Finland, Japan, and the United Kingdom. The principal modeling effort is being conducted by the United Kingdom, with complementary efforts being provided by the Lawrence Berkeley National Laboraiory (LBNL) and Golder Associates under the auspices of the DOE. The modeling efforts include the application of the discrete $\rightarrow$ fracture 7 network-flow models DISCEL (developed at LBNL) and JINX (developed at Golder Associates) to generate synthetic fracture networks based on fracture statistics and to simulate the ground-water flow in these fracture networks. The fracture statistics are derived from fracture geometry and hydraulic measurements in the rock body being investigated. Instead of the original measurements, these statistics are used to stochastically generate multiple realizations of the fracture networks. The ground-water flow is then computed for these simulated fracture networks. In theory, flow calculations using these simulated fracture networks should represent conditions in the rock body. 


\subsubsection{Bilateral Cooperation With Switzerland}

In April 1985, the DOE signed a five-year bilateral agreement with Switzerland's Nationale Genossenschaft fur die Lagerung Radioaktive Abfalle (NAGRA) or National Cooperative for the Storage of Radioactive Waste. In June 1987, DOE activities were defined, including participation in the development and testing of fractured-rock characterization and modeling techniques at Swiss research facilities.

A major focus of the characterization work is the development of an approach for integrating geophysical, geologic, and hydrologic investigations into a conceptual and mathematical model appropriate for hydrologic analysis. This work involves new seismic and hydrologic investigation and interpretation techniques specifically designed for heterogeneous fractured rock. Other characterization efforts, including well-test and borehole-fluid logging techniques, are designed to obtain information from deep, isolated boreholes in fractured rock.

Performance assessment activities include a study of two-phase flow and the coupling of geochemical reactions with mass transport. One of the sites that NAGRA is considering for waste storage is in a marl that is partially saturated and contains natural gas. Studies have focused on the effect of gas production due to corrosion and radiolysis near the canister on repository performance. More recently, the design and interpretation of air-injection tests were studied.

The DOE's work under the current agreement were completed at the end of fiscal year 1989. Reports will be developed on the methods for geophysical and hydraulic testing and analysis, methods for characterizing fracture hydrology, scoping analyses of natural gas flow in fractured rocks, considerations of two-phase (gas and water) flow effects near geologic repositories, numerical simulations of selected geochemical and mass-transport interactions, and the development of conceptual models and the numerical modeling of ground-water flow in fractured rocks at the Grimsel research site in Switzerland.

Discussions have been initiated between the DOE and NAGRA for a new cooperative agreement after the expiration of the current agreement, with the technical scope of work oriented toward the needs of the Yucca Mountain project. In particular, the studies of partially saturated media and the studies of gas flow and multiphase transformations appear to be potentially relevant to processes at the Yucca Mountain site. 
10.4.1 Participation in the OECD/NEA

The DOE is represented on various committees and groups of the OECD/NEA. The DOE Deputy Secretary for International Affairs is a member of the OECD/NEA Steering Committee for Nuclear Energy, to which the Radioactive Waste Management Committee (RWMC) reports. The DOE participates in the following advisory and working groups under the RWMC that address various aspects of the geologic disposal of radioactive waste:

- Advisory Group on In Situ Research and Investigations for Geologic Disposal (ISAG).

- Performance Assessment Advisory Group (PAAG) and the following PAAG subgroups :

- Probabilistic Safety Assessment Codes User Group (PSAG).

- Working Group on Scenario Identification and Selection.

- NEA Group on Geochemical Modeling and Data.

- Validation Oversight and Integration Committee (VOIC), a subgroup to INTRAVAL.

The RWMC and its advisory groups exchange information, develop international policy, report on the technical status and policy of national programs, and arrange symposia and topical workshops. From the U.S. side, both the NRC and the DOE are actively involved in these OECD/NEA groups, and the United States, with one of the larger radioactive-waste programs, plays an important role in these areas.

The PAAG consists of senior representatives of performance assessment programs in the member countries. Both the NRC and the DOE participate in the PAAG. The group advises the RWMC on policies and other matters related to performance assessment and meets at least once a year. It advises on such performance assessment aspects as scenario development, human intrusion, biosphere modeling, the use of natural analogs, experiment/modeling interaction, methods and procedures for assigning development priorities, and the formalized use of expert opinions. The PAAG plays an important role in strengthening national programs with the use of international experience and consensus.

The PSAG consists of technical experts in probabilistic safety assessments. It meets every six months arid focuses on the evaluation of available probabilistic methods and codes and the exchange of experience in using such methods and codes.

The Working Group on Scenario Identification and Selection is a temporary group that will produce a report evaluating available methods for scenario identification and selection. It will report to the PAAG on methods and their availability and evaluate the advantages and disadvantages of various methods. 
The NEA Group on Geochemical Modeling and Data has been recently organized and initially focused on the development of thermochemical data bases.

The VOIC, a subgroup of INTRAVAL, was formed to investigate broad issues related to demonstrating the validity of theories and models used for repository performance assessments. This includes providing a continuing technical oversight function for INTRAVAL, ensuring the integration of the individual.'test case analyses, and formulating a general validation strategy that considers both modeling and testing.

\subsubsection{Participation in the CEC}

The DOE is participating in various activities of the CEC, including the radionuclide migration project MIRAGE and the Natural Analog Working Group (NAWG).

The MIRAGE project was initiated in 1982 for conducting research on the migration of radionuclides in the geosphere (Come and Chapman, 1987). As an outcome of thls activity, the Natural Analog Working Group (NAWG) was established in 1985 to plàn research and exchange information on natural-analog studies. At present, participants in the NAWG include the IAEA and fourteen nations--namely, Australia, Belgium, Canada, Finland, France, the FRG, Italy, Japan, the Netherlands, Spain, Sweden, Switzerland, the United Kingdom, and the United States.

\subsection{OTHER INTERNATIONAL EFFORTS}

The DOE continues to explore means by which international experience and participation might help in its scientific investigations associated with the geologic repository program. For example, the DOE continues to attempt to identify appropriate new field study locations for investigating properties of unsaturated tuffacieous rock and the cooperation of other nations and agencies in experiments and modelling for these locations; analyses of the Apache Leap and Las Cruces Trench experiments being conducted by the NRC are particular exainples. The DOE is also trying to develop enhanced or new cooperative efforts in ongoing in situ experimental work with the AECL, for NAGRA, and at Stripa, described earlier. The DOE is attempting to increase cooperation in ohgoing natural analogue work such as at Cigar Lake and at uranium deposit sites in the United States. The DOE is seeking to identify sites in which cooperative investigation of geosphere and biosphere transport of radionuclides may be fruitful, such as at DOE defense high-level waste sites or Chernoby1. In these attempts the DOE is reviewing key recommendations resulting from NRC's Coupled Effects Project, DOE's Ferformance Assessment National Review Group, NRC's Advisory Committee on Nuclear Waste, the National Academy of Science, and the Nuclear Waste Technical Review Board for suggestions on appropriate and significant experimental and modelling work. 


\subsection{MILESTONES AND SCHEDULES}

Figure 10-1 shows the schedules of the major international activities in relation to the overall repository-development schedule. The milestones associated with each activity are presented in Table 10-1. Some of the activities 1isted in the schedules have been completed. These are presented to illustrate the length of the efforts being conducted. Both past and planned milestones are shown; past milestones are shown in order to identify accomplishments to date. 


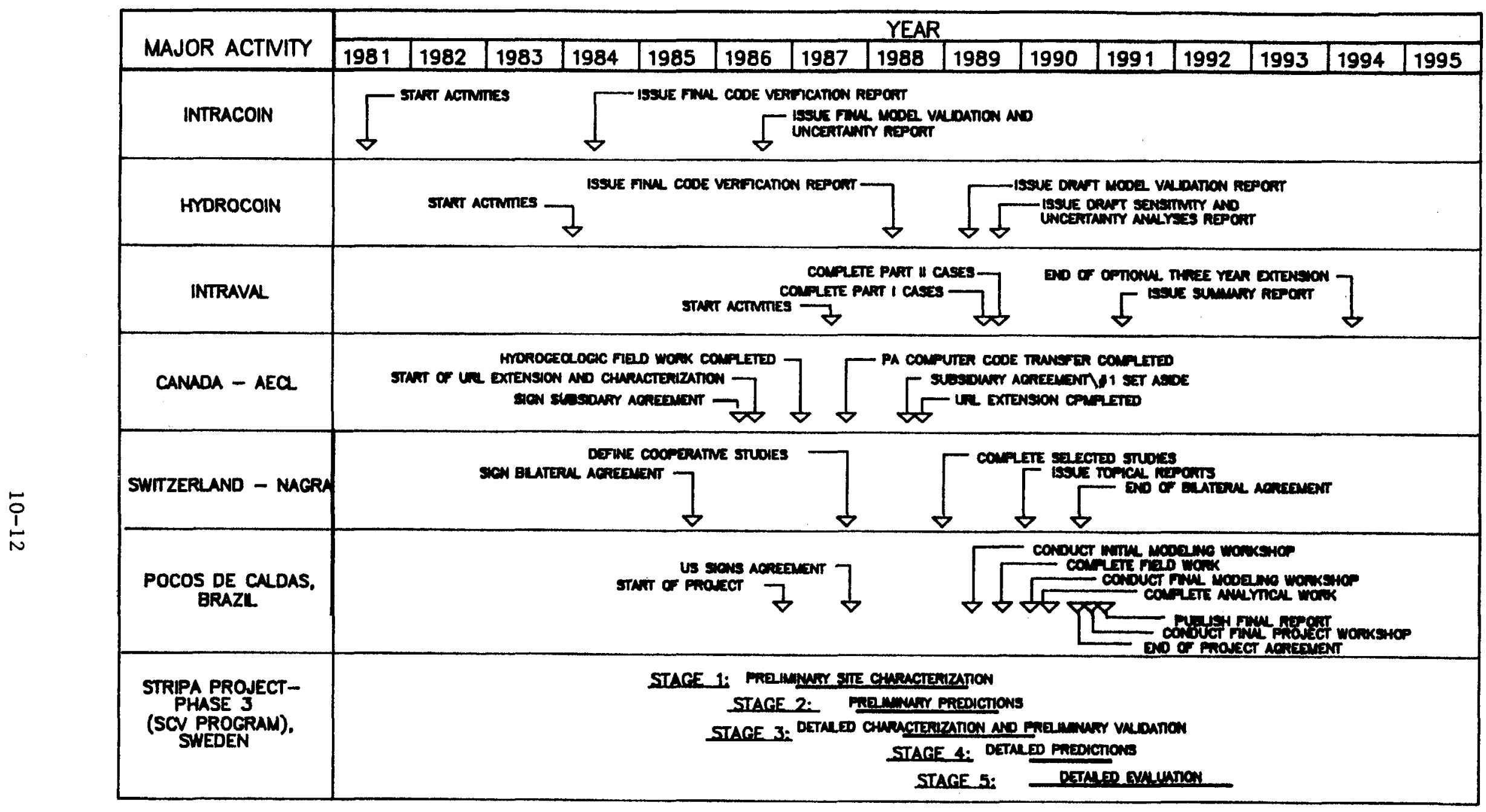

Figure 10-1. Schedule of major international activities. 
Table 10-1. Major Milestones in International Performance Assessment Activities

Event

Date

\section{INTRACOIN}

Start activities

$06 / 81$

Issue final code verification report

$09 / 84$

Issue final model validation and uncertainty analysis report

$05 / 86$

HYDROCOIN

Start activities

$05 / 84$

Issue final code verification report

$06 / 88$

Issue draft model validation report

$03 / 89$

Issue draft sensitivity and uncertainty analysis report

$09 / 89$

INTRAVAL

Start activities

$10 / 87$

Complete part I cases

$06 / 89$

Complete part II cases

$09 / 89$

Issue summary report

$03 / 91$

End of optional 3-year extensions

$03 / 94$

POCOS DE CALDAS, BRAZIL

Start of project

$05 / 86$

Agreement signed by United States

$06 / 87$

Initial modeling workshop

Complete field work

$02 / 89$

$06 / 89$

Final modeling workshop

$09 / 89$

Complete analytical work

$12 / 89$

$03 / 90$

Final project workshop

$06 / 90$

Final report

$08 / 90$

CANADA - AECL

Sign subsidiary agreement 1

$03 / 86$

Start of extension and characterization in the

$06 / 86$

Underground Research Laboratory

Hydrogeologic field work completed

$05 / 87$

$\begin{array}{ll}\text { Transfer of PA computer codes completed } & 08 / 87\end{array}$

$\begin{array}{ll}\text { Subsidiary Agreement } 1 \text { set aside } & 06 / 88\end{array}$

Extension of Underground Research Laboratory completed 08/88 
Event

Date

SWITZERLAND - NAGRA

Sign bilateral agreement

$05 / 85$

Define cooperative studies

$06 / 87$

Complete selected studies

$09 / 88$

Issue topical reports

$09 / 89$

End of bilateral agreement

$05 / 90$

STRIPA PHASE 3, SWEDEN

Stage 1, Preliminary site characterization

$08 / 86$ to $\mathrm{mid} 88$

Stage 2; Preliminary predictions

Mid 87 to mid 88

stage 3, Detailed characterization and preliminary

Early 87 to late 89 validation

Stage 4, Detailed predictions

Mid 89 to end 89

State 5, Detailed evaluation

Mid 89 to mid 91 
An integrated schedule has been developed to provide a tool for planning the performance assessment activities, identifying critical milestones for the performance assessment program, and assessing the impact of schedule changes on the program. This section provides schedules for each part of the performance assessment program. It begins with an overview that identifies and discusses key milestones and interfaces in the context of the geologic repository program.

\subsection{OVERVIEW OF THE PERFORMANCE ASSESSMENT SCHEDULE}

\subsubsection{Geologic Repasitory Program Miplestones}

The schedules in this chapter are based on the milestones presented in Chapter 2. The key milestones include issuance of a Draft Environmental Impact Statement (DEIS) in October of 1999 and a Final Environmental Impact Statement (FEIS) in March of 2001, recommendation of a site to the President in April of 2001, and submittal of the License Application (LA) to the Nuclear Regulatory Commission (NRC) in October of 2001. These schedules assume that the Advanced Conceptual Designs (ACDs) for the repository and the waste package are completed in June of 1996 and the License Application Designs (LADs) are completed in January of 2001.

The performance assessment schedules presented in this chapter have been developed by integrating the assessments described in Chapters 4 through 10 . Those in Chapters 4 through 8 are designed to support the geologic program milestones while those in Chapters 9 and 10 do not provide particular constraints on the schedules.

\subsubsection{Constraints of the Site Characterization and Design Pragrams on the Performance Assessment Schedule}

A major constraint on the performance assessments is the availability of design and site information needed for the assessments. The LADs for the repository and the waste package are not scheduled to begin until about five years before completion of the LA and, therefore, the preparations for the performance assessment for the Safety Analysis Report (SAR) requiring specification of the LADs cannot begin before this period has been initiated. Likewise some of the analyses for the DEIS, which will rely on the ACDs cannot begin until well into the ACD design effort.

At the same time, all of the analyses for a given milestone need not wait until the relevant design process is underway or until completion of the entire design. Although many details of the design are needed for the assessments, not all of them are. However, the final design will need to be taken into account before finalizing the assessments. Specific impacts of this requirement depend upon the nature of the assessment area. Assessments 
that depend strongly on repository and waste package design such as those for the engineered barrier system performance measures will require the design information. Evaluations of the ground-water travel time will depend to a lesser extent on the design information.

The current schedule shows that the ACD design effort is scheduled to begin in late 1992 and is to be completed in 1996. The LAD design effort is scheduled to start at the completion of the ACD and to be completed in 2001.

The analyses are also constrained by the availability of data from the site characterization program. Some of this information will be forthcoming from laboratory tests which require specified durations. Other information will be forthcoming from the surface-pased drilling program and this information is constrained by both the duration of the drilling program and the schedule for starting the different boreholes. The current schedule shows that this program is to begin in early 1991. Performance assessments requiring data from these boreholes will not be able to begin until some time later due to the need to process, review, and interpret the information from these boreholes.

In situ testing conducted in the Exploratory Shaft Facility (ESF) cannot begin until after this facility is constructed and some of the tests cannot be conducted until extended drifting at the repository test horizon is completed. The current strategy is that analyses for the SAR will rely on this in situ information, particularly geohydrologic data for the host rock, hydrologic information associated with faults or features that are encountered, and information regarding waste package environments. Some of these tests will require many months to conduct because of the slow process rates expected for the host rock (e.g., for movement of tracers and for wetting and drying cycles). Analyses of these tests have suggested that about eighteen months of in situ testing will be needed to provide that information for the SAR performance assessments.

Analyses for the DEIS do not require in situ data but will, as discussed in Chapter 5, rely on any available data. However, it is desirable to use information from the surface-based drilling program for these assessments in order to provide realistic evaluations of impacts. It is currently planned that data from at least six months of drilling into the units that underlie the repository horizon would be used for the DEIS performance assessments.

\subsubsection{Phases of the Performance Assessment Program}

The current schedule of major milestones and the design and site characterization programs naturally define three phases for the performance assessment program: an "early site investigation" phase, an "EIS PA" phase, and an "SAR PA" phase. The early site investigation phase extends through the early part of the site characterization program until issuance of the EIS Implementation Plan. The ACD design studies will be completed and scoping of the EIS will be conducted during this period. During this period preliminary performance assessments will be conducted to develop capabilities for the final assessments and to support the testing and site and design evaluations. 
The EIS PA phase extends from the end of the early site investigation phase to the completion of the performance assessments for the DEIS. The SAR PA phase extends from the completion of the EIS PA phase to the completion of the performance assessments for the SAR. During this last phase all of the performance assessments needed to support the site recommendation and the LA will be completed.

The primary goals of the performance assessments in the early site evaluation phase are to

- Close the gap between existing performance assessment capabilities and those required to support the major program milestones. This closure will be helped by conducting complete performance assessments during this phase.

- Evaluate the importance of potentially adverse features and conditions on safety and waste isolation as a part of the early evaluations of site suitability.

- Support ESF design efforts. The ESF design will be evaluated with respect to the design criteria to derive detailed constraints on the design and to assess the effects of design details on compliance with the criteria.

- Support planning for and evaluation of surface-based testing in order to ensure that the data needed for performance assessment are obtained and to assess the possible impacts of the testing on the future performance of the repository system.

- Support planning for in situ testing to ensure that the data needed for performance assessment will be obtained and to assess the possible impacts of the testing on the future performance of the repository system.

- Support the ACD by analyses to derive detailed constraints on the design and to assess the effects of design details on compliance with those constraints.

- Review the waste-package and repository ACD requirements to ensure consistency with performance assessment needs and to provide input to the LAD requirements.

- Assist in the preparation for EIS scoping and support the scoping exercise.

- Develop codes and models to be used for the DEIS performance assessments. 
The assessments conducted during this phase will be based on the conceptual designs of the waste package and the repository.

The performance assessments during the EIS PA phase include the following goals:

- Complete the assessments to support the DEIS.

- Continue analyses for the early site evaluations of potentially adverse conditions.

- Complete preparation for the analyses to support the SAR, and the comprehensive site-suitability analysis, including the development of methodology for the analyses. include:

The primary goals of the performance assessments during the SAR PA phase

- Conduct analyses for the SAR and the repository and waste package LAD.

- Complete conceptual model validation in preparation for the license application.

- Conduct comprehensive site-suitability analyses for the site recommendation.

- Provide information for the performance confirmation test plan.

- Assist in the response to public comments, as necessary, to develop the FEIS.

After the submittal of the LA, performance assessment will continue to support the licensing activities by responding to comments and questions raised during the licensing process. In addition, performance assessment will continue to guide the various testing programs, including performance confirmation, to ensure that appropriate data are collected and to review in situ testing programs to ensure that they do not compromise the predicted performance of the repository system.

The major performance assessment activities are methodology development, computational model development, model certification, conduct of the analysis, and documentation. Figure 11$\urcorner^{1}$ presents a general schedule for these activities and their relationship to the schedule for the three performance assessment phases.

A summary of the key performance assessment activities is presented in Table 11 1 . The table shows the various efforts needing performance assessment support in a given period and emphasizes the need to integrate the performance assessments to support multiple efforts. The schedule in Figure $11 \neg 1$ and the table show the interplay between assessments to support one effort and development of models and methodology needed for later efforts. 
Table 11-1 shows that throughout the early site investigation phase, performance assessments and performance assessment sensitivity studies will be conducted on a repeated basis. Early in this phase, the performance assessments will be designed to support the efforts for the review of the prioritization of the surface-based testing program, the development of alternate licensing strategies, and the evaluation of alternative ESF configurations and design features. These analyses will be based on existing performance assessment methodologies, the existing site and generic data base, and repository and waste package conceptual designs. An additional goal of these analyses is to support the preliminary preparations for the SAR and EIS performance assessments by identifying specific shortcomings in the performance assessment technology and developments that focus on key areas

Later in the early site investigation phase, the performance assessments will be used to guide the site characterization studies and to evaluate the adequacy of the results of those studies. As information is obtained from the testing program regarding the potentially adverse features and conditions at the site, the performance assessments will support the evaluation of these features and conditions. These analyses will also be used in the preliminary preparations for the SAR and EIS performance assessments to develop and enhance models and methodologies.

Later in this phase the focus of the performance assessment analysis will be to develop input to the ACD design requirements for the repository and the waste package. To the extent possible the analyses defined for this set will review the suitability of the site regarding the parameters important to design. The methodology development for these analyses is scheduled from October 1990 through March 1991. The development of computational models is scheduled throughout the calendar year 1991 and the assessment is scheduled from March 1991 to June 1992. The results of the analyses are to be integrated into the ACD design requirements. These analyses will use essentially the same data base as the earlier analyses, but will use improved methodology and computational models. The schedule allows about four months to finalize the ACD design requirements before initiating the ACD designs.

Later in this phase is a full-scaled effort to review site suitability based on initial data obtained from the surface-based testing and the draft ACD designs for the repository and the waste package. The schedule for the analyses assumes that the draft ACDs will be available about mid-way through the total ACD effort, about June of 1994. Another objective of these analyses is an assessment of the repository and waste package ACDs for the development of the LAD design requirements.

Then assessments will be conducted to support the EIS scoping process. These analyses are needed to assist in defining the appropriate content for the EIS. This content must reflect performance measures that that properly reflect preclosure safety and postclosure performance according to the scope agreed upon for the EIS and that can be calculated using available data and performance assessment technology. 


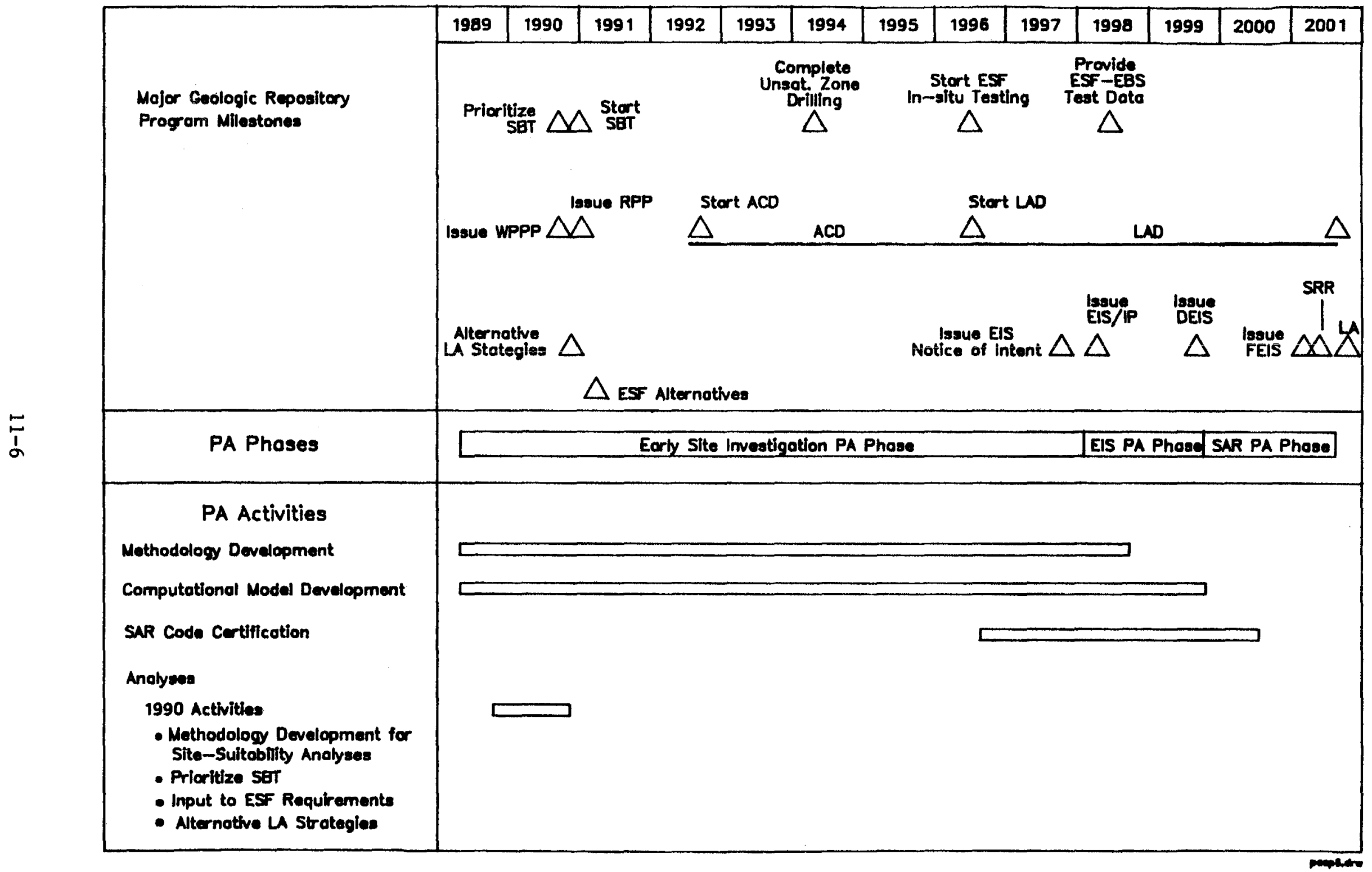

Flgure 11-1. Integrated schedule of performance assessment activities. 


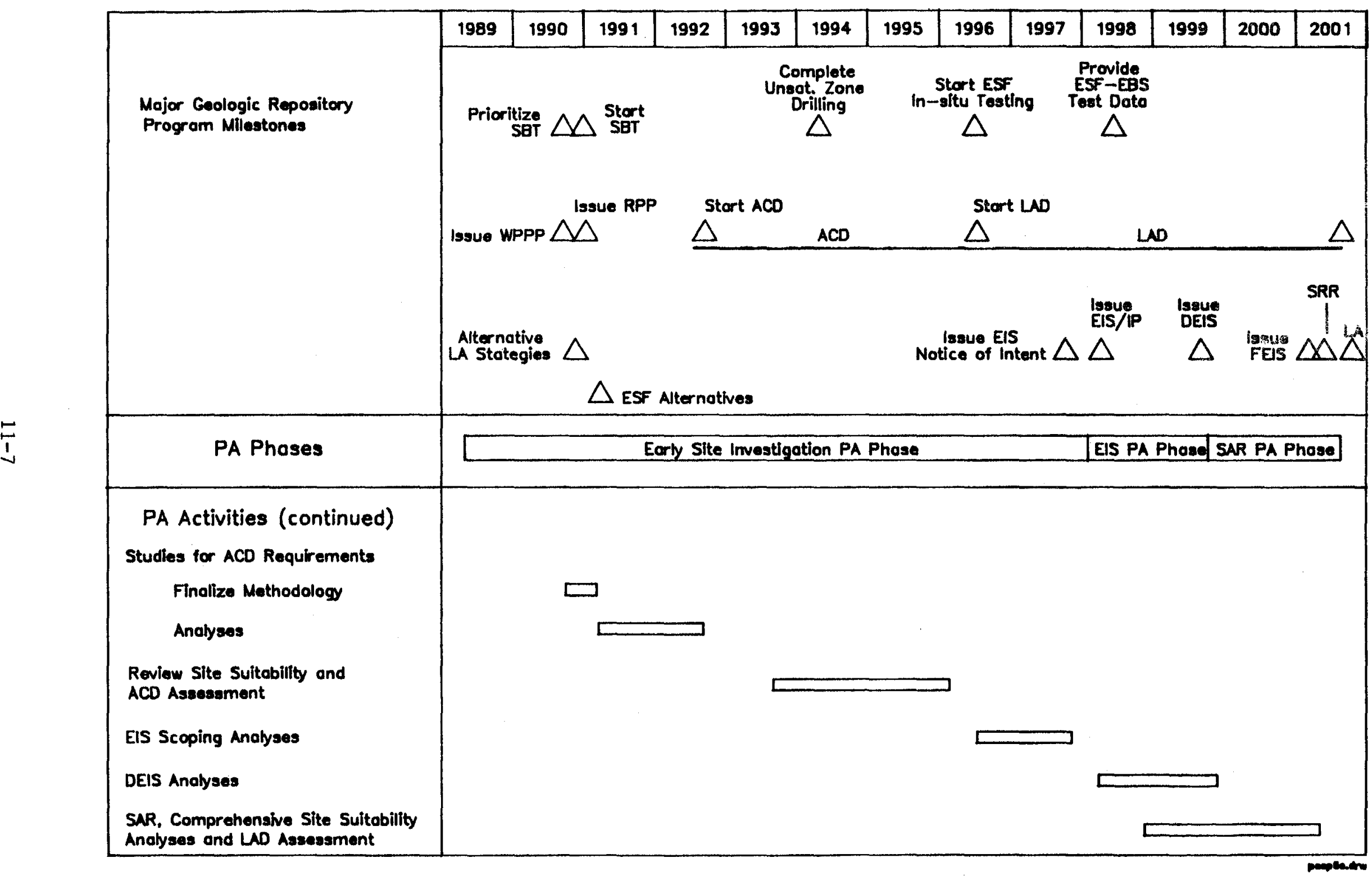

Figure 11-1. Integrated schedule of performance assessment activities. (continued) 
TABLE 11-1. General Schedule of Performance Assessment Analyses Supporting Geologic Repository Program Efforts

\section{Ear1y Site Investigation Phase}

FY 1990

Support to prioritization of surface based testing Support to evaluation of alternative licensing strategies Support to evaluation of alternative ESF designs Preliminary preparations for SAR and DEIS assessments

FY 1991

Support to early site-suitability evaluations Analyses of performance goals for early site investigations Support to development of ESF design requirements Preliminary preparations for SAR and DEIS assessments

FY 1992

Input to development of ACD design requirements Support to early site-suitability evaluations Review and assess results of surface-based testing program Preliminary preparations for SAR and DEIS assessments

FY 1993-FY 1994

Input to evaluation of ACD design against requirements Support to early site suitability evaluations Review and assess results of surface-based testing program Preliminary preparations for SAR and DEIS assessments

FY 1995

Evaluate ACD design against requirements Input to development of LAD design requirements Support to early site-suitability evaluations Review and assess results of surface-based testing program Preliminary preparations for SAR and DEIS assessments

FY 1996-mid FY 1998

Evaluate LAD design against requirements EIS scoping exercise Support to early sitęsuitability evaluations Review and assess results of surface-based testing program Review and assess results of in situ testing program Preliminary preparations for SAR and DEIS assessments 
EIS PA Phase

mid 1998-FY 1999

Evaluate LAD design against requirements

Assessments for EIS

Support to early site-suitability evaluations

Review and assess results of surface-based testing program

Review and assess results of in situ testing program

Preliminary preparations for SAR assessments

\section{SAR PA Phase}

FY 1999-FY 2001

Evaluate $L A D$ design against requirements

Assessments for SAR

Support to comprehensive site-suitability evaluations 
In the EIS PA phase the analyses are focused to the calculations needed for the EIS. The analyses are defined during the EIS scoping process, but finalization of the methodology and the models needed for the assessments must also be completed in this period. Additional objectives of these analyses are (1) final early site evaluations and (2) review of the site testing programs to determine tests that can be terminated, tests which need to be modified, or possible new test objectives. The schedule allows completion of calculations in time to feed the DEIS with a sufficient period to develop and review the DEIS before its release. These analyses will use the available site data and the ACD designs.

In the SAR PA phase the primary goal of the assessments is the support the SAR and these assessments must be completed in time for submittal of the LA in October of 2001. At the same time the comprehensive site-suitability analysis will be completed. These analyses will be fully integrated and will use several years of of surface-based testing data and ESF in situ test data and will be based on the LAD designs. The certification of the models for the SAR analyses must be completed in this period.

\subsection{INTEGRATED PROGRAM FOR PERFORMANCE ASSESSMENT AREAS}

The performance assessment activities are divided into four areas:

- Assessments of total ${ }_{-}$system performance.

- Assessments of engineered-barrier system performance.

- Assessments of natural-barriers performance.

- Assessments of preclosure safety.

These areas each involve activities in a number of categories. These categories are discussed in Chapter 3 and activities in these categories are described in Appendix $A$ (for the areas related to postclosure performance) and in Appendix B (for the preclosure safety area). The integration of the activities in these areas is described in the following sections.

\subsubsection{Assessments of Total System Performance}

Total system performance assessments will be conducted to support the EIS and the SAR analyses, for the evaluation of the suitability of the site, and for evaluation of the design. These total system performance assessments will require activities to develop predictions of the total system performance measures as discussed in Chapter 3. Activities will be needed in the category of methodology development to define the analyses to be conducted and the methods to be used in conducting them. Activities will be needed for the development and validation conceptual models identified in the methodology. Activities will be needed to develop and certify computational models for the analyses. Finally, activities will be conducted to evaluate the performance measures and to perform sensitivity and uncertainty analyses. Details of the activities in these categories are discussed in Section A.1 of Appendix A. 
In the early site investigation phase, activities are integrated to address the needs for review of the site characterization program; ACD design. requirements, assessments of the ACD against these requirements, and development of the LAD design requirements from the ACD analyses; methodology development for the early evaluation of the potentially adverse conditions and features of the site; and the preparations for the DEIS and SAR assessments. The analyses during this period will have to rely on site data existing before the surface-based drilling and in situ testing programs have provided information. Consequently the methodologies and conceptual models initially used for these analyses will be similar to those used to develop the Environmental Assessments and the Site Characterization Plan. The methodology will continue to be refined and as test data and the ACD designs become available, the models will evolve.

The activities in the EIS PA phase will include analysis of performance measures and sensitivity and uncertainty analysis for the DEIS. In this period the methodology for the SAR will be finalized as well. These analyses will use data from the surface-based drilling program and some initial data from the ESF in situ testing. Models will be based on design information developed for the ACD.

The activities in the SAR PA phase will include the analyses of performance measures and sensitivity and uncertainty analyses for the SAR. These analyses will also support the assessment of the LAD and the comprehensive assessment of site suitability. The performance confirmation program will be planned in this period using these same sensitivity and uncertainty analyses. Methodology will be finalized and conceptual models will be evaluated during this period for these analyses. All of these analyses will use information from the surface-based drilling program, data available from in situ testing, and design information developed for the LAD.

\subsubsection{Assessments of Engineered-Barrier System Performance}

Analyses of the engineered-barrier system (EBS) and comparison of the performance of the EBS against the performance objectives of 10 CFR 60.113 are required for the LA as described in Chapter 2. Therefore, analyses of the EBS will be conducted for the various stages of design, the ACD and LAD, and for the SAR. As indicated in Chapters 4 and 8 , activities in several categories will be needed to support these milestones. The activities in these categories also provide the information needed for the development of the source term for the total system performance assessments. Details of the activities in these categories are discussed in Section A.2 of Appendix A.

During the farly site investigation phase, activities will be conducted to assist in defining ACD design requirements, to evaluate the design against these requirements, and to define the LAD design requirements. The analyses will rely on information that is available before the surface-based drilling and the in situ testing programs have begun and before testing of the selected waste package materials. Therefore, these analyses will be similar to those conducted for the Environmental Assessment and the Site Characterization Plan. The assessment of the ACD will use data from the surface-based testing program, but in situ data from the ESF will not be available. 
The performance assessment activities during the EIS PA phase will focus on support to the testing programs and development of waste package models for the SAR analyses.

The activities during the SAR PA phase will include analyses of the performance measures for the SAR and for the LAD. Analyses will also be conducted to develop the waste package performance confirmation program. These analyses will use information from the surface-based drilling program and from in situ testing and will use design information developed for the LAD.

\subsubsection{Assessments of the Performance of the Natural Barriers}

As discussed in Chapter 3 analysis of the performance of the natural barrier system will be conducted to define the ground-water flow system of the site and to evaluate the ground-water travel time from the disturbed zone to the accessible environment as required in $10 \mathrm{CFR} 60.113$. The analysis of the ground-water trave1 time (GWTT) will be conducted as a part of the assessments for the SAR and, to the extent that the design affects the extent of the disturbed zone, for the ACD and LAD as we11. The analyses of GWTT will also be conducted as a part of the evaluations of site suitability. The analyses of the flow system also provide information (e.g., conceptual models) that will be used in the total system performance assessments for the DEIS as well as the other milestones. Details of the activities in these categories are discussed in Section A.3 of Appendix A.

During the early site investigation phase, activities will be conducted to support the assessment of the ACD, scoping of the EIS, and early evaluation of the potentially adverse conditions of the site. Initial assessments will rely on existing data; later assessments will take advantage of data obtained from the surface-based drilling program.

The activities in the EIS PA phase will include analyses to support the DEIS and developments of the conceptual models in preparation for the SAR. These analyses will use the data from the surface-based drilling program and initial data obtained from the ESF.

The activities in the SAR PA phase will include the calculation of the ground-water travel time and sensitivity and uncertainty analysis for the SAR. The analysis of the sensitivities will also be used to support the evaluation of site suitability for the recommendation of the site to the President. The analyses in this period will use site data from the surface-based drilling program and data available from in situ testing.

\subsubsection{Preclasure Safety Assessments}

The major milestones requiring preclosure safety assessments are the ACD and LAD designs, the EIS, and the SAR. As discussed in Chapter 3 and in the chapters that individually discuss each of the milestones, the preclosure safety assessments involve activities in several categories. The first category is that set of activities performed to evaluate site and design 
information. For example, such evaluation is conducted to determine if the new information warrants any revision of previous preclosure safety

assessments. These evaluation will be conducted at all stages of design and for both the EIS and SAR milestones.

Another category of activities is the set needed to evaluate radiological exposures of the public and workers during normal operations. Again, these activities will be performed for each of the major milestones, with appropriate updates of the analyses depending upon the changes in the data base at each stage.

A third category of activities is the evaluation of exposures to the public and essential workers resulting from accidents. These activities will also be conducted at each stage of the program. The analyses for the SAR and for the design stages will involve determination of design basis accidents and the evaluation of exposures for these. As noted in Chapter 5, the analyses for the EIS may consider a range of accidents that extends beyond the design basis.

A fourth category of activities is the evaluation of risks to the public and repository workers from normal operations as well as the risks to the public from accidents that will be performed to support the EIS assessments. The final category of activities is the certification of computational models used in the analyses. Details of each of these five categories are discussed in Appendix B.

Activities in each of these categories are conducted in all phases of the program to support the major milestones. In the early site investigation phase, these activities are conducted to support the development of the ACD design requirements. The preclosure safety assessments will be used to develop design requirements for radiological protection and those that apply to prevention and mitigation of accidents, e.g. those resulting from external events and natural phenomena such as earthquakes. Design requirements for radiation protection include those for radiation shielding, design and operational concepts (e.g., design and operational tradeoffs to reduce occupational exposures) and effluent control. Their development will need information on source terms for normal operations. Design requirements for the accident conditions will require analogous information.

Later activities during this phase will also include the evaluation of the ACD against the design requirements as the design progresses. That is, after a reference design is established analyses are performed to determine if modifications are needed in order to meet the design requirements. The activities of this case include identification, evaluation and refinement of design-specific failures and operational prors which could be initiators of internally-generated accidents. Available population and site data (e.g. meteorology) will be utilized at this stage of the evaluation. It is expected that several iterations will be required before the ACD could be frozen. A key output of the iteration process is a more focused and more firmly based identification of the postulated design 7 and site-specific events, both internal and external, that will form the bases for the later design and safety assessments. 
Understanding gained from the assessments of the ACD will be used to develop the LAD design requirements. In addition, during this phase preparations (data needs, identification of scenarios to be evaluated, etc.) for the DEIS assessments will made.

In the EIS PA phase the analyses for the DEIS will be performed. The ACD design information will be the basis for these analyses. The nature of the exposure evaluation for normal operations and for accidents will be somewhat different than for the ACD assessment, however, because of the need to understand the environmental impacts rather than to ensure that design criteria are met. Thus there will be less reliance on bounding analyses for the DEIS analyses and the analyses will consider a wider range of accidents. Further, in addition to doses, radiological risks will be evaluated.

In the SAR PA phase, activities will be conducted to support the LAD design. These analyses will provide the basis for the SAR preclosure safety assessments. Details of each of the categories of activities as they apply in each stage are discussed in Appendix B. 
This glossary has been assembled from various sources. In the case of definitions taken from regulations, the source is cited.

absorbed dose--energy imparted by ionizing radiation per unit mass of irradiated material at the location of interest. The units of absorbed dose are the rad and the gray (Gy) (1 gray = 100 rads).

accessible environment--The atmosphere, the land surface, surface water, oceans, and the portion of the lithosphere that is outside the controlled area (10 CFR Part 960).

ACD (advanced conceptual design)--The design phase that will be used to explore selected design alternatives and will firmly fix and refine the design criteria and concepts to be made final in later design efforts. The project feasibility will be demonstrated, life-cycle costs estimated,preliminary drawings prepared, and a construction schedule developed as required by U.S. Department of Energy Order 6410.1.

AECL--Atomic Energy of Canada Limited.

airborne radioactive material--material dispersed in the air in the form of dusts, fumes, particulates, mists, vapors, or gases (10 CFR Part 20).

ALARA (as low as reasonably achievable)--Making every reasonable effort to maintain exposures to radiation as far below the dose limits in 10 CFR Part 20 as is practical (1) consistent with the purpose for which the licensed activity is undertaken and (2) taking into account the state of technology, the economics of improvements in relation to benefits to the public health and safety, and other societal and socioeconomic considerations(10 CFR Part 20).

ANSI--American National Standards Institute.

anticipated operational occurrences--Nonstandard occurrences that are expected to occur at least once during the life of the facility. In the SCP the DOE assumes a minimum frequency of 0.01 per year.

anticipated processes and events--Those natural processes and events that are reasonably likely to occur during the period the intended performance objective must be achieved. To the extent reasonable in the light of the geologic record, it has to be assumed that those processes operating in the geologic setting during the Quaternary Period continue to operate but with the perturbations caused by the presence of emplaced radioactive waste superimposed thereon (10 CFR Part 60).

aquifer--A formation, a group of formations, or a part of a formation that contains sufficient saturated permeable material to yield significant quantities of water to wells and springs (10 CFR Part 960). 
ASME-American Society of Mechanical Engineers.

barrier--Any material or structure that prevents or substantially delays the movement of water or radionuclides (10 CFR Part 960).

benchmarking--A method of verification in which a comparison of the results of a computer code calculation is made with the results of calculations of other computer codes developed to perform the same type of analysis. The particular problem for which this comparison is made is called a "benchmark problem."

candidate site--An area, within a geohydrologic setting, that is recommended by the Secretary of Energy under Section 112 of the Act for site characterization, approved by the President under Section 112 of the Act for characterization, or undergoing site characterization under Section 113 of the Act (10 CFR Part 960).

CCDF--Complementary cumulative distribution function for 10,000-year cumulative releases to the accessible environment.

CD--Conceptual design.

CDR--Conceptual design report.

CEC--Commission of European Communities.

CEQ--Council on Environmental Quality.

certification--Documentation, verification, and validation of computer codes and their models as required by NUREG-0856, consistent with interpretation by, and the policy of, the DOE.

CFR-Code of Federal Regulations.

closure--Permanent closure of the remaining open operational areas of the underground facility and boreholes after the termination of waste emplacement, culminating in the sealing of shafts, ramps, and boreholes.

computational mode1--Computer codes (e.g., codes to evaluate ground-water flow in the unsaturated zone or mass transfer from the waste packages) or other analytic techniques.

conceptual model--A pictorial or narrative description of a process, system or subsystem that represents all relevant processes, components, and structures, the interactions among them, and any internal or external processes that affect the overall performance of the system or subsystem.

container-The metal-barrier portion of the waste package that surrounds the waste form. 
containment--The confinement of radioactive waste within a designated boundary (10 CFR Part 60).

controlled area--(1) A surface location, to be identified by passive institutional controls, that encompasses no more than 100 square kilometers and extends horizontally no more than 5 kilometers in any direction from the outer boundary of the original location of the radioactive wastes in a disposal system; and (2) the subsurface underlying such a surface location (40 CFR Part 191).

cumulative releases of radionuclides--The total number of curies of radionuclides entering the accessible environment in the 10,000-year period after permanent closure,normalized on the basis of radiotoxicity in accordance with 40 CFR Part 191.

decommissioning--The permanent removal from service of surface facilities and components necessary for preclosure operations only, after repository closure, in accordance with regulatory requirements and environmental policies (10 CFR Part 960).

DEIS--Draft Environmental Impact Statement.

deterministic mode1--A mathematical or physical model that is based solely on physical relationships or phenomena and that requires single values of parameters which need to be specified a priori in a model.

disposal container--See "container."

disqualifying condition--A condition that, if present at a site, would eliminate that site from further consideration (10 CFR Part 960).

disturbed zone--That portion of the controlled area, excluding shafts, whose physical or chemical properties are predicted to change as a result of underground facility construction or heat generated by the emplaced radioactive waste such that the resultant change of properties could have a significant effect on the performance of the geologic repository (10 CFR Part 960).

DOE--U.S. Department of Energy.

dose equivalent--The product of absorbed radiation dose, quality factor, and al1 other necessary modifying factors at the location of interest in tissue. The units of dose equivalent are the rem and the sievert (Sv) (1 sievert $=100$ rem . .

dose limits--The permissible upper bounds of radiation doses. They apply to the dose equivalent received during the period of time covered(generally a calendar year), the committed effective dose equivalent resulting from the intake of radioactive material during the same period, or the effective dose equivalent received in a year (10 CFR Part 20). 
effective dose equivalent--The sum of the products of the radiation dose equivalent to the organ or tissue and the weighting factors applicable to each of the body organs or tissues which are irradiated (10 CFR Part 20).

EIS--Environmental Impact Statement.

engineered barriers--The set of barriers designed to prevent the movement of radionuclides and water through the repository system, including the waste package, repository seals, and shaft, ramp, and borehole seals.

engineered-barrier system--The waste package and the underground facility (10 CFR Part 60). The system of all engineered barriers except the shaft, ramp, and borehole seals.

Environmental Impact Statement--The document required by Section 102(2)(C) of the National Environmental Policy Act of 1969. Sections $114(\mathrm{a})$ and 114(f) of the Nuclear Waste Policy Act of 1982 include certain limitations on the National Environmental Policy Act requirements as they apply to the preparation of an environmental impact statement for the development of a repository at a characterized site (10 CFR Part 960).

EPA--U.S. Environmental Protection Agency.

ESF (Exploratory-Shaft Facility)--The exploratory shafts, any associated surface structures, and underground openings constructed for the purpose of site characterization.

expected repository performance--The manner in which the repository is predicted to function, considering those conditions, processes, and events that are likely to prevail or occur during the time period of interest (10 CFR Part 960).

exposure-the degree of subjection to ionizing radiation or to radioactive material (10 CFR Part 20).

external dose--That portion of the dose equivalent received from radiation sources outside the body (10 CFR Part 20).

fault--A fracture or a zone of fractures along which there has been displacement of one side relative to one another parallel to the fracture or zone of fractures (10 CFR Part 960).

favorable condition--A condition that, though not necessary to qualify a site, is presumed, if present, to enhance confidence that the qualifying condition of a particular guideline can be met (10 CFR Part 960).

FEIS-Final Environmental Impact Statement.

geohydrologic system--The geohydrologic units within a geologic setting, including any recharge, discharge, interconnections between units, and any natural or man-induced processes or events that could affect ground-water flow within or among those units (10 CFR Part 960). 
geohydrologic unit--An aquifer, a confining unit, or a combination of aquifers and confining units comprising a framework for a reasonably distinct geohydrologic system (10 CFR Part 960).

geologic repository--A system requiring licensing by the NRC that is intended to be used, or may be used, for the disposal of radioactive waste in excavated geologic media. A geologic repository includes (1) the geologic-repository operations area and (2) the portion of the geologic setting that provides isolation of the radioactive waste and is located within the controlled area (10 CFR Part 960).

geostatistics--Set of statistical methods designed for geologic or, more generally, earth-science applications. These methods first quantify the intrinsic correlation structure of the physical or chemical process being studied with statistical summaries such as variogram functions and then use this structure to tailor more-precise and risk-qualified estimates of performance with estimation methods such as kriging.

ground water--A11 subsurface water as distinct from surface water(10 CFR Part 960). All water that occurs below the land surface (10 CFR Part 60).

ground-water travel time--The time required for a unit volume of ground water to travel between two locations. The travel time is the length of the flow path divided by the velocity, where velocity is the average ground-water flux passing through the cross-sectional area of the geologic medium through which flow occurs, perpendicular to the flow direction, divided by the effective porosity along the flow path. If discrete segments of the flow path have different hydrologic properties, the total travel time will be the sum of the travel times for each discrete segment (10 CFR Part 960).

GWTT--Ground-water travel time.

high-level radioactive waste--(1) the highly radioactive material resulting from the reprocessing of spent nuclear fuel, including liquid waste produced directly in reprocessing and any solid material derived from such liquid waste that contains fission products in sufficient concentrations and (2)other highly radioactive material that the NRC, consistent with existing law, determines by rule requires permanent isolation (10 CFR Part 960).

HLW--High-level radioactive waste.

host rock--The geologic medium in which the waste is emplaced,specifically the geologic materials that directly encompass and are in close proximity to the underground facility (10 CFR Part 960).

hydraulic conductivity--The volume of water that will move through a medium in a unit of time under a unit hydraulic gradient through a unit area measured perpendicular to the direction of flow (10 CFR Part 960). 
hydraulic gradient--A change in the static pressure of ground water, expressed in terms of the height of water above a datum, per unit of distance in a given direction (10 CFR Part 960).

HYDROCOIN--Hydrologic Code Intercomparison.

ICRP--International Commission on Radiological Protection.

important to safety--With reference to structures, systems, and components means those engineered structures, systems, and components essential to the prevention or mitigation of an accident that could result in a radiation dose to the wholle body, or any organ, of 0.5 rem or greater at or beyond the nearest boundary of the unrestricted area at any time until the completion of permanent closure (10 CFR Part 60).

INTRACOIN--Internationa1 Nuclide Transport Code Intercomparison.

internal dose--That portion of the dose equivalent received from radioactive material taken into the body (10 CFR Part 20).

INTRAVAL--International Transport Code Validation.

isolation--Inhibiting the transport of radioactive material so that the amounts and concentrations of this material entering the accessible environment will be kept within prescribed limits (10 CFR Part 960).

LA (1icense application)--An application for a license from the U.S. Nuclear Regulatory Commission to construct a repository.

LAD (License Application Design)--The design phase that completes the resolution of design and licensing issues identified and assessed in earlier design phases and will develop the design of the items necessary to demonstrate compliance with the design requirements and performance objectives of 10 CFR Part 60 . Design requirements resulting from safety and reliability analyses will be fully integrated in this design to support the Safety Analysis Report.

1ithosphere--The solid part of the Earth, including any ground water contained within it (10 CFR Part 960).

member of the public--Any individual who is not engaged in operations involving the management, storage, and disposal of radioactive waste.A worker so engaged is a member of the public except when on duty at the geologic-repository operations area (10 CFR Part 960).

mined geologic disposal system--A system, requiring licensing spent fuel and by the U.S. Nuclear Regulatory Commission, that is used for the disposal of high-level radioactive waste in excavated geologic media. It is synonymous with "geologic repository." 
mitigation--(1) Avoiding the impact altogether by not taking certain action or part of an action; (2) minimizing impacts by limiting the degree or magnitude of the action and its implementation; (3) rectifying the impact by repairing, rehabilitating, or restoring the affected environment; (4) reducing or eliminating the impact over time by preservation and maintenance operations during the life of the action; or (5) compensating for the impact by replacing or providing substitute resources or environment (10 CFR Part 960).

Monte Carlo simulation--Computer-based sampling experiment utilizing random numbers drawn from appropriate probability distributions. The Monte Carlo method consists of solving various problems of computational mathematics by means of the construction of some random process for each such problem, with the parameters of the process equal to the required quantities of the problem. These quantities are then determined approximately by means of observations of the random process and the computation of its statistical characteristics, which are approximately equal to the required parameters. For example, the uncertainty in ground-water travel time through a rock body with unknown hydraulic conductivity might be approximated by selecting random conductivities from an appropriate probability distribution and then calculating the flow with each conductivity. The experimental variance of the calculated ground-water travel times could then be taken as an estimate of the required travel time uncertainty (Shreider, 1966).

MRS--Monitored retrievable storage.

Monitored Retrievable Storage Facility--A facility for receiving and storing spent fuel and staging spent-fuel shipments to the repository.

NAGRA--Nationale Genossenschaft fuér die Lagerung Radioaktive Abfalle (Nationa1 Cooperative for the Storage of Radioactive Waste of Switzerland).

natural background exposure--Exposure to cosmic radiation and radionuclides or radiation from terrestrial sources of naturally occurring radioactive material, including technologically enhanced radioactive material, such as plasterboard and fertilizer, but not including byproduct material or radioactive material specifically intended to be a radiation source ( 10 CFR Part 20).

natural barriers--the set of naturally occurring barriers to movement of radionuclides and water at the site. These barriers include the geologic units within the controlled area as well as those outside the controlled area.

NEPA--National Environmental Policy Act of 1969.

NRC--U.S. Nuclear Regulatory Commission.

NWPA--Nuclear Waste Policy Act of 1982.

NWPAA--Nuclear Waste Policy Amendments Act of 1987. 
occupational radiation dose--The dose received by an individual in a restricted area or in the course of employment in which the individual's assigned duties involve exposure to radiation and to radioactive material from licensed and unlicensed sources of radiation, whether in the possession of the licensee or other person. Occupational dose does not include dose received from natural background; as a patient from medical practices, from voluntary participation in nedical research programs, or as a member of the general ptablic(10 CFR Part 20).

OCRWM-Office of Civilian Radioactive Waste Management (DOE).

OECD/NEA-Organization for Economic Cooperation and Development/Nuclear Energy Agency.

PA--Penformance assessment.

PAIP--Performance Assessment Implementation Plan.

PAMP--Performance Assessment Management Plan.

PASP--Performance Assessment Strategy Plan.

peer review--A documented, fully traceable review performed by qualified personnel who are independent of the original work performed but have the technical expertise to perform the work. Peer reviews are in-depth, critical reviews and evaluations of documents, material, or data that require interpretation and judgment to verify or validate results or conclusions or when the conclusions, material, or data contained in the report were obtained by methods that go beyond the existing state of the art.

performance assessment,--The activities needed for quantitative analyses of the behavior of the repository system and its components in terms of preclosure radiation safety and postclosure performance to assess compliance with the technical criteria in 10 CFR Part 60 and to support the development of the repository.

performance confirmation--The program of tests, experiments, and analyses which is conducted to evaluate the accuracy and adequacy of the information used to determine with reasonable assurance that the performance objectives for the period after closure will be met (10 CFR Part 60).

permanent closure-Final backfilling of the underground facility and the sealing of shafts and boreholes (10 CFR Part 60).

postclosure-The period of time after the closure of the geologic repository (10 CFR Part 960).

potentially adverse condition-A condition that is presumed to detract from expected system performance, but further evaluation, additional data, or the identification of compensating or mitigating factors may indicate that its effect on the expected system performance is acceptable (10 CFR Part 960). 
preclosure--The period of time before and during the closure of the geologic repository (10 CFR Part 960).

pre-waste-emplacement--Before the authorization of repository construction by the NRC (10 CFR Part 960).

probabilistic mode1-A mathematical or physical model that is based solely on statistical relationships which involve a consideration of ranges or statistical distributions of parameter values.

probability of an uncertain scenario or event--The probability that a scenario or an event will occur during a specified period of interest, expressed as an expected frequency of occurrence $(e . g .$, number of occurrences per year) or as a fraction between zero and one.

public dose-The dose received by a member of the public from exposure to radiation and to radioactive material released by a licensee, or to another source of radiation either within a licensee's controlled area or in unrestricted areas. It does not include occupational dose, or dose received from natural background, as a patient from medical practices, or from voluntary participation in medical research programs (10 CFR Part 20).

qualifying condition--A condition that must be satisfied for a site to be considered acceptable with respect to a specific guideline (10 CFR Part 960).

Quaternary period--The second period of the Cenozoic Era, following the Tertiary, beginning 2 to 3 million years ago and extending to the present(10 CFR Part 960).

radiation (ionizing radiation)--Alpha particles, beta particles,gamma rays, $x$-rays, neutrons, high-speed electrons, high-speed protons, and other particles capable of producing ions. Radiation, as used in this part,does not include nonionizing radiation, such as sound, radio, or microwaves, or visible, infrared, or ultraviolet light (10 CFR Part 20).

radioactive waste or waste--High-level radioactive waste and other radioactive materials, including spent nuclear fuel, that are received for emplacement in a geologic repository (10 CFR Part 960).

radiological-related to the consequences (doses, health effects) associated with exposure to ionizing radiation or radionuclides.

radionuclide retardation-The process or processes that cause the time required for a given radionuclide to move between two locations to be greater than the ground-water travel time, because of physical and chemical interactions between the radionuclide and the geohydrologic unit through which the radionuclide travels (10 CFR Part 960).

repository system--Synonymous with "geologic repository" (10 CFR Part 960). 
restricted area--Any area access to which is controlled by the DOE for purposes of protecting individuals from exposure to radiation and radioactive materials before repository closure, but not including any areas used as residential quarters, although a separate room or rooms in a residential building may be set apart as a restricted area (10 CFR Part 960).

retrieval--The act of intentionally removing radioactive waste before repository closure from the underground location at which the waste had been previously emplaced for disposal (10 CFR Part 960).

SAR--Safety analysis report.

saturated zone--That part of the Earth's crust beneath the water table in which all voids, large and small, are ideally filled with water underpressure greater than atmospheric (10 CFR Part 960).

scenario--Sequence of events or an account of a projected course of action.

SCP--Site characterization plan.

sensitivity analysis--An analysis in which one or more parameters are varied to observe the effects of variation(s) on the performance of a system or some part of it.

significant source of ground water--(1) An aquifer that (i) is saturated with water having less than 10,000 milligrams per liter of total dissolved solids; ( $i i)$ is within 2,500 feet of the land surface; (iii) has a transmissivity greater than 200 gallons per day per foot, provided that any formation or part of a formation included within the source of ground water has a hydraulic conductivity greater than 2 gallons per day per square foot; and(iv) is capable of continuously yielding at least 10,000 gallons per day to a pumped or flowing well for a period of at least a year; or (2) an aquifer that provides the primary source of water for a community water system as of the effective date of this Subpart ( 40 CFR Part 191).

site--The location of the controlled area (10 CFR Part 60).

site characterization--Activities, whether in the laboratory or in the field, undertaken to establish the geologic conditions and the ranges of the parameters of a candidate site relevant to the location of a repository, including borings, surface excavations, excavations of exploratory shafts, limited subsurface lateral excavations and borings, and in situ testing needed to evaluate the suitability of a candidate site for the location of a repository, but not including preliminary borings and geophysical testing needed to assess whether site characterization should be undertaken (10 CFR Part 960).

siting guidelines-Part 960 of Title 10 of the code of Federal Regulations "General Guidelines for the Recommendation of Sites for the Nuclear Waste Repositories" (10 CFR Part 960).

SKI--Statens Kaernkraftinspektion (Swedish Nuclear Power Inspectorate). 
source term-The inds and amounts of radionuclides that make up the source of a potential release of radioactivity (10 CFR Part 960).

special source of ground water--Those class I ground waters identified in accordance with the $\mathrm{RA}^{\mathrm{P}}$ 's ground-water protection strategy published in August 1984 that (1) are within the controlled area encompassing a disposal system or are less than five kilometers beyond the controlled area; (2) are supplying drinking water for thousands of persons as of the date that the Department chooses a location within that area for detailed characterization as a potential site for a disposal system (e.g., in accordance with Section 112(b)(1)(B) of the NWPA); and (3) are irreplaceable in that no reasonable alternative source of drinking water is available to that population (40 CFR Part 191).

spent nuclear fuel--Fuel that has been withdrawn from a nuclear reactor following irradiation, the constituent elements of which have not been separated by reprocessing (10 CFR Part 960).

surface facilities--Repository support facilities within the controlled area.

surface water--Any waters on the surface of the Earth, including fresh and salt water, ice, and snow.

system--The geologic setting at the site, the waste package, and the repository, all acting together to contain and isolate the waste (10 CFR Part 960).

tectonic-of, or pertaining to, the forces involved in, or the resulting structures or features of, "tectonics."

tectonics--The branch of geology dealing with the broad architecture of the outer part of the Earth, that is, the regional assembling of structural or deformational features and the study of their mutual relations, origin, and historical evolution (10 CFR Part 960).

total system--Synonymous with "repository system" and "geologic repository."

unanticipated processes and events--Those processes and events that are judged not to be reasonably likely to occur during the period the intended performance objective must be achieved, but which are nevertheless sufficiently credible to warrant consideration. These processes and events include both natural processes or events or those initiated by human activities not licensed for the repository system. Processes and events initiated by human activities may only be found to be sufficiently credible to warrant consideration if it is assumed that: (1). The monuments provided for by this part are sufficiently permanent to serve their intended purpose; (2) the value to future generations of potential resources within the site can be assessed adequately under the applicable regulations; (3) an understanding of the nature of radioactivity and an appreciation of its hazards have been retained in some functioning institutions; (4) institutions are able to assess risk and to take remedial action at a level of social organization and technological competence equivalent to, or superior to, that which was applied in initiating the processes or events concerned; and (5) relevant records are preserved, and remain accessible, for several hundred years af ter permanent closure (10 CFR Part 60). 
uncertainty analysis--An analysis that estimates the uncertainty in a system's performance resulting from uncertainty of one or more factors associated with. the system; such an analysis requires definition of a system,description of uncertainties in the factors that are to be investigated, and the characteristics of the system that is to be observed.

underground facility-The underground structure and the rock required for support, including mined openings and backfill materials, but excluding shafts, boreholes, and their seals (10 CFR Part 960).

undisturbed performance-The predicted behavior of a disposal system, including consideration of the uncertainties in predicted behavior, if the disposal system is not disrupted by human intrusion or the occurrence of unlikely natural events ( 40 CFR Part 191).

unrestricted area-Any area, access to which is not controlled by the licensee for purposes of protection of individuals from exposure to radiation and radioactive materials, and any area used for residential quarters(10 CFR Part 60).

unsaturated zone--The zone between the land surface and the water table. Genera11y, water in this zone is under less than atmospheric pressure, and some of the voids may contain air or other gases at atmospheric pressure. Beneath flooded areas or in perched water bodies, the water pressure locally maybe greater than atmospheric (10 CFR Part 960).

URL--Underground Research Laboratory.

validation--Assurance that a model as embodied in a computer code is an appropriate representaiion of the process or system for which it is intended.

verification--Assurance that a computer code correctly performs the operations specified in the numerical model.

waste form--The radioactive waste materials and any encapsulating or stabilizing matrix (10 CFR Part 960).

waste package--The waste form and any containers, shielding,packing, and other absorbent materials immediately surrounding an individual waste container (10 CFR Part 960).

water table-That surface in a body of ground water at which the water pressure is atmospheric (10 CFR Part 960).

MMP-U.S. Department of Energy Yucca Mountain Project Office. 
APPENDIX A

POSTCLOSURE PERFORMANCE ASSESSMENT ACTIVITIES

A-1 
A.1 TOTAL SYSTEM PERFORMANCE ASSESSMENT. . . . . . . . . . . A-4

A.1.1 Methodology Development ........... A-4

A.1.2 Conceptual Models and Model Validation ....... A-5

A.1.2.1 Models for scenario classes .......... A-5

A.1.2.2 Source-term models ............ A-5

A.1.2.3 Models for transport in engineered barriers . . A-6

A.1.2.4 Models for transport of radionuclides by ground

water in the natural barriers ........ A-6

A.1.2.5 Models for transport of gases in the unsaturated zone ................. . A-6

A.1.2.6 Models for direct release of radionuclides . A-6

A.1.2.7 Models for biosphere transport and consequence
assessment .................... A-6

A.1.3 Computational Models and Model Verification. . . . A-7

A.1.4 Calculation of Performance Measures ....... . A-7

A.1.5 Sensitivity and Uncertainty Analyses ........ A-7

A. 2 ENGINEERED BARRIER SYSTEM PERFORMANCE. . . . . . . . . . . . A-7

A.2.1 Problem Definition and Methodology Development . . . A-7

A.2.2 Conceptual Models and Model Validation ....... A-8

A.2.2.1 Scenario models .............. A-8

A.2.2.2 Near-field environments ........... A-8

A.2.2.3 Waste package degradation models ....... . A-8

A.2.2.4 EBS release models .............. A-9

A.2.2.5 Source term models .............. A-9

A.2.3 Computational Model Development and Verification . . A-9

A.2.4 Calculation of Performance Measures . . . . . . A-9

A.2.5 Sensitivity and Uncertainty Analyses ........ A-9 
A.3 NATURAL BARRIERS PERFORMANCE . . . . . . . . . . . . A-10

A.3.1 Problem Definition and Methodology Development .... A-10

A.3.2 Conceptual Models and Model Validation ....... A-10

A.3.2.1 Models of the pre-emplacement groundwater system . A-10

A.3.2.2 Models for the disturbed zone ......... A-10

A.3.2.3 Models for the postclosure groundwater system . . A-11

A.3.3 Computational Model Development and Verification . . A-11

A.3.4 Calculation of Performance Measures ........ A-11

A.3.5 Sensitivity and Uncertainty Analyses . . . . . . A-11

A.4 DEVELOPMENT OF PROCESSS-LEVEL COMPUTATIONAL MODELS . . . . . A-11

A-3 


\section{APPENDIX A}

POSTCLOSURE PERFORMANCE ASSESSMENT ACTIVITIES

Chapter 3 of the Performance Assessment Strategy Plan (PASP) gives the general strategy for the postclosure performance assessments to be conducted in the geologic repository program. Chapters 4-8 of the PASP describe the applications of this general strategy to support the Safety Analysis Report (SAR), the Draft and Final Environmental Impact Statement (DEIS and FEIS), the site suitability analyses, the site characterization and performance confirmation programs, and the design programs. This appendix describes the categories of postclosure performance assessment activities that will be conducted to implement the strategy for the major milestones in each of these areas. The integrated schedules of activities prescribed in chapter 11 of the PASP are structured around the categories of activities described in this appendix.

The categories of activities in many cases naturally fall under one of the general postclosure performance areas and total system performance, engineered barrier system performance, or natural barriers performance) and these activities are described below according to their performance assessment area. In come cases, however, some activities $(e, g$. , the development of certain process models or the development of computer codes to evaluate processes) may be applicable to several areas at once: these activities are described separately.

The activities described in this appendix will all be conducted under element 1.2.1.4 (Performance Assessment) of the Work Breakdown Structure (WBS). They include the performance assessment activities conducted as a part of the resolution of performance issues $1.1-1.9$ and design issues 1.10-1.12 (See Section 2.2 the PASP).

\section{A.1 TOTAL SYSTEM PERFORMANCE ASSESSMENT}

This section describes the activities associated with total system performance assessment. They include those activities conducted under WBS element 1.2.1.4.1 as well as WBS elements that are closely related to total system performance assessment. The activities include those conducted to resolve issues $1.1,1.2$, and 1.3 of the Issues Hierarchy and the performance assessment activities associated with issues $1.8,1.9$, and the postclosure design issues 1.11 and 1.12 .

\section{A.1.1 Methodology Development}

This category of activities includes those to define elements of the system that will be analyzed, the performance measures for these elements, and the analyses to be conducted to evaluate the measures. It includes the activities to identify the methods to be used to conduct the analyses. Considerable activity has already taken place in this regard; Sections 
8.3.5.13-8.3.5.18 of the SCP give preliminary descriptions of the analyses to be conducted in this area and the methods to be used. However, as the program progresses these descriptions will need to be refined and tailored to address new site and design information.

\section{A.1.2 Conceptual Models and Mode1 Validation}

This category includes all of the activities to develop and validate the conceptual models needed for the total system performance assessments. There are several subcategories corresponding to the various types of conceptual models needed. These activities include those to develop the representations for the scenarios that will be considered in the assessments and the various site and process models that will be considered. These activities include the analyses of natural analogues and the analyses conducted as part of international efforts such as INTRAVAL to develop transport models. The activities also include those analyses used to guide the testing programs to validate models.

\section{A.1.2.1 Models for scenario classes}

This category includes the activities associated with the development of expected-performance scenarios and scenario classes for volcanic activity, faulting, extreme climate change, human intrusion, or other disturbances. Activities included in this category are the identification and screening of processes and events, assembly of the processes and events into sequences to describe scenarios, selection of scenarios to represent a scenario class, estimation of scenario class probabilities, and screening and prioritization of the scenario classes.

Again efforts have been already been made to identify a preliminary set of scenarios in order to help guide the site characterization program: these scenarios are listed in Section 8.3.5.13 of the Site Characterization Plan. These scenarios will be systematically reviewed in the early stage of the program and then updated as new information becomes available.

\section{A.1.2.2 Source-term models}

This category includes the activities needed to define source terms for the transport analyses. They include the activities to consider the assessments conducted for the engineered barrier system (EBS) to define radionuclide release rates from the EBS and to develop source terms for anticipated conditions based upon this information. The activities also include the efforts to generalize these release rates to those for the conditions that would be associated with the disturbed performance scenarios. Thus, these activities will depend heavily upon the activities conducted for EBS performance assessment (See Section A.2) 


\section{A.1.2.3 Models for transport in engineered barriers}

This category includes the activities to evaluate transport of radionuclides through engineered barriers such as shaft, borehole, and ramp seals and seals in the underground facility. It includes the activities to evaluate the transport properties of any other engineered barriers (e.g., backfill, grout, etc.) and the transport characteristics of interfaces between the engineered barriers and the host rock. It does not include the activities to evaluate transport through components of the waste package which are addressed in category A.1.2.2 or A.2.

\section{A.1.2.4 Models for transport of radionuclides by ground water}

This category includes the activities to develop and test models for transport of radionuclides in the geohydrologic system. It includes the activities to develop models of chemical and mechanical retardation and to integrate these models with the ground water flow models. These activities depend upon those conducted for assessment of natural barriers performance; that is, the ground-water velocity fields developed for evaluation of pre-waste-emplacement ground-water travel time will also be used here to evaluate the postclosure velocity field. Thus, these activities will be coordinated with those identified in Section A.3.

\section{A.1.2.5 Models for transport of gases in the unsaturated zone}

This category of activities addresses the transport of gas-phase radionuclides such as carbon-14 dioxide through the unsaturated zone. These activities do not address release of gaseous radionuclides from the waste packages, which is evaluated in the source-term development activities (Section A.1.2.2).

\section{A.1.2.6 Models for direct release of radionuclides}

This category includes the activities to address certain scenarios in which release to the accessible environment may occur by means other than ground-water or gas movement. For example, scenarios involving human intrusion may involve extraction of the waste. Volcanic scenarios may involve entrainment of the waste in magnetic material. The analyses of the transport of radionuclides in these scenarios are addressed by their activities.

\section{A.1.2.7 Models for biosphere transport and consequence assessment}

This category of activities includes those to develop models for transport along biosphere pathways, for uptake by humans, and for dose or health effects. 


\section{A.1.3 Computational Models and Model Verification}

This category includes all the activities to develop the relevant subsystem-level and total-system-level computer codes, to verify the codes, and to document them suitably for the license application. The subsystem-1evel codes include the TOSPAC and SUMO codes now being developed. A subsystem-1evel code will be needed early for the analyses of the ACD and early evaluation of the site. The total-system-level codes include the simple total system simulator that can handle various scenarios. The activities also include testing of these models through code comparisons and benchmarking.

\section{A.1.4 Calculation of Performance Measures}

This category of activities includes all those to calculate consequences for the expected performance and disturbed performance scenario classes. They include the analyses to calculate cumulative release to the accessible environment, the CCDF, doses to individuals, concentrations in special sources of ground water and risk associated with potential releases by ground water pathways, gas-phase pathways, or direct-release pathways, individual activities in this category will be conducted for each of the different scenario classes: expected-performance scenarios, volcanic activity scenarios, faulting scenarios, extreme climate change scenarios, human intrusion scenarios, and others.

\section{A.1.5 Sensitivity and Uncertainty Analyses}

This category of activities includes those activities to evaluate sensitivities and uncertainties in the assessments of total system performance. They include the sensitivity and uncertainty analyses conducted to develop design requirements at the ACD and LAD stages of design, and to evaluate the importance of site characteristics for the site suitability analysis and other analyses, and as part of the general assessment that will be described in the EIS and SAR.

\section{A.2 ENGINEERED BARRIER SYSTEM PERFORMANCE}

This section describes the categories of activities associated with engineered barrier system (EBS) performance assessment, that is, those activities to evaluate the performance measures for the EBS (containing lifetime and EBS release rates) and those to support development of the source term for the total system performance assessment. These activities are conducted under WBS element 1.2.1.4.2 and related WBS elements and include those performance assessment activities needed to involve issues $1.4,1.5$, and 1.10 of the issues hierarchy (See section 2.2 of the PASP).

\section{A.2.1 Problem Definition and Methodology Development}

This category of activities includes all of those needed to define the EBS performance assessments for the SAR. They include those to define the performance measures and the methods to calculate them in order to demonstrate 
compliance with 10 CFR 60.113. Preliminary statements of the problem and the associated methodologies are presented in Section 8.3.5.9 and 8.3.5.10 of the SCP for the EBS performance and in Section 8.3.5.13 for the source term aspects of the total system performance. These methodologies will be refined or changed according to new information at each stage of design. The analysis for the LAD will be the same as those for the SAR.

\section{A.2.2 Conceptual Models and Model Validation}

The activities in this category include all of those to develop and validate the models needed for the EBS performance assessments and to support the source term development for the total system performance assessments. Subcategories of this category address models for the scenarios, models for the near-field environment, models of container degradation, and models of radionuclides transport and release for the waste package. These activities include those to develop EBS models for defense wastes in cooperation with the defense programs and to interface with the MRS and Transportation program to define waste characteristics.

\section{A.2.2.1 Scenario models}

These activities include those to define the expected-performance scenarios and the modes of release in these scenarios needed to evaluate EBS performance. These activities include those to define realistic expected performance (i.e., involving the "dry" release mode) and various bounding scenarios (e.g., those involving the "wet-drip" and "wet-continuous" release modes) used to define the limit of the expected performance.

\section{A.2.2.2 Near-field environments}

These activities include those to extract information from the testing program to define the environments expected for the waste package and the EBS. They include the activities to model the thermal, thermomechanical, fluid, chemical, and radiation conditions that will be encountered and the incorporation of these models into an overall EBS performance model.

\section{A:2.2.3 Waste package degradation models}

These activities include those to model deterministically the degradation rates of the container, to extract information from the materials testing programs to define statistical correlations suitable for this modeling, and to incorporate these models and correlations into an overall EBS performance model. 


\section{A.2.2.4 EBS release models}

These activities include the efforts to model performance of the waste form, release of radionuclides from the waste form, transport within the waste package, and release from the waste package into the near-field environment. These activities include the evaluation of spent fuel test data, cladding performance, and information on other components that can affect release to develop the overall EBS performance model. These activities also include the interfaces with the total system source term model development. These activities depend upon the other EBS model activities described in Section A.2.2.1-A.2.2.3.

\section{A.2.2.5 Source term models}

This category includes the activities to support definition of source terms for the total system performance assessments. It includes the activities to provide the information to develop source terms for expected performance scenarios, taking into account the waste package performance for expected conditions and the distribution of waste throughout the repository, and it includes the activities to support development of source terms for disturbed-performance scenarios. These activities depend upon the results of activities in categories A.2.2.3 and A.2.2.4.

\section{A.2.3 Computational Model Development and Verification}

These activities include all those to develop, verify, and document suitability for the License Application the Computational model for the EBS. The current plan is to develop the AREST and PANDORA Computer Codes. These models are appropriate for both subsystem-level and tota1-system-1evel analyses.

\section{A.2.4 Calculation of Performance Measures}

This category of activities includes all those to evaluate containment of radionuclides within the waste packages and the rate of release of radionuclides from the EBS, backing into account anticipated processes and events. These calculations will be conducted for the ACD and, at the SAR stage, for both the LAD and the SAR.

\section{A.2.5 Sensitivity and Uncertainty Analyses}

This category of activities includes any sensitivity studies that may be conducted for the EBS. The general strategy described in Section 3.7 .2 indicates that sensitivity studies in this case will be limited and that bounding analysis will be relied upon to account for uncertainties. Nevertheless, some sensitivity studies will be conducted to support EBS design and to identify site information needs. Those activities are included in this category. 


\section{A. 3 NATURAL BARRIERS PERFORMANCE}

This section describes the categories of activities to evaluate the pre-waste-emplacement ground-water travel time (GWTT) and to support development of postclosure ground water velocity fields for the total system performance assessments. These activities are conducted under WBS element 1.2.1.4.4.1, as well as other elements in which a GWTT evaluation is needed, and include the activities to resolve issue 1.6 of the issues hierarchy.

\section{A.3.1 Methodology Development}

The activities is this category include all those to define the analyses that will be conducted to calculate the GWTT and to provide ground water velocity fields for the total system performance modeling. They include the activities to define the methods for these analyses. Preliminary statements of the problem and the associated methodologies are presented in Section 8.3.5.12 for the GWTT evaluation and in Section 8.3.5.13 for the ground water flow aspects of the total system performance assessment. These methodologies will be modified according to new site information produced by the testing program.

\section{A.3.2 Conceptual Models and Mode1 Validation}

This category includes all the activities to develop and support the conceptual models needed to evaluate the GWTT and to provide ground water velocity field for total system performance assessments. The models include those for the ground water flow system and those to define the extent of the disturbed zone.

\section{A.3.2.1 Models of the pre-emplacement ground-water system}

These activities include those to extract information from the site characterization program to define the elements of the flow system and the features of the site that affect the flow system, flow mechanisms both on a microscopic scale and a macroscopic, and the boundary and initial conditions for the flow system. The activities include the evaluations to guide the testing programs to validate the models and the information activities such as INTRAVAL to develop and valid conceptual models. The activities also include the interfaces with the total system performance assessments to develop representations for the postclosure ground-water flow system and to develop ground-water velocity fields for those total system performance assessments.

\section{A.3.2.2 Models for the disturbed zone}

The activities include those to develop the conceptual models to evaluate that extent of the disturbed zone. They include the activities to define the models to estimate the changes to the flow system due to the heat generated by the emplaced waste, to estimate impacts of stresses induced by the 
construction of the underground facility on flow paths and hydrologic properties and to estimate other changes (e.g., in geochemistry) that may define the extent of the disturbed zone.

\section{A.3.2.3 Models of the postclosure ground-water system}

These activities include those to support the evaluation of ground-water velocities and fluxes needed for the assessments of postclosure performance of the total system.

\section{A.3.3 Computational Model Development and Verification}

This category includes the activities to develop computer codes to analyze the ground water flow system at the site and to verify and document the codes suitably for the License Application. The current plan is to develop one- and two-dimensional versions of the LLUVIA code and one-, two-, and threedimensional versions of the PORFLO and NORIA codes.

\section{A.3.4 Calculation of Performance Measures}

The activities is this category are those that will be conducted to calculate the GWTT as defined in 10 CFR 60.113. It includes the activities to estimate the extent of the disturbed zone, to identify likely paths of radionuclides transport, and to calculate the GWTT along these pathways. These analyses will be conducted for the SAR and for the various design stages. These analyses may also be conducted for the site suitability analyses.

\section{A.3.5 Sensitivity and Uncertainty Analyses}

These activities include those that will be conducted to assess sensitivities and uncertainties of the GWTT analyses and the importance of alternate conceptual models. These analyses include those to evaluate the effect of potentially adverse conditions in the flow system. The analyses will be conducted for the SAR and the site suitability analyses.

\section{A.4 DEVELOPMENT OF PROCESS-LEVEL COMPUTATIONAL MODELS}

This category of activities includes all those conducted to develop and test computer codes needed to simulate processes important to the development and evaluation of conceptual models for performance assessments. The computer codes in this case are those needed to calculate near-field and far-field temperatures, residual stresses due to thermomechanical effects and excavation, isothermal unsaturated flow, and geochemistry. Particular computer codes that will be considered include the TRACR-3D isothermal flow and transport, the EQ3/EQ6 geochemical reaction code, and the ORIGEN reaction and depletion code for radionuclide inventories. The activities include final development of these codes, verification and benchmarking, and documentation. 
APPENDIX B

PRECLOSURE SAFETY ASSESSMENT ACTIVITIES

$$
\text { B-1 }
$$


APPENDIX B

TABLE OF CONTENTS

B.1 METHODOLOGY DEVELOPMENT .................... B-4

B.2 EVALUATION OF SITE DATA AND DESIGN INFORMATION . . . . . . . . B-4

B.3 SOURCE-TERM CHARACTERIZATION FOR NORMAL CONDITIONS . . . . . . B-5

B.4 RADIATION AND RADIONUCLUDE-TRANSPORT ANALYSIS FOR NORMAL CONDITIONS B-5

B.5 EXPOSURE CALCULATION FOR NORMAL CONDITIONS ........... B-6

B.6 IDENTIFICATION OF CREDIBLE INITIATING EVENTS FOR

B.7 ACCIDENT-SCENARIO ANALYSIS. . . . . . . . . . . . . B-7

B.8 ACCIDENT SOURCE TERM ..................... B-7

B.9 ACCIDENT DOSE ASSESSMENT .................... B-7

B.10 ACCIDENT RISK ASSESSMENT . . . . . . . . . . . . . . B-8

B.11 CERTIFICATION OF PRECLOSURE SAFETY ASSESSMENT CODES . . . . . . . B-8 
Chapter 3 of this Performance Assessment Strategy Plan (PASP) gives the general strategy for the preclosure safety assessments to be conducted in the geologic repository program. This appendix provides a categorization scheme for the activities that will implement this general strategy. Chapter 11 of the PASP provides an integrated schedule and milestones to meet the major milestones described in Chapters 4-10 that is structured according to these categories.

The categories in this section are those that fall under the Work Breakdown Structure (WBS) element 1.2.1.4.3.2. These categories include the performance assessment activities that will be conducted as a part of the resolution of issues $2.1-2.5$.

The calculational scheme that is described is based on the general strategy described in Chapter 3 of this PASP and the following additional factors:

- Preclosure safety assessments can rely on calculational models that have been developed and previously applied in safety analyses and licensing of other nuclear facilities, such as nuclear power plants, which are modified to account for differences in facility characteristics and parameters relevant to repository assessment; in this case code certification means to verify that any such modifications are correct and to document the codes suitably for the analyses.

- Preclosure safety assessment is closely linked to design and reliability of assessment results is more dependent upon availability of design information rather than upon site data;

- The initial exercise of preclosure safety assessment methodology has already been performed during the conceptual design (CD) phase of the repository.

As mentioned in Chapter 3, the preclosure safety assessment program will build upon the experience and the results during the Conceptual Design phase, conduct additional work in some areas (e.g., source term development), and progressively refine the assessment for the ACD and LAD stages. The assessment results on public worker doses during normal and accident conditions for the License Application Design (LAD) can be directly utilized, without major modifications, for preparation of the requirements of the Safety Analysis Requirements (SAR). Similarly, the preclosure safety assessments of the Advanced Conceptual Design (ACD) can be used for the preparation of the Draft Environmental Impact Statement (DEIS).

The following sections discuss the specific categories of preclosure safety assessment activities to be performed. The initial focus of the preclosure PA program is on the ACD assessment. The need for and extent of 
updating the ACD analyses for the LAD stage will depend on the outcome of the sensitivity analyses for certain activities and the extent of the design changes after the ACD.

The end products of the activities (i.e., data, models and assumptions, and results) will generally be applicable to the preparation of the DEIS and SAR, with appropriate modifications depending on specific applications. The categories discussed below are related to methodology development (Section B.1), analyses for normal operations (Section B.2-B.6) analyses for accident conditions (Sections B.7-B.10), and code certification (Section B.11).

\section{B.1 METHODOLOGY DEVELOPMENT}

This category of activities includes all those activities to define the system to be evaluated and to identify the performance measures to be evaluated. As mentioned, the activities in this area will be largely refined in terms of the efforts that have already been conducted, both for the repository and for related nuclear facilities. It is not expected that substantial methodology development will be conducted for the preclosure safety assessments.

\section{B. 2 EVALUATION OF SITE DATA AND DESIGN INFORMATION}

This category of activities includes the evaluation of available site data and design information relevant to radiation-dose assessments. The information obtained from site programs (e.g., environmental monitoring, site characterization) on population distribution, meteorology, land uses, etc. will be reviewed and evaluated. The data to be used for evaluating external and internal doses to members of the public will be identified and documented.

Available repository design information will also be evaluated, and the items related to the radiation safety of the public and repository workers will be identified and documented. Among the attributes of repository design of interest for radiation-dose calculations are the following:

- Waste throughput (i.e., schedule and amount of waste received per year).

- Containment characteristics of the waste form (i.e., fuel elements, waste package, etc).

- Barrier shielding thicknesses, composition, and the distance between the sources and the exposed individuals.

- Characteristics of confinement and ventilation systems.

- Effectiveness of effluent-treatment systems.

- Characteristics of radioactive-material release point (e.g., stack height, exit velocity). 


\section{B.3 SOURCE-TERM SHARACTERIZATION FOR NORMAL CONDITIONS}

The objective of this category of activities is to characterize the potential sources of radiation and release mechanisms that can contribute to the routine exrosure of members of the public and repository workers. The specific infornation needed about potential source terms includes the radionuclides involved, their quantity and concentration, the type and energy of the emitted radiation, and physical and chemical forms. In addition to sources resulting from repository operations (e.g., waste-handling activities), naturally occurring radionuclides(e.g., radon and its daughters) released from the host rock will also be considered to ensure adequate protection for the repository workers and the public and to determine compliance with the radon monitoring and control provisions established by the Mine Safety and Health Administration in 30 CFR Part 57, which the DOE has chosen to comply with.

The activities include examination of radionuclide inventories in the "cladding" gap of spent-fuel rods, preexisting spent-fuel particles, external crud on spent-fuel cladding, and volatile radionuclides and examination of naturally occurring radionuclides can come from underground excavations and the spoils pile. The condition of spent fuel on arrival and the range of stresses that the spent fuel could be subjected to during normal operations, including anticipated operational occurrences are also evaluated in these activities.

The expected output of activities in this category include a characterization of radiation fields and radionuclide releases, along with estimated ranges of uncertainties, resulting from normal repository operation, surveillance and maintenance activities. Uncertainty analys is will be conducted to evaluate ranges of parameters and assumptions that could affect the radiation-dose assessments.

\section{B.4 RADIATION AND RADIONUCLIDE-TRANSPORT ANALYSIS FOR NORMAL CONDITIONS}

After its release from confinement systems or repository facilities, the radioactive material undergoes a number of physical and chemical processes during transport. Among these processes are atmospheric dispersion, deposition on the ground, and chemical alteration.

There are differences between the environmental pathways for members of the public and those for repository workers. Members of the public in the unrestricted area might receive doses from the releases of radioactive material through either direct (e.g., air, soil) or indirect (e.g., vegetation, animals) pathways. For repository workers, the dominant pathway is likely to be direct radiation from the radiation fields and external doses from airborne radionuclides.

Analytical tools in the form of dispersion and pathway models will be required to perform the radionuclide-transport evaluation for members of the public. The ability to perform an adequate transport simulation depends heavily on the suitability of the analytical or computational tools for 
modeling the transport processes. For repository workers, analytical tools will be required for determining direct-radiation dose rates in all areas of the repository as well as for determining ventilation leakage and the filtration of airborne radionuclides in the repository airstream.

The objectives of the activities in this category include selection of (1) computational models to simulate the atmospheric transport phenomena appropriate to the Yucca Mountain environment for evaluating the doses delivered to the public and (2) radiation-shielding codes for calculating worker exposures. Sensitivity studies will also be conducted to identify the important transport phenomena and to determine which factors require further investigation or refinement.

The selected transport and radiation-shielding codes will be applied to the assessments relating to exposures under the normal conditions. They can also be used in accident analyses with due consideration of appropriate assumptions for accident conditions (see Section B.9, "Accident Dose Assessment").

\section{B.5 EXPOSURE CALCULATION FOR NORMAL CONDITIONS}

The activities in this category include (1) evaluation of the radiation doses to members of the public from routine operations, both for the maximally exposed individual and for the population within 80 kilometers of the repository, (2) quantification of the dose received by workers in the various work categories from routine operations, and (3) demonstration that the applicable regulatory dose limits and the ALARA requirement are met.

Radiological consequence assessment computational models used in evaluating the safety of nuclear power plants and other nuclear facilities will be adopted for use in the repository to quantify the public and worker exposures. The information needed to calculate doses with these models will be by activities in other categories (See Sections B.2, B.3 and B.4).

The methodology for the radiological assessments for both the ACD and the LAD will be the same. The assessment for the SAR will be in terms of doses, whereas that for the DEIS will also include estimates of health effects. In addition, the computations in the DEIS will be expected to use more-realistic assumptions (e.g., for meteorological parameters) that the bounding values used in the SAR.

\section{B.6 IDENTIFICATION OF CREDIBLE INITIATING EVENTS FOR ACCIDENT ANALYSES}

The activities in this category include those to (1) establish the method for identifying and screening the initiating events to be considered in accident analyses and (2) apply this method in establishing the credible initiating events that could challenge the equipment and the operations of the repository. The types of initiating events that will be considered include external natural phenomena (e.g., earthquakes), external human-induced events (e.g., airplane crashes), equipment failure (e.g., crane failures)and human error (e.g., transporter collisions). 
These activities include the evaluation of existing techniques for systematically identifying a comprehensive list of accident initiators and screening them to determine the risk-significant ones. There are several methods the could be adopted for the Yucca Mountain Project, such as the Entity-Relationship Model developed for the Basalt Waste Isolation Project and the Hazard Identification Technique (HAZIT) employed in the chemical process industry.

Other techniques include the identification of credible initiating events for the repository conducted in previous studies (e.g., the studies reported in SAND 85-7192 and SAND 87-7029; and SAND 84-2641), coupled with a detailed examination of the repository design and the projected operational, surveillance, and maintenance activities.

\section{B.7 ACCIDENT-SCENARIO ANALYSIS}

The activities in this category include (1) identification of the potential accident sequences that could occur after the initiating events, (2) description of the events within the sequence, and (3) quantification of the accident sequences to determine the likelihood of the accident scenarios. The information obtained from the activities described in Section B.6 will be used for these activities.

\section{B.8 ACCIDENT SOURCE TERM}

The objectives of the activities in this category are to (1) define and quantify the physical phenomena for the accident sequences identified in the activity described in Section B.7 and (2) determine the source term for the accident sequences. Since the conditions expected for accidents are more severe than those of normal operations, a separate activity (i.e., in addition to those described in Section B.3) is planned for developing the source term for accident conditions. This activity will characterize radionuclide releases from breached spent-fuel and high-level-waste containers for different accident conditions (e.g., impacts and fires).

The activities include study of the results of source-term work under the transportation program and results of experiments and previous studies (MacDougall et a1., 1987). These evaluations will include sensitivity analyses of parameters that could influence the nature and magnitude of the radionuclide releases.

\section{B.9 ACCIDENT DOSE ASSESSMENT}

The objective of the activities in this category is to evaluate the radiological consequences of postulated repository accidents to members of the public and essential repository workers and to demonstrate that the applicable regulatory dose limits are met.

These activities will use the results of the activities described in Sections B.6, B.7, and B.8. In addition, the dispersion and pathway models 
established for routine operations (Section B.3) will be used with appropriate modifications of assumptions and input parameters for applicability to accident conditions.

\section{B.10 ACCIDENT RISK ASSESSMENT}

The objective of activit:es in this category is to perform accident risk assessments. For example, starting with the doses to members of the public from the spectrum of accidents considered for the DEIS, risks will he estimated in terms of health effects. Standard factors for converting radiation doses to health effects will be used in this assessment.

\section{B.11 CERTIFICATION OF PRECLOSURE SAFETY ASSESSMENT CODES}

This category includes the activities conducted to test and document the calculatioral models for the preclosure safety assessments. Many of these codes will already be suitably documented; however, any additional work needed in this area will be accomplished by these activities. 